\title{
COMPARATIVE EFFECTS OF GENTLE TEACHING AND VISUAL SCREENING ON SELF-INUURIOUS BEHAVIOUR
}

\author{
LINZI J. JONES
}

\author{
A Thesis \\ submitted in partial fulfilment \\ of the requirements for the Degree of \\ MASTERS OF ARTS IN PSYCHOLOGY \\ University of Canterbury \\ December 1987
}


CONTENTS

PAGE

Acknowledgements

Abstract

Introduction and Literature Review

1

Introduction

Prevalence

Etiology

Treatment

The Present Study

Method

Results

Discussion

References 
ACKNOWLEDGEMENTS

I am grateful for the assistance, advice, and expertise of my supervisor, Dr Nirbhay Singh. The helpful comments of Oliver Mudford prior to the commencement of the study were also appreciated. I am indebted to Gay Tyler-Merrick, Lorinda Creighton, and Joy Rogers for the substantial contribution they made in carrying out the study in terms of hard work, dedication, and support.

Thanks also to the staff at Templeton Hospital which includes Jenny Jordan, Psychologist; Dr Marshall, Medical Superintendent; the nursing staff of Rimu and Briar Villas; and Jeff's special nursing staff Phillipa Grant and Heather Knowles; and Glen, the technician.

A special thanks to Mary Burrow for typing the manuscript.

Many thanks to my family for their support and encouragement. 
The effects of gentle teaching and visual screening on the self-injurious and collateral behaviours of three profoundly retarded persons was evaluated using an alternating treatments design. Visual screening and gentle teaching significantly reduced the headbanging of one subject compared to a no-treatment control phase. In addition, visual screening reduced face slapping in a second subject to near-zero levels, whereas gentle teaching failed to reduce the behaviour. Both procedures failed to substantially reduce mouthing by a third subject. However, overcorrection produced immediate and substantial reductions in mouthing. The presence of toys and functional activities in the no-treatment control condition did not decrease self-injurious behaviour. Differential reinforcement procedures conducted prior to treatment had some effect on headbanging but did not reduce face slapping and mouthing. 
INTRODUCTION AND LITERATURE REVIEW

Introduction

Self-injurious behaviour (SIB) has been described as one of the most extreme forms of human psychopathy (Carr, 1977). SIB occurs in a variety of populations, although it is commonly associated with mentally retarded persons and psychotic children (Singh, 1981a).

Infrequently it occurs in normal children who exhibit behaviours such as head banging, picking, scratching, hair pulling, and hitting (Singh, 1981a). In psychotic persons it tends to involve a single dramatic act during a psychotic episode and may take the form of self enucleation (Ananth, Kaplan, \& Lin, 1984) or the amputation of bodily limbs and digits (Demuth, Strain, \& Lombardo-Maher, 1983). It has also been found to occur in prisoners (Swett, 1985) and in antisocial adolescents in institutional settings (Pattison \& Kahan, 1983). When SIB occurs in non psychotic adolescents and adults, who are not mentally retarded or brain damaged, they are commonly diagnosed as meeting the criteria for borderline personality disorder in the Diagnostic and Statistical Manual of the American Psychiatric Association - Revision III (1980) (DSM III) (Garaner \& Cowdry, 1985; Schaffer, Carroll, \& Abramowitz, 1982). In these individuals SIB commonly involves repetitive and superficial self-cutting or lacerations to parts of the body. 
SIB has been noted in isolation-reared monkeys and can involve a variety of behaviours including head banging, self-biting, clasping, rubbing, slapping and mouthing IGluck, Otto, \& Beauchamp, 1985; Levinson, 1970; Pond \& Rush, 1983). In animals such as rabbits or mice it can occur following a drug induced state or brain lesions and denervation (Mueller, Saboda, Palmour, \& Nyhan, 1982; Wiesenfield \& Hallin, 1983) and commonly takes the form of self-biting.

A number of labels have been used to describe SIB including "masochistic, self-punitive, autoaggressive, suicidal, destructive, and self-mutilative" (Baumeister \& Rollings, $1976, \mathrm{p} 3)$. Some of these terms reflect a psychoanalytic orientation (Watson, Singh, \& Winton, 1986). However self-injurious behaviour is the most commonly used term to describe the behaviour. This term describes the physical consequences of the behaviour without implying intent. This may be the most appropriate approach at present while there is still speculation regarding the etiology and the factors involved in the maintenance of the behaviour (Baumeister \& Rollings, 1976; Maisto, Baumeister and Maisto, 1978; Matson \& Frame, 1986). 
SIB can be defined as behaviour which produces physical injury to the individual's own body (Tate \& Baroff, 1966). This definition was chosen because it is broad enough to include behaviours which cause injury mainly because of their cumulative effects such as pica and rumination or single episodes of SIB such as amputation in psychotic persons. Other definitions have the advantage in some cases of being perhaps more operationally defined. However, they are often too specific to include such behaviours or emphasise the repetitive nature of SIB which while common is not always the case.

It has been suggested by Schroeder, Mulick, and Rojahn (1980) and Rojahn (1984) that a more restricted definition of SIB is not warranted at present due to the parameters requiring further investigation, the taxonomy of the behaviour not being agreed upon among researchers, and the heterogeneous topographies the definition must emcompass. In view of this, they argue that whether SIB constitutes a response class is unknown at present.

In contrast, Matson (1986) recommends that SIB should be included in present diagnostic schemes such as the DSM III. At present SIB and stereotypic behaviours are combined to form a subcomponent called Atypical 
Stereotypic Movement Disorder under the childhood disorders classification of stereotyped movement. These behaviours are regarded as occurring mainly in childhood. SIB is also mentioned as a feature of the borderline personality disorder. Matson feels that the area of psychopathology among mentally retarded persons has been largely neglected to date. He suggests that the various theoretical disciplines involved in the treatment of SIB should consider whether SIB constitutes a psychopathological disorder. This may not have tended to occur as the different disciplines are involved in the treatment of different populations of subjects.

The behavioural treatment approach has predominated with mentally retarded persons and psychotic children, whereas the psychoanalytic model has predominated with psychotic persons and persons meeting the diagnostic criteria for borderline personality disorder. This may be due to mentally retarded persons, particularly the profoundly and severely retarded, not being regarded as suitable candidates for psychoanalysis as they do not possess the necessary thought processes (Singh, 1981a). In an article in the psychiatric literature published prior to Matson making this suggestion, Pattison and Kahan (1983) suggested that SIB in the form that tends to be exhibited by individuals who are not mentally retarded or psychotic should be included in the DSM IV as a separate diagnostic syndrome as it differs considerably from other forms of SIB. 


\section{Prevalence}

Surveys have been conducted to determine the prevalence of SIB in the various populations and figures vary accordingly. Among normal children the majority of studies have dealt with head banging. The incidence has ranged from $3.3 \%$ to approximately 20\% (Singh, 1981a). An incidence of $7 \%$ reported by Kravitz and Boehm (1971) is a commonly cited figure. These authors also found that head banging was approximately 3 times more frequent in boys than girls. The behaviour tends to appear towards the first year of life and disappear at approximately 3-years-of-age (Singh, 1981a). Its emergence appears to be associated with other stereotyped movements (DeLissovoy, 1961) and there is some evidence that it is most likely to occur during teething episodes (Kravitz \& Boehm, 1971).

In a more recent study Abe, Oda, and Amatomi (1984) conducted a 5-year follow-up study of 3-year-old children who displayed either headbanging or breath-holding. From the results of a questionnaire administered to the infants' mothers it was found that these infants did not differ significantly from age matched controls in terms of problem behaviours or developmental milestones at follow-up, apart from being more restless and perhaps more unstable in mood. At 3 years-of-age headbanging was associated with 
sleepwalking and encopresis. This finding has not been observed in earlier studies. It is possible that the children who headbanged in this study may not be representative of the majority of children who headbang as they still displayed the behaviour at 3 years-of-age. Nagata, Suehiro, and Niikawa (1984) found that of 300 infants 298 had self-inflicted scratches on their faces. The degree of injury caused by the scratch was actually lower for the low birth weight infants, preterm infants, infants with delivery complications, and infants delivered by cesarean. This may have been due to these infants having under-developed fingernails or poorer motor relexes. The authors concluded that the scratches were made during normal bodily movements and could possibly reflect the maturity and physical development of the infant.

Headbanging among normal children occurs in mild forms and disappears with age (Baumeister \& Rollings, 1976; Singh, 1981a). The lack of treatment studies suggest it is not viewed by clinicians as a significant problem and it does not appear to be associated with other serious behaviour problems (Abe et al., 1984).

Pattison and Kahan (1983) reviewed 56 case reports mostly from the psychiatric literature on SIB they found 
that SIB in such forms as repetitive self-cutting commonly occurred during adolescence. The occurrence of SIB after 30-years-of-age was rare except in psychotic patients as a single episode with severe physical consequences. The SIB of the first subgroup tends to be associated with symptoms commonly associated with the borderline personality disorder such as depression (Phil, 1983). Psychotic patients particularly schizophrenics who exhibit bizarre and severe SIB often experience hallucinations, delusional thinking, or bizzare ideas related to the act (Schaffer et al., 19821 .

The incidence for psychotic children may be as high as 40\% (Green, 1967); however, these results are only suggestive.

Prevalence rates for mentally retarded persons in institutional settings have ranged from $5 \%$ to $37 \%$ (Singh, 1981a). However prevalence rates of $8 \%$ to $14 \%$ have been considered the most representative (Baumeister \& Rollings, 1976). A number of factors outlined by Singh may account for the varying prevalence rates. These include the level of retardation of the population being surveyed, differing definitions of SIB, the length of the observation period, and the method of data collection for example direct vs retrospective methods. 
A study which exemplifies how the length of the observation period might effect prevalence rates was conducted by Bartak and Rutter (1976). They found that 71\% of retarded persons had displayed SIB at various points in time but only $6 \%$ did in the test situation. Additional factors include how accurately SIB is recorded by staff (Rojahn, 1984) and how strict the inclusion criteria are (Rojahn, 1986).

Rojahn (1986) conducted a prevalence survey in Germany that had the advantage of being both nationwide with a much larger sample than previous studies and involved non-institutionalised persons on whom there is little information available in this respect. The survey involved 25,872 persons from 294 service facilities. Among this group the prevalence rate was $1.7 \%$, a much lower figure than previously reported in institutionalised populations. The obvious reason to explain this would be the fact that there is an inverse relationship between IQ and SIB with more severely and profoundly retarded persons exhibiting. SIB (Griffin, Williams, Stark, Altmeyer, \& Mason, 1986; Maisto, Baumeister, \& Maisto, 1978). These groups are also more likely to reside in institutions than community placements. However, this study used stricter inclusion criteria than previous research as subjects were only included if they had displayed SIB within the last 14 days. 
The most common forms of SIB have varied from study to study in how the behaviour ranked from the most common to the least common. However the behaviours which were reported as common tend to be consistent and include headbanging, self-biting, scratching, head and body hitting, hair pulling, gouging, and pinching in various combinations (Barron \& Sandman, 1984; Griffin et al., 1986; Maisto et al., 1978; Maurice \& Trudel 1983; Rojahn, 1984, 1986; Schroeder, Mulick, \& Rojahn, 1980; Schroeder, Schroeder, Rojahn, \& Mulick, 1980; Schroeder, Schroeder, Smith, \& Daldorf, 1978). Eye gouging is more common among blind persons (Maisto et al., 1978).

The majority of individuals exhibit two or more topographies of SIB (Griffin et al., 1986; Maurice \& Trudel, 1982; Rojahn, 1984, 1986). This may be related to the level of retardation as mild and moderately retarded persons who display SIB are more likely to display only one self-injurious behaviour (Rojahn, 1986).

A number of attempts have been made to present a classification system of the various SIB topographies using multivariate analysis. This research has identified two major subcategories of SIB labelled social SIB which includes the most common SIB behaviours and non-social SIB which includes mouthing, stuffing 
orifices, rumination, coprophaghy, aerophaghy and polydipsia (Schroeder, Mulick, \& Rojahn, 1980; Schroeder, Schroeder, Rojhan, \& Mulick, 1980; Schroeder, et al; 1978). Similar results were reported by Rojahn (1984, 1986). However rumination appears to be a difficult behaviour to classify (Rojahn, 1986). Rojahn (1984) found that rumination occurred in the social category while Rojahn (1986) found that rumination and teeth grinding formed a separate category. Whether teeth grinding can be regarded as SIB is debatable.

The relationship between SIB and stereotypic behaviours has also been investigated (Rojahn, 1986). As Rojahn has pointed out there is a lack of knowledge regaraing the relationship between stereotypy and SIB. The clarification of this relationship is important for classification and treatment purposes. At present some researchers regard SIB as a subset of stereotypy, others do not make a qualitative aistinction between the behaviours while the majority of researchers clearly differentiate between the two behaviours. Rojahn found a significant relationship between body rocking and self-hitting. Although no causitive explanation is possible the author hypothesised that this may be evidence that self-hitting may develop from body rocking. 
Among mentally retarded persons SIB can vary in intensity from very mild forms to life threatening behaviours (Foxx \& Livesay, 1984). Its frequency can also show wide variations. It may have detrimental effects on every facet of the individual's development (Demchak \& Halle, 1985) and engender feelings of helplessness in caregivers (Demchak \& Halle, 1985; Jenson, Rovner, Cameron, Peterson, \& Kesler, 1985; Lovaas \& Simmons, 1969).

As the behaviour involves physical risk to the person immediate action is often taken by caregivers to control the behaviour, often involving pharmacological intervention and the use of restraint devices (Altmeyer, Locke, Griffin, Ricketts, Williams, Mason, \& Stark, 1987; Griffin et al., 1986) rather than a systematic attempt to identify antecedents and develop treatment programmes (Durand \& Carr, 1985; Iwata, Dorsey, Slifer, Bauman \& Richman, 1982; Johnston \& Baumeister, 1978). Mentally retarded persons who engage in SIB are often excluded from training groups because of the disruptive nature of their behaviour. This means they often spend the majority of their day in barren dayrooms with few opportunities to learn adaptive behaviours to replace SIB. If they are in restraint devices they may be physically unable to participate, while the effects of 
medication may impede their ability to learn (Singh, 1981a). In such an environment SIB may be one of the few behaviours that are effective in gaining social attention, particularly in severely and profoundy retarded persons with few adaptive communication skills (Lovaas \& Simmons, 1969). It may also have a detrimental effect on mentally retarded person's placement in the community resulting in an increased probability of being admitted or readmitted to institutions (Larkin, Hill, Hauber, \& Bruininks, 1983) or remaining in institutional care.

Individuals who exhibit SIB also tend to show a higher incidence of other maladaptive behaviours such as aggression and stereotypy (Griffin et al., 1986; Maisto et al., 1978; Maurice \& Trudel, 1982). In addition Griffin et al. found a higher incidence of property destruction, personal maladaptive behaviours such as clothes tearing, undressing inappropriately, and handing faeces, avoidance behaviour, and sleep disturbances. Individuals who displayed aggressive-destructive behaviours and sleep disturbances were also more likely to receive psychoactive medication. There was a high incidence of visual, auditory, and motor disabilities regardless of whether the subject displayed SIB. However, Rojahn (1986) found that although approximately two-thirds of the SIB 
subjects displayed stereotypy, this was not a higher incidence than for subjects who did not display SIB, except for self-restraint which was more frequent in the SIB group.

A large proportion of individuals who display SIB, particularly if the behaviour is severe, also receive psychoactive medication and/or are placed in restraint devices (Altmeyer et al., 1987; Griffin et al., 1986). It was also found that females were more likely to receive medication and/or be placed in restraints. Griffin et al. (1986) found that $46.4 \%$ of SIB clients received medication and/or restraint. While $39.9 \%$ were on a formal treatment programme the majority $(33.1 \%)$ were on a differential reinforcement programmes and a small percentage $(6.8 \%)$ were on an aversive programme combined with differential reinforcement.

Altmeyer et al. (1987) found that $38.8 \%$ of the SIB population had received psychoactive medication to reduce SIB over a 12 month period. The frequent use of restraints was common when differential reinforcement procedures were used but not when aversive procedures were used. The use of psychoactive medication was greater when behavioural programmes were used than when no behavioural programmes were used. Of the clients who received medication $14.5 \%$ were treated with aversive procedures, $40.1 \%$ received differential reinforcement procedures and $45.4 \%$ received no behavioural treatment. 
These results led the authors to conclude that the use of medication that clients with SIB received had not changed over the past 10 years. In addition almost half the subjects with frequent SIB received no form of treatment and $16.1 \%$ were on a purely pharmacological management programme. A similar pattern was found for clients with severe SIB. For clients who exhibited both severe and frequent SIB, 19\% were treated solely with drugs and $32 \%$ did not receive any form of treatment.

The demographic variables related to SIB have been investigated. As previously mentioned there is an inverse relationship between $I Q$ and SIB. The relationship between gender and SIB remains unclear as inconsistent results have been reported. Maisto et al. (1978) found that the sex of the subject was related to both the prevalence and topography of SIB. SIB was more Erequent among females who were more likely to engage in multiple forms of SIB compared to males. However, SIB occurred in milder forms and self-biting was the most common SIB topography. Males were more likely to engage in headbanging and single and multiple forms of SIB occurred equally. However, Schroeder et al. (1978) and Barron and Sandman (1984) found no significant differences related to SIB for males and females. 
There is some evidence that SIB is more prevalent among younger-aged residents who have been institutionalised longer than residents who do no display SIB (Maisto et al., 1978; Schroeder et al., 1978). However replication of these results is required before any conclusions can be drawn (Singh, 1981a).

\section{Etiology}

Currently the most widely accepted account of the etiology of SIB is the behavioural approach which has generated numerous treatment studies that have proved effective in controlling SIB. This approach has achieved more empirical support than any of the other approaches (Carr, 1977). Carr has outlined five major hypotheses regarding the etiology of SIB and has summarised the relevant literature relating to each of these hypotheses. The hypotheses include: (1) the positive reinforcement hypothesis; (2) the negative reinforcement hypothesis; (3) the self-stimulation hypothesis; (4) the organic hypothesis, and (5) the psychodynamic hypothesis.

A summary of the major findings and additional research will be presented in this review. 


\section{Behavioural}

The major evidence to support the behavioural theory of etiology has been reviewed in detail elsewhere (Carr, 1977; Demchak \& Halle, 1985; Durand \& Carr, 1985; Durand \& Crimmins, 1987).

In the behavioural approach SIB is regarded as a learned behaviour which is maintained by either positive reinforcement and/or negative reinforcement. Positive reinforcement may include social attention or tangible consequences such as preferred activities or food. According to this theory if the individual is able to gain positive reinforcement or escape from an unpleasant situation contingent on SIB the probability of engaging in SIB will increase. This hypothesis was first put forward by Skinner (1953) and attempts to explain how SIB originates and is maintained.

According to behavioural principles if the contingent relationship between the environment and behavioural consequences are changed this would result in a:decrease or increase in the behaviour. Thus, a decrease in social attention or withholding reward should decrease SIB eventually, although an initial increase in SIB known as an "extinction burst" may occur initially (Lovaas \& Simmons, 1969). If SIB is followed by an aversive event this should also decrease the behaviour. 
In fact behavioural research to be discussed has provided empirical evidence to support these hypotheses. The rate of SIB has been found to increase if social attention (Lovaas, Freitag, Gold, \& Kassorla, 1965) or preferred activities (Lovaas \& Simmons, 1969) is made contingent on SIB. Withholding social attention has resulted in a decrease in SIB eventually (Lovaas \& Simmons, 1969). Social attention was identified in maintaining SIB of an organic origin lcontact dermatitis) and removing social attention decreased the SIB (Carr \& McDowell, 1980). Removal of a preferred object was found to result in an initial increase in SIB similar to an extinction burst (Peterson \& Peterson, $1968)$.

As Singh (1981a) pointed out a number of studies have shown that individuals released from restraints may show increased rates of SIB and this may be equivalent to having tangible rewards removed. Lovaas et al. (1965) were able to show how SIB and adaptive behaviours that had been shaped with reinforcement were functionally related. The behaviours were appropriate music behaviour and bar pressing, extinction of these responses resulted in increases in SIB. 
As Baumeister and Rollings (1976) pointed out mentally retarded individuals with a limited behavioural repertoire have few adaptive responses available to obtain reward or terminate unpleasant activities. As SIB is difficult to ignore and is often immediately attended to retarded persons may quickly learn how to identify persons and situations associated with reward and punishment and the consequences SIB results in. If this training occurs on an intermittent schedule it becomes difficult to extinguish the behaviour.

This point is exemplified by the following studies. Wieseler, Hanson, Chamberlain, and Thompson (1985) administered a questionnaire to staff in a residential institution regarding the typical consequences of stereotypy and SIB. The results showed that $30 \%$ of SIB was typically followed by staff attention, $38 \%$ led to escape or avoidance of a task and $32 \%$ was not associated with any observable consequences. Durand and Crimmins (1987) also demonstrated that subjects were successful in achieving social attention or escape from tasks by engaging in SIB.

A study which indirectly indicates that individuals engage in SIB to gain social attention was conducted by Burke, Burke, and Forehand (1985). The authors found that SIB was significantly less likely to occur 
following positive interpersonal interactions with staff and SIB was significantly more likely to occur in the absence of these interactions. The earlier studies in which social attention was provided or withdrawn to demonstrate its effect on behaviour are less likely to occur in recent research due to ethical reasons (Demchak $\&$ Halle, 1985).

A number of studies have found that SIB increases for some individuals following aversive events such as high task demands or difficult tasks (Carr, Newsom, \& Binkoff, 1976; Edelson, Taubman, \& Lovaas, 1983; Gaylora-Ross, Weeks, \& Lipner, 1980; Iwata, et al., 1982; Weeks \& Gaylord-Ross, 1981).

Edelson et al. (1983) conducted a naturalistic observational study of social interactions between staff and autistic, schizophrenic, and mentally retarded children in an institutional setting. For 19 of the 20 subjects demands, the withdrawal of positive reinforcement, or punishment such as verbal reprimands resulted in a marked increase in SIB.

Weeks and Gaylord-Ross (1981) examined the relationship between task difficulty and the level of demands on the SIB of three mentally retarded and schizophrenic children. Higher rates of SIB were observed in the demand 
condition compared to the no demand conditions and with difficult tasks compared to easy tasks. A similar effect for task demands was reported by Carr et al. (1976) and Iwata et al. (1982). Carr and Durand (1985) found that a lack of adult attention and high task demands resulted in increased SIB in three retarded children. Based on these findings a communication skills programme was developed. Teaching alternative verbal responses resulted in decreases in SIB.

An individuals behaviour may be maintained by both positive and negative reinforcement in that an individual may use the same SIB behaviour for different functions depending on the circumstances (Baumeister \& Rollings, 1976). Similarly, different SIB topographies may serve different functions (Durand, 1982b). Durand found that while head hitting and face hitting appeared to be maintained by sesnory consequences, face hitting also increased with increases in task difficulty.

Ecological analysis have been conducted often in institutional settings to determine antecedent conditions that may affect the rate of SIB. The results of such studies have been reviewed elsewhere (Schroeder, Mulick, \& Rojahn, 1980; Schroeder, Schroeder, Rojahn, \& Mulick, 1980). Such studies examine the 
inter-relationships between the individual, behaviour, and the environment. It appears that such factors as environmental conditions, background settings, and the type of daily activities may exert an influence on SIB.

The majority of behavioural research has focussed on treatment interventions rather than identifying antecedents (Johnson \& Baumeister, 1978; Schroeder, Mulick, \& Rojahn, 1980). This may be due to a lack of resources, time, trained staff (Durand \& Crimmins, 1987) or the need to gain rapid control of the behaviour to prevent further SIB. Only a few of the earlier studies identified antecedents relating to SIB (Lovas et al., 1965 ) however, there appears to be a renewed interest in this area. This may be due to factors outlined by Carr (1977) who suggested that unsuccessful treatment interventions with some individuals may be due to a lack of understanding of the motivational factors involved in their SIB.

A number of assessment techniques have been developed recently to meet this need by determining the function of SIB in a variety of situations (Carr, 1977; Iwata et al., 1982; Durand \& Crimmins, 1987; Weisler et al., 1985). Suggestions have also been made of how such information might be utilised in developing treatment programmes (Carr \& Durand, 1985; Demchak \& Halle, 1985; Durand \& Carr, 1985). 
Weisler et al. (1985) developed a short survey questionnaire that was given to caregivers to determine the most common consequences for an individual's SIB. This questionnaire was based on a similar questionnaire developed by Carr (1977). Data were obtained for 60 residents and reliability checks involving direct observations were conducted. Reliability between staff ratings and direct observations was very high.

Iwata et al. (1982) assessed the function of SIB using a series of analogue situations involving (a) the presence or absence of play materials; (b) high or low experimenter demands, and (c) contingent, non-contingent, or no social attention.

Some subjects displayed SIB when demands were high while others displayed SIB when social attention was contingent on SIB.

The Motivation Assessment Scale (MAS) is a rating scale designed by Durand \& Crimmins (1987). The situations are similar to those used by Iwata et al. with the addition of a tangible reinforcement condition and an unstructured condition. The addition of the tangible condition was to determine whether social attention and tangible consequences may have separate effects on SIB. In addition a new method for assessing the role of 
sensory influences was proposed. Previous research in this area has been unable to eliminate the possibility that other factors may be involved in the maintenance of SIB. These procedures usually involve masking or extinguishing the sensory consequences of SIB by placing the individual in restraints or providing competing sensory stimulation. The authors have suggested providing unlimited access to tangible reinforcers, social attention, and no demands being placed on the individual. If the individual continues to engage in SIB sensory consequences may be maintaining the behaviour.

Preliminary investigations of the reliability and validity of the scale are promising. Ratings by teachers predicted how students behaved in analogue situations. As the authors point out the scale has the advantage of being less time consuming and requiring less trained staff than the analogue assessment method.

A number of useful treatment implications have been generated by this recent research. Durand and Crimmins (1987) are conducting research using the MAS to determine whether this information can be used to select effective reinforcers. Individuals who engage in maladaptive behaviours such as SIB to escape demands or gain social attention have been taught more appropriate means of communicating with signs, gestures, or words (Carr \& Durand, 1985). This resulted in decreases in 
the maladaptive behaviours. Other treatment possibilities include requiring individuals who use SIB to escape from demands to continue to co-operate with the demand (Demchak \& Halle, 1985; Durand \& Carr, 1985). Alternatively brief breaks from tasks demands could be scheduled and used as a potent reinforcer in treatment (Durand \& Crimmins, 1987).

In view of the recent development in assessment methods Durand and Crimmins (1987) have suggested that maladaptive behaviours should be classified and treated according to their function rather than the present emphasis on the type of maladaptive behaviour.

\section{Self-Stimulation Hypothesis}

The self-stimulation hypothesis is based on the assumption that individuals require a certain level of sensory stimulation (Demchak \& Halle, 1985). If the level of stimulation falls below or rises above the optimum level of stimulation individuals may engage in behaviours to increase or decrease stimulation (Carr, 1977). Mentally retarded persons often live in barren institutional environments in which there may be inadequate stimulation. Physical and sensory handicaps commonly associated with mental retardation may also inhibit efforts to obtain sensory stimulation appropriately. Therefore the individual must engage in 
self-stimulatory behaviour such as stereotypy or SIB to address this imbalance (Sandler \& McLain, 1987).

Horner (1980) compared the rates of stereotypy and SIB of five profoundy retarded subjects in enriched versus barren environments. Rates of SIB and stereotypy were lower in the enriched environments. In addition, incorporating differential reinforcement procedures in the enriched environment increased the rates of appropriate behaviours. However, the majority of subjects in this study engaged in stereotypy rather than SIB .

Sensory extinction or masking procedures have been successful in reducing stereotypy (Rincover, 1978; Rincover, Cook, Peoples, \& Packard, 1979) and SIB (Rincover \& Devany, 1982). These procedures may involve using protective equipment such as gloves or helmets, or alternative forms of stimulation such as vibration to mask or extinguish the sensory consequences of the behaviour. Rincover and Devany (1982) used these procedures in combination with differential reinforcement procedures so it is not possible to say which component of treatment was effective in reducing SIB. 
Favell, McGimsey, and Schell (1982) found that toys that provided the same sensory stimulation to the sense modalities involved in SIB reduced SIB. A differential reinforcement programme was added to the procedure to increase appropriate behaviour as in the previous condition SIB had tended to be replaced by stereotypy.

Wells and Smith (1983) provided vestibular and tactile stimulation non-contingently to the parts of the body involved in SIB. Reductions in SIB were reported although the study suffers from a number of methodological flaws.

Sandler and McLain (1987) examined reinforcer preference by five multihandicapped severely retarded children. Reinforcers involved vestibular stimulation, food, praise, visual, and auditory stimulation. Subjects were required to press a switch to obtain the various reinforcers and the rate of responding was the dependent variable in the study. Vestibular stimulation was the preferred reinforcer for four of the five subjects. However, the blind child in the study preferred contingent music (auditory stimulation).

The major limitations of the self-stimulation hypothesis include its inability to rule out rival hypotheses (Demchak \& Halle, 1985; Durand \& Crimmins, 1987; 


\begin{abstract}
Rincover \& Devany, 1982) and the circularity of the explanation (Baumeister \& Rollings, 1976). Elements of positive reinforcement, negative reinforcement, and/or punishment may be involved in the procedures which would provide alternative explanations for the reduction in SIB. As Baumeister and Rollings (1976) point out the theory involves a circular argument. If SIB occurs there is a lack of stimulation in the environment or alternatively if there is inadequate stimulation in the environment SIB will occur.
\end{abstract}

This led Demchack and Halle (1985) to conclude that until the theory has eliminated these alternative explanations the results remain speculative. Possibly the assessment procedure developed by Durand and Crimmins (1987) offers an alternative method of assessing the role of sensory reinforcement in SIB.

\title{
Organic Hypothesis
}

The major evidence for an organic basis for SIB comes from the identification of two syndromes of organic origin in which SIB is an associated feature, i.e., the Lesch-Nyhan and Cornelia de Lange syndromes.

Lesch and Nyhan (1964) identified a sex-linked disorder which affects only males and is due to an inborn error of purine metabolism. Mental retardation, cerebral 
palsy, choreoathetosis, self-biting, and hyperuricemia are some of the distinctive clinical features. The self-biting in the disorder is characterised by its frequent and severe nature. Individuals may be constantly restrained as the self-biting often results in deformities of the mouth and lips. On occasions individuals have amputated their fingers through biting (Nyhan, 1976). It has been speculated that decreased levels of the neurotransmitters dopamine or seretonin may be responsible for the SIB exhibited by Lesch-Nyhan patients (Cataldo \& Harris, 1982). However, pharmacological methods to control the disorder and the SIB require further investigation (Singh, 1981a).

The clinical features of de Lange syndrome are low birth weight, mental retardation, retarded growth, enlarged eyebrows and eye lashes, excessive growth and abnormal distribution of hair, and small hands and feet (Bryson, Sakati, Nyhan, \& Fish, 1971). The disorder is associated with a wider range of SIB behaviours than the Lesch-Nyhan syndrome but the behaviour tends to: be less intense. Unlike the Lesch-Nyhan syndrome, little is known regarding the organic factors involved in the etiology of the syndrome (Singh, 1981a). 
SIB has also occurred in a small number of patients with chromosonal abnormalities (Singh, 1981a).

In one study headbangers were found to have a significantly higher incidence of otitis media (midale ear infection) than normal controls (De Lissovoy, 1963). This finding led De Lissovoy to the hypothesis that headbanging might be explained in terms of a stress reaction or as a form of distraction and pain relief. The child would headbang to replace one pain by another. Although this may suggest why SIB emerges it does not explain how the behaviour is maintained (Demchak \& Halle, 1985).

A more recent theory suggests that SIB may be due to a disturbed endogeneous opiate system (Barron \& Sandman, 1983; Sandman et al., 1983). It has been hypothesised that this may result in an elevated pain threshold making individuals insensitive to pain. An alternative hypothesis is that engaging in SIB may release opiates providing pain relief. If opiates were released tolerance and dependence would result due to the opiates addictive properties and this would explain how SIB is 
maintained. The authors suggest that both of these hypotheses may be valid. This would mean that the elevated pain threshold would enable individuals to inflict a sufficient level of pain to release opiates and this would lead to tolerance developing. Richardson and Zaleski (1986) have suggested that as endorphins have similar chemical qualities to morphine the release of endorphins would result in euphoria. This would provide positive reinforcement for engaging in SIB. While withdrawal from endorphins by not engaging in SIB would provide negative reinforcement. This would make SIB more likely to occur.

If SIB is reinforced by the release of endorphins onto opiate receptors then blocking these receptors should prevent the reinforcing consequences occurring and eventually result in the extinction of SIB (Richardson \& Zaleski, 1983). It was hoped that naloxone hydrochloride (an opiate antagonist) would perform this function and SIB would decrease. However, inconsistent results have been reported regarding the effectiveness of naloxone (Beckwith, Couk, \& Schumacher, 1986; Davidson, Kleene, Carroll, \& Rockowitz, 1983; Richardson \& Zaleski, 1983; Sandman et al., 1983). 
In a similar line of research, Barron and Sandman (1983, 1985) investigated the relationship between sedative hypnotic response and SIB and/or stereotypy in mentally retarded persons. Sedative hypnotic drugs depress the central nervous system causing such behaviours as drowsiness. However, paradoxical excitement to these drugs was found in individuals with SIB who exhibited wakefulness and aggressive-disruptive behaviours. Clients who engaged in both SIB and stereotypy were more likely to display paradoxical excitement (68\%), compared to SIB alone (39\%), stereotypy alone (35\%), and neither behaviour (0\%)(Barron \& Sandman, 1983). However, there were several methodological flaws in this study including retrospective data collection, no reliability checks, and subjective measures of behaviour rather than behavioural observations.

In a further study, Barron and Sandman (1985) replicated these results with $70 \%$ of clients with both SIB and stereotypy showing a paradoxical response. Paradoxical responders were also more likely to have a lower $M A$, history of perinatal trauma, SIB, and aggressive behaviour compared to normal responders. These are associations often found in individuals who display SIB. This finding led the authors to suggest that a 
paradoxical response to sedative hypnotics may be a useful biological index for identifying individuals whose SIB is maintained by intrinsic reinforcers and for this group pharmacological intervention may be appropriate. However, further replication of these results in required and effective pharmacological interventions to reduce SIB to near zero levels or eliminate the behaviour have not been identified (Singh \& Millichamp, 1984, 1985).

Animal research has been conducted to provide evidence for an organic basis of SIB. Previous studies have found that caffeine and amphetamine administered to rats will produce self-injury in the form of self-biting. In these studies however the doses of the drugs were often artificially high. However, recently Mueller, Saboda, Palmour, and Nyhan (1982) found that low continuous doses of amphetamine and caffeine produced self biting in rats but not stereotypy. They hypothesised that caffeine and amphetamine may affect central dopamine neurotransmission. Haloperidol, a dopamine antagonist and antipsychotic drug was only minimally effective in controlling SIB produced by daily caffeine administration but pimozide which is also a dopamine antagonist prevented SIB by the amphetamine 
rats. Further research is needed to determine how these results relate to SIB in humans and whether these findings are significant in terms of pharmacological treatment.

As Baumeister and Rollings (1976) point out SIB occurs in a wide variety of populations and can take may forms. For an organic theory to be regarded as a major theoretical position it would have to be more broad and general than it is at present. SIB of an organic nature may also be maintained by environmental factors lCarr \& McDowell, 1980). Both the Lesch-Nyhan and Cornelia de Lange syndromes have been treated effectively with behaviour modification techniques (Duker, 1975; Singh \& Pullman, 1979). Behavioural methods to control SIB have proved to be the most effective to date (Carr, 1977) while pharmacological interventions have been largely ineffective in the reduction and elimination of SIB (Singh \& Millichamp, 1984, 1985).

\section{Psychodynamic}

The number of studies dealing with mentally retarded persons and psychotic children are relatively few compared to psychiatric populations. The literature in this area has involved predominantly single case studies and the results of treatment have been reported ancedotally. 
Although a variety of speculations have been made regarding the etiology of SIB there are some common themes that appear frequently in the literature. SIB has been conceptualised as an attempt to establish ego boundaries, aggression turned inwards, regression of the ego and displacement (Baumeister \& Rolings, 1976; Demchak \& Halle, 1985; Singh 1981a).

The common underlying theme in the literature is that SIB is symbolic (Baumeister \& Rollings, 1976). An example of this is a study by Zuk (1960). Zuk suggested that mentally retarded children were unable to differentiate between their own body and objects in the environment due to regression of the ego identity so that aggressive impulses were directed towards the most available object in the child's environment (their own body) .

An often mentioned criticism of psychodynamic theories is that they cannot be evaluated empirically and the terms cannot be operationally defined. Those: studies which have published results have tended to be unsuccessful (Bachman, 1972). Some behavioural researchers have also found that providing social attention and empathetic statements actually increases SIB (Lovaas et al., 1965). Due to the lack of empirical evidence to support this theory no conclusions can be made regarding its validity. 


\section{Treatment}

\section{Medical Treatment}

The use of drugs to control maladaptive behaviours in mentally retarded persons is common (Singh \& Aman, 1983). In fact, while the most frequently used intervention for SIB involves non-contingent physical restraint and/or drugs (Altmeyer et al., 1987; Griffin et al., 1986) the most well researched interventions are those that involve behavioural procedures (Russo, Carr, \& Lovaas, 1979).

Possible reasons for this may be due to a number of factors including: an adherence to the medical model in the treatment of mentally retarded persons; an assumption that they will not benefit from psychotherapy (Singh, 1981a); less time and resources are involved in such procedures; or an attempt to rapidly control the behaviour to prevent physical injury.

However, the consequences of such procedures can be serious for the patient. The possible side effects of drug tréatments include tardive dyskenesia and movement disorders (Gualtieri \& Hawk, 1981) which can only be identified following withdrawal from drugs. There are problems with identifying the disorder because of frequent stereotypic behaviour in this population (Singh, 1981a). Drugs may also depress behaviour 


\begin{abstract}
generally and interfere with learning (Aman, 1984). Sovner and Hurley (1985) have provided some useful guidelines for the use of psychoactive drugs with mentally retarded persons that deal with such issues as side effects.
\end{abstract}

The literature relating to the pharmacological treatment of SIB in mentally retarded persons has been reviewed extensively elsewhere (Singh \& Millichamp, 1984, 1985). The major conclusions reached were that despite the wide-spread use of drugs to control SIB the majority of the studies used weak experimental designs. These studies often involved open trials with numerous methodological inadequacies.

However, recently a few better controlled studies have been conducted. These studies meet the basic methodological requirements for drug research and experimental design such as double-blind, cross-over designs, reliability checks, and behavioural measures of SIB. These studies tend to be less optimistic regarding the effectiveness of the various drugs when compared to previous research.

In terms of the major tranquillisers minor reductions in SIB have been reported in the better controlled studies. It can be concluded that thioridazine (Melleril) and 
haloperidol (Haldol) appear to be the most effective with lithium carbonate showing some promise but it can have serious side effects.

Singh and Aman (1981) reported a small but statistically insignificant reduction in SIB in a double-blind cross-over trial of thioridazine with 19 mentally retarded persons. These results were confirmed by Singh and winton (1984). As the authors point out the study involved naturalistic observations so that the way in which the drugs were prescribed may mean there was a possibility of interaction effects. This study was interesting in that it was able to show that the way in which drugs are prescribed in institutions may not be related to behavioural changes in a patient's SIB.

Durand (1982a) compared the effectiveness of Haloperidol and a mild punishment (hand squeeze) on the SIB and collateral behaviours of a profoundly retarded subject. Using a double-blind withdrawal design it was found that neither medication or punishment alone was effective in significantly reducing SIB. The time the subject spent in bed and drooling increased with haloperidol. While more correct responses were made on fine motor tasks when the treatments were combined. SIB reduced to near zero levels only when the interventions were combined. As the author pointed out the study did not 
include a no-treatment baseline. Haloperidol may have acted as a setting event as it increased sensitivity in the hands. Whether the effectiveness of this combination is unique due to the setting event or it may be effective with other behavioural interventions requires further investigation. However, it is one of the few comparative studies available.

Recently a few studies have investigated the effects of naloxone in the treatment of SIB following the hypothesis that SIB may be caused by a disturbed endogenous opiate system (Barron \& Sandman, 1983, 1985; Deutsch, 1986; Sandman et al., 1983). However, inconsistent results have been reported regarding the effects of naloxone on SIB (Beckwith et al., 1986; Davidson et al., 1983; Richardson et al., 1983; Sandman et al., 1983). In contrast to the majority of arug studies these studies have involved adequate methodological designs and behavioural measures of SIB with the exception of the Richardson et al. study.

Sandman et al. (1983) administered 0.1 to $0.4 \mathrm{mg}$ of naloxone to two profoundly retarded subjects. They reported immediate but short-term reductions in SIB. However, no prebaseline data were reported and clinical trials of the drug were brief. 


\begin{abstract}
Various doses of Naloxone $(0.1,0.2$, and $0.4 \mathrm{mg})$ were ineffective in reducing the SIB of two profoundly retarded females (Beckwith et al., 1986).
\end{abstract}

Davidson et al. (1983) Eailed to suppress SIB in their treatment of an 8-year-old severely retarded boy with severe SIB although a reduction in the intensity of SIB was reported ancedotally.

Richardson and Zaleski (1983) also reported unsuccessful results in the treatment of a 15-year-old boy with SIB that resembled that of Lesch-Nyhan patients. However, this was a methodologically weak study with no double-blind, cross-over design, reliability checks, or behavioural measures of SIB and naloxone was administered over only two days.

The majority of evidence appears to indicate that naloxone is ineffective in reducing SIB.

In a study using a double-blind, cross-over design Primrose (1979) used baclofen (Lioresal) a gamma-amino-butyric acid (GABA) to treat SIB in 22 mentally retarded persons. He reported successful results in most subjects even after some had discontinued treatment. However, subjective measures of behavioural change were used, other medication the 
subjects received was not kept constant, the dosage was not standardised across subjects, and only those subjects who responded to the drug initially were followed up.

Successful results were reported with L-5-hydroxytryptophan. However, better controlled studies have failed to replicate these results (Singh \& Millichamp, 1984, 1985).

It appears that of the few better-controlled drug studies that exist the results are suggestive and require further investigation before definite conclusions can be reached regarding their effectiveness. As the use of arugs in the treatment of SIB in mentally retarded persons is common it is important that research in this area continue with better controlled studies and medical practitioners being made aware of this information.

Singh and Millichamp (1984, 1985) have made a number of valuable recommendations concerning the direction that drug research might take in the future. It is suggested that drug research initially should focus on group 
designs to establish the most effective drugs. These studies should meet the methodological requirements of drug research and experimental design. Single subject designs should also incorporate applied behaviour analysis methodology. Collateral behaviours such as prosocial and learning behaviours could be measured to determine the drugs effect on these behaviours. There is also a need for comparative research of various dosages of drugs, combinations of drugs, and other forms of treatment. Longterm measures of drug effects and side effects are also required.

\section{Behavioural}

Early studies using punishment procedures often involved the use of electric shock in cases of severe SIB. However, since that time other effective punishers that are less intrusive and are more likely to be ethically and legally acceptable have been found to be effective in controlling SIB. Recently a model for selecting treatments based on the level of intrusiveness has been developed. This has been reviewed by Morris and Brown $(1983)$.

The Least Intrusive Treatment model ranks procedures according to their level of intrusiveness. Level I involves differential reinforcement procedures and extinction. Level II includes time out and response 
cost. Level III includes punishment procedures and seclusion. Researchers are required to empirically demonstrate that Level I procedures have been ineffective in controlling SIB before Level II procedures are used. This also applies to the use of Level III procedures. Before Level III procedures are used Level II procedures must be shown to be ineffective. It has also been recommended that punishment procedures be used in combination with differential reinforcement procedures so that individuals learn adaptive behaviours to replace SIB (Favell, Azrin, et al., 1982).

\section{Electric Shock}

A common punishment procedure used in the early research involved the contingent use of electric shock to treat SIB. Electric shock is administered for a few seconds following SIB by either a hand held remote control device or by an inductorium (shock prod) applied to the subjects limbs. Although the shock is perceived as painful it is physically harmless (Favell, Azrin et al., 19821 .

Singh (1981a) reviewed over 20 studies using electric shock and found that only 7 of the studies were methodologically adequate. The majority of studies in this area use single subject case studies (Baumeister \& 
Rollings, 1976) employing $A B$ or $B$ designs, often reliability data were not reported and generalisation and follow-up were not employed. This probably reflects the fact that the majority of studies were used with chronic cases of SIB where clinical results are of greater significance than experimental control.

Ethical and legal restraints have now curtailed the use of electric shock. Johnson and Baumeister (1978) reviewed 60 published studies and found that electric shock alone or in combination with other techniques was the most common procedure. Recently other effective punishment procedures have been shown to be effective. Gorman-Smith and Matson (1985) reviewed studies sighted in psychological abstracts over the period 1976 to 1983 . They found that overcorrection followed by physical restraint, facial screening, and Differential Reinforcement (DRO) procedures were the most commonly employed treatment interventions. However, these results are only suggestive. Winton and Singh (1983) noted that electric shock had not been used in the treatment of rumination since 1977, due to ethical and legal restrictions.

Electric shock has produced immediate and dramatic reductions in SIB in the majority of studies, leading some researchers to regard electric shock as the most 
effective treatment for SIB (Baumeister \& Rollings, 1976; Favell, Azrin, et al., 1982). However, some failures have been reported (Jones, Simmons, \& Frankell, 1974; Romanczyk \& Goren, 1975).

Parameters of electric shock in the treatment of SIB has received very little investigation possibly for similar ethical and legal restraints (Baumeister \& Rollings, 1976; Lichstein \& Schreibman, 1976). Some general guidelines have emerged, however. Electric shock should be delivered immediately and consistently (Schroeder, Schroeder, Rojahn, \& Mulick, 1980) and be used to treat all SIB's so that complete suppression of SIB is achieved (Young \& Wincze, 1974). At times this is difficult to achieve in practice as the therapist is dependent on equipment. With the shock prod there may be a delay in the time of application while the therapist reaches the subject and applies the equipment to the body (Tate \& Baroff, 1966). There are also problems with remote control equipment being unreliable (Sherman, Swinson, \& Lorimer, 1984). Sherman et al. made a number of recommendations on how remote control equipment could be adapted and used to increase the reliability, after unreliable equipment led to electric shock losing its potency for suppressing SIB.

It has been pointed out by winton and Singh (1983) that some researchers have used low levels of shock and after 
finding it unsuccessful in reducing SIB increased the level of shock. This might account for variations in the rate of suppression and the length of time taken to achieve suppression. They recommend that shock be introduced at high levels which do not cause physical damage to avoid this problem.

The results achieved with electric shock do not tend to generalise across settings and therapists. However, this can be overcome usually with only a few shocks by having different caregivers administer the shock in different settings (Corte, Wolf, \& Locke, 1971; Lovaas \& Simmons, 1969). To avoid temporary suppression of SIB, SIB reappearing, or other maladaptive behaviours developing, it has been suggested that differential reinforcement prodecures be used in combination with electric shock to teach adaptive behaviours (Lichstein \& Schreibman, 1976).

The side-effects produced by the procedure have been reviewed in detail by Lichstein and Schreibman (1976). The authors concluded that the majority of side effects were positive. Of the studies reviewed 25 reported positive side-effects, 13 reported negative side-effects of which 8 were directly related to reactions to the shock device. Positive side effects included increased social behaviour and positive emotional reactions. 
While negative side-effects included fear of the shock apparatus, negative emotional behaviour following shock such as crying and whining, and increases in maladaptive behaviour.

The ethical and legal issues relating to shock are still unresolved (Fulcher, 1984). Some researchers have put forward the argument that the treatment which will be of the most benefit to the client should be used (Lovaas et al., 1965). While electric shock may be an intrusive procedure it will possibly have more immediate and dramatic results so less SIB will result. On the other hand researchers have suggested that other procedures have been developed of similar effectiveness so that electric shock should only be used as a last resort in life threatening situations or when all other appropriate procedures have failed (Winton \& Singh, 1983). As shock is a highly intrusive procedure, its use requires the consideration of such issues and professional standards being strictly adhered to (Favell, Azrin et al., 1982). Electric shock has the potential, as with other punishment procedures, to be abused by caregivers or staff.

\section{Aromatic Ammonia}

Aromatic ammonia capsules have been used as a punishing stimulus contingent on SIB. In this procedure capsules 
containing the vapour are released under the patients nose so that only the fumes are inhaled for a few seconds.

Although there are only a limited number of studies in this area the majority are well designed (Singh, 1981a). The results tend to indicate rapid and substantial reductions or the elimination of SIB (Altman, Haavik, \& Cook, 1978; Baumeister \& Baumeister, 1978; Jones \& Anderson, 1981; Singh, Dawson, \& Gregory, 1980; Tanner \& Zeiler, 1975), with the exception of one study in which aromatic ammonia exacerbated SIB in one of the subjects (Jones \& Anderson, 1981). This result may have been due to not using the procedure for a sufficient length of time. Rojahn, McGonigle, Curcio, and Dixon (1987) using a simultaneous treatments design found that while aromatic ammonia resulted in an initial increase in pica in a 16-year-old severely retarded autistic girl it eventually led to a decrease to near zero levels. However, water mist produced a more consistent decrease in pica so this procedure was continued as the treatment of choice.

The procedure has also been used to treat other maladaptive behaviours including breathholding, tics, running away, and hyperventilation (Singh, 1981a). 
Face slapping and hitting in a deaf and blind profoundy retarded girl were substantially reduced but not eliminated with aromatic ammonia (Singh, Dawson \& Gregory, 1980). An $A B A B C$ design was used in which the subject inhaled the fumes for a maximum of 3 seconds. Generalisation across settings and staff was programmed and the effects were maintained during this phase. A slight increase but not a complete return to baseline levels was reported during reversal.

In a study by Baumeister and Baumeister (1978) for one of the subjects in which SIB occurred at a high rate ammonia was given intermittently to avoid the aversive side effects of the procedure. Rapid elimination of SIB was reported. However, methodological problems in the study mean these results are only suggestive.

Immediate and rapid suppression of face slapping in a 20-year-old autistic woman was reported in one study (Tanner \& Zeiler, 1975). However, generalisation did not occur until ward staff were trained in the procedure. Only 21 days of follow-up were conducted and no baseline recordings were reported.

Altman et al. (1978) used ammonia to treat hair-pulling and hand biting in two mentally retarded children. A multiple baseline design showed generalisation of the 
results across settings. In one subject SIB was eliminated and maintained at follow-up a year later, while in the other subject it was reduced to near zero levels but showed some increase at a two month follow-up but did not reach baseline levels. A 3-second duration of ammonia was used.

In another experiment in which aromatic ammonia was used to treat the SIB of two mentaliy retarded children (Jones \& Anderson, 1981), successful results were reported with one of the subjects but the SIB increased in the other subject. The authors found that staff showed some resistance to the procedure and the problems associated with the procedure led them to suggest that it may not be suitable to use.

Various advantages and disadvantages have been pointed out by researchers who have used the procedure. The major advantage appears to be the rapid and dramatic results it has produced suggesting it may be only exceeded by electric shock in its effectiveness (Singh, 1981a). Singh (1981a) also described various advantages of the procedure when compared to electric shock which include it being possibly more acceptable to staff than electric shock, inexpensive, small, portable, and easy to use. The capsule size also allows them to be hidden easily so that the subject is less able to discriminate 
between safe and unsafe persons and/or situations (Baumeister \& Baumeister, 1978).

The disadvantages of the procedure include the need to restrain the subject who is likely to show resistance to the procedure such as struggling, crying, and coughing (Baumeister \& Baumeister, 1978). The procedure may be difficult to implement with physically large subjects (Singh, 1981a). It is also unpleasant to administer with mucous discharge and resistance to treatment being reported (Baumeister \& Baumeister, 1978) and appears to be a relatively strong aversive procedure in terms of the subjects resistance to treatment. There is also the risk of damage to the nasal mucosa and the skin surrounding the nostrils if the procedure is used too frequently or is not diluted sufficiently. (Singh, 1981a; Tanner \& Zeiler, 1975).

\section{Restraint}

Noncontingent physical restraint is one of the most commonly used interventions for the management of SIB (Russo, Carr, \& Lovaas, 1979). Side effects from the use of restraint can be serious and include restricted motor development, muscular atrophy, shortening of tendons and decreased mobility (Lovaas \& Simmons, 1969; Rincover \& Devany, 1982). Persons who are restrained or who self restrain voluntary may also be less likely to 
be included in educational and social activities limiting their ability to learn adaptive behaviours to replace SIB (Rojahn, Schroeder, \& Mulick, 1980). There is also the possibility that restraint will become reinforcing which, in turn, increases the likelihood of SIB and the need for restraint (Favell, McGimsey, Jones, \& Cannon, 1981). It has been noted that SIB may increase immediately following a release from restraints which may be a similar effect to an extinction burst (Singh, 1981a).

The studies to be discussed in this section have used restraint contingently as part of a treatment package to reduce or eliminate SIB. Restraint has been used in treatment as a reinforcer, punisher, consequence, or antecedent (Dorsey, Iwata, Reid, \& Davis, 1982).

Restraints function and relationship to SIB should be determined prior to treatment (Favell et al., 1981). As these authors point out, restraint may acquire reinforcing properties because it is paired with social attention or escape from aversive situations. This effect may be responsible for DRO not working if used in combination as restraint may be more rewarding. There is empirical evidence to show that for some individuals restraint functions as a reinforcer (Favell, McGimsey, \& Jones, 1978; Favell et al., 1981; Foxx \& Dufrense, 
1984). In these studies restraint was contingent upon appropriate behaviour. These authors were able to show that if restraint is contingent on the nonoccurrence of SIB, SIB will be reduced. Alternatively if restraint is contingent on appropriate behaviour, such as learning tasks, these behaviours will increase.

Foxx and Dufrense (1984) were successful in virtually eliminating SIB in a profoundly retarded subject, "Harry", by using restraint as a reinforcer and gradually extending the period of no SIB in combination with time out from restraint for SIB. Mechanical restraint was replaced by voluntary self-restraint by the subject. However, this was reduced by fading the size of the objects used for self-restraining. Self-restraint was eventually replaced by an appropriate form of self-restraint which involved wearing a pair of spectacles. A high density of reinforcement for not engaging in SIB may have also contributed to the successful results. These effects were maintained at a 4-year-follow-up. Successful results have been reported using a similar procedure (Hamad, Isley, \& Lowry, 1984).

Evidence to suggest that restraint may function as a punisher for some individuals comes from studies which have shown that SIB will decrease if restraint is contingent on SIB. Dorsey et al. (1982) have suggested 
a number of possible reasons for restraint functioning as a punisher. These include masking sensory stimulation, time out from preferred activities, and/or social attention, or the aversive properties of restraint.

The majority of studies in this area have incorporated restraint as part of a treatment package in combination with DRO or time out so that the effectiveness of restraint only is unable to be determined (Singh, Dawson, \& Manning, 1981). Recently there has been an increasing trend to use punishment in combination with DRO procedures so that adaptive behaviours may be learned to replace SIB. Also, in clinical and ethical terms, the priority is to reduce SIB as rapidly as possible so it can be of greater significance for experimental reasons to identify the effectiveness of the various components in a treatment package.

In one of the few studies to evaluate the effects of restraint used alone, Singh, Dawson, and Manning (1981) found that one minute restraint was more effective than 3 minute restraint. This is useful information for the clinician as it is preferable for ethical reasons to use the shortest effective duration for a punishment procedure and it also allows more repetitions of the procedure to occur during treatment sessions. This is 
particularly important when working with mentally retarded persons who require more repetitions to learn an association (Jenner, 1984). Restraint and DRO have been found to be more effective than either procedure alone (Parrish, Iwata, Dorsey, Bunck, \& Slifer, 1985).

Singh (1977) found that restraint and DRO in combination reduced SIB but it was only when a punishment procedure (tap on the fingers) was added that SIB was eliminated. In a 3-year follow-up study Singh, Gregory, and Pulman (1980) used a treatment package involving various combinations of physical punishment (tap on the fingers), verbal reprimand, time out, and physical restraint of 30 seconds duration. Successful results were reported with complete suppression of SIB for 2 subjects and near-zero levels in the other 3 subjects.

Paniagua, Braverman, and Capriotti (1986) used a treatment package of verbal reprimand, the removal of objects/fingers from the subjects mouth, physical restraint, and DRO to reduce pica and mouthing in a 4-year-old profoundly retarded girl to near zero levels. Stereotypy was treated simultaneously using response interruption and positive practice. As the authors point out treating multiple behaviour problems simultaneously has advantages in terms of time, resources, and cost effectiveness. 
Restraint has also been used as an antecedent (Dorsey et al., 1981). The philosophy behind such procedures appears to be that more acceptable forms of restraint such as jackets with pockets or helmets could be substituted for less adaptive forms such as splints or self-restraint. These new more adaptive forms of restraint are gradually faded and adaptive behaviours are reinforced to replace SIB and self-restraint (Rincover \& Devany, 1982; Rojahn, Mulick, McCoy, \& Schroeder, 1978; Silvermann, Watanabe, Marshall, \& Baer, 1984). Silverman et al. attempted to reduce a retarded male's face punching, leg kicking, and corresponding arm and leg restraint using protective clothing. They compared three conditions; no protective clothing, a helmet, and a helmet and padded slippers. The procedures were used in combination with DRO. The padded helmet reduced face punching and arm restraint and the addition of padded slippers reduced leg kicking and leg restraint. The authors also reported increased levels of adaptive behaviours such as manipulating blocks.

Two recent studies have recognised the importance of systematically assessing the function of SIB for a given individual and developing a treatment package accordingly (Parrish et al., 1985; Radler, Plesa, Senini, \& Reicha, 1985). 
Parrish et al. (1985) used a motivational assessment model the authors had developed earlier (Iwata et al., 1982) to determine whether SIB was maintained by positive, negative, or sensory reinforcement (Carr, 1977). SIB was measured in terms of academic demand, social attention, and an alone condition. After identifying that SIB occurred at higher levels in the alone condition it was hypothesised that SIB might be due to the witharawal of social attention or sensory reinforcement. Contingent protective equipment applied for one minute and DRO were found to be more effective in reducing SIB than continuous protective equipment or DRO used alone. However, the design used does not rule out the possibility of sequential effects. A multiple baseline was used across only two time periods making the study methodologically weak.

Radler et al. (1985) asked staff to record the most common antecedents and consequences for SIB. From this information it was hypothesised that SIB was most likely to occur after a break in contact with staff or as an avoidance behaviour. Accordingly a treatment package involving verbal reprimand and physical restraint by the therapist of 15 or 30 seconds duration for engaging in SIB was used. The subject was redirected back to the task to avoid SIB functioning as an avoidance behaviour. To provide the subject with appropriate means of 
obtaining staff attention and to increase adaptive behaviours differential reinforcement procedures were incorporated into treatment.

Favell et al. (1981) have developed a questionnaire for assessing the function of restraint for the individual. Considering the variety of functions SIB and/or restraint may have for any individual it would seem appropriate for future research to incorporate assessment procedures to address these issues.

Spain, Hart, and Corbett (1984) have suggested some useful guidelines for the use of restraint. They emphasised that the fading of such devices should be the longterm aim and the need to evaluate the use of restraint with behavioural methods. How restraint will be incorporated in a treatment package will depend on such factors as the function and nature, frequency, and the typography of SIB (Hamad et al., 1983).

Researchers have also attempted to develop restraint devices that are less restrictive to motor development and therefore less likely to result in adverse side-effects for the individual. A mouth guard (Wurtele, King, \& Drabman, 1984) and flexible arm splints (Ball, Datta, Rios, \& Constantine, 1985) have been used to control SIB in Lesch-Nyhan patients. 
Future research may begin with the less restrictive forms of restraint to avoid the subject inflicting damage and incorporate this device into a treatment package with the aim of reducing SIB and eliminating the need for restraint.

\section{Aversive Tasting Substances}

Aversive tasting substances such as lemon juice and tabasco sauce have been applied contingently on the occurrence of SIB to control the behaviour.

Lemon juice, normally approximately $5 \mathrm{mls}$, is squirted into the subject's mouth contingent on SIB. Lemon juice has been successful in reducing face-punching and headbanging in a profoundly retarded boy to near-zero levels which were maintained at follow-up (Mayhew \& Harris, 1979).

Rumination has been reduced to near zero levels using the procedure (Sajwaj, Libet, \& Agras, 1974; Becker, Turner, \& Sajwaj, 1978).

Tabasco sauce has been used to eliminate self-injurious finger-biting in an infant of normal intelligence with spina bifida and diminished pain sensitivity (Altman, Haavik, \& Higgins, 1983) and the self-biting and biting of others of a 16-year-old severely mentally retarded 
and blind female (Altmeyer, Williams, \& Sams, 1985). However, in both of these studies tabasco sauce was employed as part of a treatment package so its contribution to the reduction of SIB is unable to be determined. Sequential effects were also not controlled for and both studies contained various methodological flaws.

Singh (1979) found lemon juice to be more effective than pepper sauce in suppressing the rumination of a profoundly retarded boy. Although lemon juice initially reduced SIB it increased again to baseline levels while pepper sauce eliminated rumination. In a further experiment the author found that it was important to punish the first link in the response chain to suppress the behaviour before possible reinforcement associated with rumination could occur. Singh (1979) suggested that this factor might account for differences in the suppression rates of rumination in other studies. This study used an $A B A C$ design in determining the differential effectiveness of the two treatments. Future research might utilise an alternating treatments design .

It is likely that individual factors play a major part in determining which aversive tasting substance is likely to be the most effective. Altman et al. (1983) employed a taste test to determine the most aversive 
substance for the subject in terms of subject reactivity such as turning the head away.

Further research with well designed studies incorporating generalisation and follow-up data is required before conclusions can be drawn regarding the effectiveness of the procedures in treating SIB. Aversive substances have been less well researched than other punishment procedures (Favell, Azrin et al., 19821 .

The procedures have the advantage of being likely to be more ethically acceptable than some punishment procedures (Winton \& Singh, 1983) and can be topographically related to maladaptive behaviour (Dick \& Jackson, 1983b). However, it has been pointed out that it can be a difficult procedure to apply immediately and with precision. The aversive taste will also remain in the subjects mouth for a certain period following administration so there may be problems teaching adaptive behaviours simultaneously (Singh, 1981b). There is also the possibility of irritation of the mouth and surrounding skin or the subject inhaling lemon juice into the lungs (Singh, 1981a).

\section{Water Mist}

Water mist spray in which a small quantity of water is sprayed onto the subject's face contingent on SIB has received limited research. A few studies have been 
carried out but there have been methodological problems with design and the procedures have for the most part been used in combination with a verbal reprimand (Singh, 1981 a)

A combination of differential reinforcement and water mist paired with a verbal reprimand virtually eliminated SIB in an autistic child (Jensen et al., 1985). The size of the water bottle was gradually faded to prompt generalisation of the procedure. Although the effects were maintained at a 6-month follow-up the design, which was $A B$, does not permit strong conclusions to be drawn from this study.

A similar combination of procedures was used to treat the stereotypic and self-injurious hand/mouth biting of a severely retarded autistic boy (Bailey,Pokrzywinski, \& Bryant 1983). An $A B A B$ design was used in the study and near-zero levels of the behaviours were achieved rapidy. However, during the initial B phase there were changes in the therapist administering the procedure and the subject's medication. No maintenance data were reported.

Dorsey, Iwata, Ong, and McSween (1980) used water mist to treat a variety of SIB behaviours in seven profoundly retarded subjects. An $A B A B$ design was used for most subjects and SIB was reduced to low levels. 
Rojahn et al. (1987) compared the effectiveness of aromatic ammonia and water mist using a simultaneous treatment design on the pica of a 16-year-old autistic and severely retarded girl. Collateral SIB and aggressive behaviours were also monitored. Aromatic ammonia resulted in an initial increase in pica before a decrease to near zero levels occurred while water mist rapidly suppressed pica to similar levels. Treatment effects were maintained at a 3-month follow-up in which the treatment had been transferred to other settings and therapists. During the final phase of treatment the water bottle was faded by hiding it from the view of the subject. There was a decrease in collateral SIB behaviours during treatment although aggressive behaviours emerged during the final treatment phase but only at a low level.

Further research with methodologically sound studies is needed with generalisation and maintenance data. Little information is available regarding the effective parameters of this technique such as the amount of water needed, the temperature of the water, and the distance it should be sprayed from (Singh, 1981a). These issues require further investigation. Room temperature water has been successfully used to treat SIB (Bailey et al., 1983; Jenson et al., 1985). If this proves to be 
effective in further studies this would be preferable to using cold water for ethical reasons.

One advantage of the procedure is that unlike many of the available punishment techniques the subject is unlikely to struggle so it would not be a difficult procedure to implement (Bailey et al., 1983). The possibility of chafing as a result of treatment has been suggested (Favell, Azrin et al., 1982). However, this has not been reported as an adverse effect in any of the studies to date.

\section{Screening}

Screening procedures in which the subject's vision is blocked briefly contingent on the target behaviour have been used to treat SIB and a variety of other maladaptive behaviours. A terrycloth bib lfacial screening), the therapist's hand(s) (visual screening), or a blindfold are used to cover the subject's eyes (Singh \& Winton, $1984 \mathrm{~b}$ ).

Facial screening has been used successfully to reduce a variety of SIB topographies including trichotillomania (Barmann \& Vitali, 1982), thumbbiting (Singh, 1980), handbiting (Demetral \& Lutzker, 1980) and face/head slapping and/or head hitting (Lutzker, 1978; Singh, Beale, \& Dawson, 1981; Singh, Watson \& Winton, 1986; Winton, Singh, \& Dawson, 1984.) 
It has been used with maladaptive behaviours such as public masturbation (Barmann \& Murray, 1981); disruptive hand-clapping (Zegiob, Jenkins, Becker, \& Bristow, 1976) and screaming (Singh, Winton, \& Dawson, 1982).

The blindfold procedure has been used successfully to treat pica (Singh \& Winton, 1984b), face hitting (Winton et al., 1984) and face slapping in combination with other procedures (Murphy, Ruprecht, \& Nunes, 1978).

Visual screening has been effective in controlling self-injurious finger sucking (Watson, Singh, \& Winton, 1987); face hitting and interfering with others belongings/trespassing (Kohleis, 1986); stereotypy and self-injurious ear bending (McGonigle, Duncan, \& Barrett, 1982); screaming (Dick \& Jackson, 1983a) and compulsive rituals (Barrett, Staub, \& Sisson, 1983).

Screening procedures have tended to produce rapid results when they have been effective llutzker \& Wesch, 1983 ) often after the first few applications (Barmann \& Murray, 1981; Dick \& Jackson, 1983a; Lutzker, 1978; Singh, Beale, \& Dawson, 1981; Singh \& Winton, 1984b; Singh, Winton, \& Dawson, 1982; Watson et al. 1986; winton et al. 1984). However, treatment failures are unlikely to be reported in the literature (Lutzker \& Wesch, 1983). These authors have suggested on the basis 
of clinical experience that the failure rate may be as high as $40-50 \%$.

The procedures have been used in a wide variety of settings and have been implemented by various behaviour change agents (Lutzker \& Wesch, 1983). The parameters of the procedure have received some attention. It appears that the critical component of the procedures in suppressing SIB is the blocking of the subject's vision (Winton et al., 1984). Wearing the bib around the neck or having the head held in the same manner as the screening procedures does not suppress SIB (zegiob et al., 1978).

Determining the most effective duration contributes to the effectiveness and ease with which the procedure can be implemented (Singh, Beale, \& Dawson, 1981). These authors found that a one-minute duration of facial screening was more effective than either a 3 -second or 3-minute duration in suppressing SIB. These results were partially confirmed in a further study (Singh, Winton, \& Dawson, 1982) in which a one-minute duration of facial screening was more effective than a 3-second or 30-second duration in suppressing screaming. However, durations as short as 5 seconds of visual or facial screening have been shown to be effective in reducing SIB (MCGonigle et al., 1982; Watson et al., 19861 . 
The contingent application of facial screening has been found to be more effective than noncontingent application in reducing SIB (Demetral \& Lutzker, 1980). Facial screening applied on an intermittent basis in which the subject was screened on approximately every third self-injurious response has been found to be effective in reducing SIB (Lutzker, 1978). As the author points out this is probably more typical of how the procedure is likely to be implemented in less strictly controlled environments such as the home or institutions. However, replication of both these results is required.

McGonigle et al. (1982) regard screening procedures as a mildly aversive punishment procedure in terms of the subject's reactions following implementation of the procedure. Resistance to treatment has been noted in which the subject has struggled, attempted to remove the screening device, cried, or attempted to remove the therapist's hands. However, in the majority of cases this was only for the first few applications (Singh, 1980; Singh, Beale, \& Dawson, 1981; Singh, Winton, \& Dawson, 1982; Singh \& Winton, 1984b; Winton et al., 1984; Zegiob et al., 1976). In one study the subject showed no resistance to the procedure even though it was successful in reducing SIB (Lutzker, 1978). 
An interesting phenomenon in which the subject would occasionally self-administer the procedure contingent on the target behaviour has also been noted (Zegiob et al., 1976; Singh, Winton, \& Dawson, 1982). Avoidance behaviour associated with persons administering the procedure has not been reported as yet (Singh, Beale, \& Dawson, 1981; Zegiob et al., 1976).

Positive side-effects have been reported following successful results with screening procedures. Substantial increases in spontaneous toy play have been reported (McGonigle et al., 1982). Watson et al. $(1986)$ also found an increase in toy play but only after toy play training was provided. Another study which systematically measured side-effects found that collateral behaviours associated with pica such as picking up and handling objects decreased along with aggressive and destructive behaviour. Positive interactions with staff also increased (Singh \& Winton, $1984 \mathrm{~b})$. Improved language performance has also been reported (Zegiob et al., 1976). Ancedotal reports of positive side-effects include a decrease in clothes tearing behaviour, increases in engaging in previously avoided recreational activities, and interaction with peers (Kohleis, 1986). 
Researchers have also commented that the procedures are easily administered (Barmann \& Murray, 1981; Kohleis, 1986; McGonigle et al., 1982; Zegiob et al., 1976), required minimal staff training (Barmann \& Murray, 1981; Zegiob et al., 1976), involve minimal time and effort (Barmann \& Murray, 1981; Barmann \& Vitali, 1982; Kohleis, 1986), are portable and cost effective (Barmann \& Murray, 1981; Kohleis, 1986), posed few physical risks (McGonigle et al., 1982), and require minimal supervision (Zegiob et al., 1976) unless the client struggles too vigorously in which case supervision would be needed to ensure the procedure did not drift into unethical practices (McGonigle et al., 1982).

Social validation measures have been taken to assess the acceptability of the various screening procedures. Visual screening has been rated subjectively as an acceptable treatment procedure by a psychopaedic hospital staff as long as it is used in combination with differential reinforcement procedures (Mudford, 1986). It has been rated by parents/caregivers and observers as effective which reflected changes in objective data (Dick \& Jackson, 1983a). Facial screening only has been rated as ethical, easy to administer, and effective by parents and teachers after they administered the procedure in the home and school environment (Barmann \& Vitali, 1982). 
Comparative studies of both the various screening procedures and the differential effectiveness of screening procedures compared to other treatments has been somewhat limited. However, some preliminary research exists.

Barrett et al. (1981) found that facial screening and differential reinforcement combined were more effective than differential reinforcement alone in suppressing disruptive behaviour. Overcorrection was found to be effective in reducing SIB but only when it was combined with visual screening was SIB significantly reduced (Kohleis, 1986). However, there were problems with carry over effects with the design used in this study.

In comparison to other punishment techniques teachers have found facial screening to be preferable to time out because it involves less time to implement and it does not disrupt classroom activities to any great extent (zegiob et al., 1976). In comparison to the traditional overcorrection techniques it involves less time and effort to administer (Dick \& Jackson, 1983a).

Assessment procedures which provide information on which treatment will be the most effective is lacking.. This applies to screening procedures as it does to other techniques (Lutzker \& Wesch, 1983). However, procedures 
for assessing the client's motivation for SIB have recently been developed (see Durand \& Crimmins, 1987).

Lutzker and Wesch (1983) have suggested that information provided by caregivers regarding the subject's reaction to screening has informally proved to be useful information in determining treatment success. This observation is based on clinical experience, however. It also appears that if screening is likely to be effective the decrease will occur rapidly.

Comparing the effectiveness of visual and facial screening in reducing the SIB of two profoundly retarded subjects, it was found that both procedures reduced SIB more than a no-treatment control. However, visual screening was more effective for one of the subjects (Watson et al., 1986). The authors suggested that the results may only have been applicable to the 5-second duration used in this study.

Facial screening and the blindfold procedure were found to be equally effective in controlling the SIB of a profoundy retarded subject. Removal of the screening device was contingent on one minute of nondisruptive behaviour (Winton et al., 1984).

In addition, caregivers have been found to prefer visual screening over facial screening as it does not require 
special equipment (Watson et al., 1986). Facial screening was preferred over the blindfold as the subject was able to remove the blindfold continually (Winton et al., 1984).

Visual screening may be preferable to both facial screening and the blindfold as it does not require special equipment (McGonigle et al., 1982). This is an important consideration for generalisation and maintenance. Facial screening may also be less preferable compared to visual screening for aesthetic reasons (Lutzker \& Wesch, 1983). There is also the concern that facial screening may interfere with the subject's breathing. However, this has not been noted to occur in any of the studies mentioned.

The majority of studies in this area have been well designed and many have included generalisation and maintenance data, reflecting the fact that screening procedures are a more recent technique to be developed. It has been suggested that screening procedures may be particularly effective with hearing-impaired subjects (Fulcher, 1984) if in fact visual blocking is the critical component in suppressing SIB.

\section{Overcorrection}

Overcorrection, a treatment package developed by Foxx and Azrin (1972), has been used to treat a variety of 
maladaptive behaviours including SIB or to increase appropriate behaviours. During overcorrection the individual is required: (a) "to overcorrect the environmental effects of the inappropriate act and/or (b) to repeatedly practice correct forms of relevant behaviour in situations where the misbehaviour occurs" (Foxx \& Bechtel, 1982a p.230).

To meet the criteria for overcorrection, a procedure should be: (a) "directly related to the misbehaviour, that is, require topographically related or similar responses; (b) require the client's active participation; (c) be applied immediately; and (d) include instructions and graduated guidance so that the potential for escape and avoidance conditioning exists" (Foxx \& Bechtel, 1982a p.280). Foxx and Bechtel (1982a) have suggested that the various labels given to the procedures should be abandoned to avoid definitional. problems and misconceptions.

Overcorrection has been used successfully to treat a variety of SIB behaviours. The studies have been reviewed in detail elsewhere (Foxx \& Bechtel, 1982a, $1982 b)$

An overcorrection procedure in which the limbs are moved in accordance with the therapist's directions and guidance has been the most commonly used overcorrection 
procedure with SIB (Foxx \& Bechtel, 1982b). If the limbs are moved without the subject being given the opportunity to co-operate this does not constitute an overcorrection procedure. This procedure is often used for behaviours such as headbanging or self-hitting.

Halpern and Andrasik (1986) reported an immediate reduction in headbanging to near-zero levels in a profoundly mentally retarded male. At an 11-month follow-up, although there was a slight increase in headbanging, it was still well below baseline levels. Ancedotal reports of an increase in sociability in an untreated setting were made by staff. An inability by staff to implement the programme may have contributed to the continued low levels of SIB. In this study a $3-5$ minute duration of requiring the subject to move his head in response to therapist's instructions was used.

The procedure was used to rapidly reduce headhitting in a profoundly retarded boy (Gibbs \& Luyben, 1985). The duration of the procedure was 5 minutes in this study. Follow-up at 2-months revealed that treatment effects had been maintained.

A commonly used procedure to reduce behaviours such as mouthing, rumination, pica, and copraphagy involves contingent tooth brushing with an oral hygiene solution 
(e.g., Listerine) for an extended period of time. This procedure in combination with satiation was used to treat rumination in two profoundly retarded subjects (Foxx, Synder, \& Schroeder, 1979). Satiation alone reduced the behaviour to low levels. However, the addition of a procedure in which the subject was told "no" and instructed to clean their teeth with a toothbrush soaked in Listerine for 2-minutes and then wipe their lips with a facecloth reduced rumination to near-zero levels.

An oral hygiene procedure was used by Singh, Manning, and Angell (1982) without satiation to reduce the rumination of profoundly retarded monozygous twin males to near-zero levels. These effects were maintained at a 6-month follow-up. In addition, prosocial and stereotyped behaviours were directly measured. Both behaviours increased compared to baseline levels. The authors suggested that a differential reinforcement procedure be added to reinforce appropriate behaviours. This may lessen the chances of an increase in stereotypy.

This procedure has also been successfully used to eliminate pica in two profoundy retarded subjects (Singh \& Winton, 1985). This is one of the few studies to involve a component analysis of an overcorrection 
procedure. The authors used an alternating treatments design to compare the components of an overcorrection treatment package to treat pica. The other components included tidying in which the subject was required to remove the inedible object from their mouth, place it in the rubbish tin, and empty it. While personal hygiene involved removing the object from the mouth and scrubbing their fingernails for 5-minutes. Both of these procedures reduced pica to low levels however the contingent toothbrushing procedure produced the most significant reductions and eventually eliminated the behaviour.

Overcorrection procedures normally function as punishing stimuli in that they often decrease maladaptive behaviour when they are applied contingent on the behaviour. The procedure may also involve negative reinforcement if an adaptive response terminates the procedure and this response increases. Extinction and time out from reinforcement may be involved as the overcorrection responses are applied immediately and prevent the subject from gaining reinforcement for the target behaviour (Foxx \& Bechtel, 1982a).

Overcorrection appears to be becoming an increasingly popular method of treating SIB (Gorman-Smith \& Matson, 1985 ) as legal and ethical restraints have curtailed the 
use of electric shock and other aversive techniques. Despite this fact overcorrection appears to be one of the least understood procedures with misconceptions regarding how the procedure should be implemented. Foxx and Bechtal (1982a) reviewed 97 studies using overcorrection with a wide range of behaviours and found that $18 \%$ had used procedures which did not meet the requirements for overcorrection and were incorrectly labelled overcorrection. This is probably due in part to the fact that the procedures are not standardised (Winton \& Singh, 1983). The replication of studies that were effective might be helpful in this regard.

Earlier studies tended to use extended durations of overcorrection. However, these do not appear to be necessary to reduce maladaptive behaviours. In the majority of studies 5-10 minute durations have been used (Foxx \& Bechtel, 1982a). However, durations as short as one or two minutes have been effective in reducing a wide range of SIB behaviours (Jenner, 1984).

To determine how well the effects of overcorrection were maintained, Foxx and Livesay (1984) followed up 8 subjects treated with overcorrection procedures 10 years earlier. Progress was determined on the basis of client records, direct observations, and interviews with staff. The maladaptive behaviours treated included 
disruptive-aggressive behaviours, coprophagy, pica, and failure to attend classes. The maintenance of treatment effects varied considerably across subjects. Lower functioning individuals who displayed pica and coprophagy behaviours showed the least maintenance of treatment effects in terms of response suppression and duration of suppression when compared to the higher functioning subjects. The authors also found that the institutional staff were likely to revert to their previous methods of managing the behaviour particularly with the lower functioning subjects once the programme was terminated and this problem increased with time.

Several suggestions were made to increase the probability that the effects of overcorrection would be maintained such as simpler and less complicated overcorrection procedures. In fact staff sometimes adapted the overcorrection procedures themselves to achieve this aim. They recommend longterm maintenance data of at least 12 months across therapists, settings, and time and an emphasis on maintenance of treatment effects rather than the present emphasis on immediate and dramatic suppression of SIB.

Duker and Seys (1983) conducted a follow-up study of one mildy retarded and 10 severely retarded subjects. Subjects were previously treated with either extinction 
or overcorrection. The follow-up period ranged from 7.5 to 84 months. The effects of overcorrection were maintained for 5 of the 6 behaviours treated. Although the effects of only 2 of the 7 treatments were maintained with extinction direct comparison is not possible between the effectiveness of the procedures as only $A B$ designs were used with the extinction studies so that caution is required in interpreting the results.

Gibbs and Luyben (1985) investigated the effects of contingent versus noncontingent application of an overcorrection procedure with a profoundly retarded boy who engaged in headhitting. The subject was required to hold his arms in various positions when requested. The procedure was found to be effective when applied noncontingently, but reduced SIB to near-zero levels when applied contingently. However, sequential effects cannot be eliminated due to the design used in this study. The authors suggest that this confirms the procedure is functioning as a punishing stimuli rather than fulfilling an educative role of teaching an alternative response. This point however has already been acknowledged by Foxx and Bechtel (1982a).

Component analysis of overcorrection procedures has received little empirical investigation. At present the most helpful approach may be that adopted by singh and 
Winton (1985) in which a single overcorrection procedure which had formally been incorporated into a treatment package of several overcorrection procedures was found to be effective alone. This would simplify the procedures and save time and effort by staff which has been a common criticism of overcorrection.

\section{Differential Reinforcement}

Differential reinforcement procedures involve ignoring $S I B$ and reinforcing the subject for engaging in incompatible behaviour (DRI), alternative behaviour (DRA), or the absence of SIB (DRO) (Baumeister \& Rollings, 1976). Reinforcement commonly involves verbal and tactile praise, sensory reinforcement, or edibles.

Differential reinforcement procedures are commonly used in conjunction with other procedures such as time out or extinction and the contribution of the various components has not usually been evaluated (Singh, 1981a). However, in a few studies differential reinforcement procedures have been used alone. It has been pointed out that such procedures should be incorporated into any treatment package including those involving punishment. This provides the subject with the opportunity to develop alternative behaviours so that reinforcement can be obtained for engaging in adaptive behaviour rather than maladaptive behaviour (Favell, Azrin et al., 1982). 
The effectiveness of differential reinforcement procedures depends partly on the potency of the reinforcer. Establishing effective reinforcers for clients who engage in SIB may be difficult as the majority of subjects are severely or profoundly retarded and may have sensory and/or physical handicaps (Sandler \& McLain, 1987). However, a number of procedures have been developed recently which enable researchers to establish reinforcer preference and potency prior to treatment (Pace, Ivancic, Edwards, Iwata, \& Page, 1985; Rincover \& Newsom, 1985; Sandler \& McLain, 1987). Some useful suggestions on how a functional analysis might be used to provide such information has also been made (Durand \& Crimmins, 1987). Such procedures would enhance the probability of treatment success.

The teaching method may also affect the rate of SIB and how frequently adaptive behaviours occur. A common problem with increasing adaptive behaviours in profoundly retarded subjects is to teach the subjects in such a way that they may become independent on a task so that the activity can become intrinsically rewarding. Singh and Millichamp (1987) were able to achieve such results with profoundly retarded subjects using a teaching technique that encouraged independent and social toy play. Rather than use a full hands on teaching method subjects were encouraged to play with 
the toys independently. If this did not occur partial guidance or, if necessary, full guidance was used. SIB was reduced to low levels while independent toy play increased.

Accessibility of toys has also been found to alter the rate of SIB and toy play (Lockwood \& Bourland, 1982). With nonambulatory retarded subjects toy-play was almost doubled when toys were attached to an apparatus and could not be misplaced, while SIB was approximately doubled when toys were loose. However, some caution is needed in interpreting the results of this study as in the toys loose condition, toys were not returned until the end of the 5-minute session if the toys were thrown away or dropped. While this may reflect what would happen in a natural environment, it also means that SIB is decreased in this condition as a function of the way the procedure was implemented.

The comparative effectiveness of the various reinforcement procedures has not been adequately established and inconsistent results have been reported (Singh, 1981a). If DRO is used the opportunity to obtain reward is maximised. However, there is the possibility that other maladaptive behaviours or SIB may be accidentally reinforced, while DRI and DRA have the advantage of teaching the individual adaptive behaviours 
that may compete with SIB. Differential reinforcement of low rates of behaviour (DRL) which may be appropriate for high rates of SIB has not been researched with this behaviour (Baumeister \& Rollings, 1976; Fulcher, 1984).

Fulcher has pointed out that it has been used successfully to control stereotypy (Singh, Dawson \& Manning, 1981); to achieve complete suppression of the target behaviour DRL could be changed to DRO later in treatment (Deitz, 1977; Singh, Dawson, \& Manning, 1981).

Differential reinforcement procedures have been reviewed elsewhere (Favell, Azrin et al., 1982; Fulcher, 1984; Singh, 1981a). There are a few well designed studies using differential reinforcement alone that have provided evidence to suggest that SIB can be reduced to near-zero levels with some individuals (Singh, 1981a).

However, the generalisation and longterm maintenance of SIB requires further investigation. If the subject is exposed to the previous contingencies that maintained SIB, a return to the previous level of responding can be expected (Baumeister \& Rollings, 1976). As Baumeister and Rollings point out differential reinforcement procedures may be carried out in settings that are artificial and/or may reinforce a very restricted range of responses. If DRA or DRI is used it may be an 
artefact of treatment that the subject is engaging in an incompatible response as it is not possible to engage in SIB, particularly if manual guidance is used. This makes it particularly important that the individual's behavioural repetoire is expanded so that generalisation can occur.

Differential reinforcment procedures have the advantage of being more socially and ethically acceptable than punishment procedures (Singh, 1981a). According to the least intrusive treatment model differential reinforcement procedures must be proven to be ineffective in reducing SIB before punishment can be implemented (Morris \& Brown, 1983). This means it is particularly important that the question of the longterm maintenance and generalisation of treatment effects is addressed.

Differential reinforcement procedures share similar disadvantages to those commonly associated with extinction (Horner \& Barton, 1980). For example, the subject is still free to engage in SIB. This is probably more of a problem with DRO procedures as manual guidance can be used with DRI and DRA which would limit the subject's ability to engage in SIB. 


\section{Communication Training}

Carr and Durand (1985) have suggested that SIB could be replaced with functional communication skills. This reflects a theoretical perspective that some mentally retarded persons' behaviour problems may be conceptualised as a non-verbal means of communication. Using functional analysis to determine the motivation of maladaptive behaviour, Carr and Durand (1985) found that both low levels of adult attention and high levels of task difficulty resulted in maladaptive behaviour. Subjects who were moderately to severely retarded were trained to use verbal phrases that were effective in obtaining staff attention, task assistance, or both depending on the individual's motivation for SIB. The results confirmed the authors' hypothesis that by teaching subjects phrases that were functionally related to the motivation underlying their behaviour problems, SIB and other maladaptive behaviours decreased to low. levels. Teaching subjects phrases that were not functionally related to their behaviour problems did not significantly reduce maladaptive behaviours.

As the authors point out the advantages of such a procedure include the subject taking an active role in treatment and it avoids some of the ethical problems of punishment procedures. In addition, subjects are taught an adaptive behaviour that may have a higher probability 
of preventing SIB than other adaptive behaviours. It is acknowledged that the subject is still free to engage in SIB and if the problem is severe, functional communication training used alone may not be appropriate and a punishment procedure may be required to reduce the behaviour rapidly. However, functional communication training may still be used in combination with such a procedure when teaching alternative behaviours to replace SIB. With subjects who are non-verbal, for example, some profoundly retarded persons, it is possible that a similar procedure could be used but signing or gestures instead of phrases could be taught.

Further research is needed in this area to establish the effectiveness of this technique.

\section{Gentle Teaching}

Gentle teaching, a multicomponent treatment package which involves both differential reinforcement procedures, has received considerable publicity in New zealand. The procedures are designed to eliminate maladaptive behaviours in the retarded and are thought to be particularly suitable for self-injurious, aggressive, avoidant, and self-stimulatory behaviours (McGee, 1985a).

Gentle teaching techniques are focussed on reducing maladaptive behaviour and teaching bonding (McGee et 
al., in press, p.5l. McGee views bonding as a humanising social attachment between the caregiver and the individual (McGee, 1985d). Bonding can be operationally defined (Mudford, 1987). An individual who has bonded will display such behaviours as smiling, laughing, teasing, and interacting socially with the caregiver (McGee et al., in press, p.16).

According to the philosophy upon which gentle teaching is based mentally retarded individuals who display maladaptive behaviours are thought not to have bonded or to have lost the value of human interaction. The goal of gentle teaching is to enable the individual to learn the value and reward of human interaction through verbal and tactile praise. For this reason only social reward is considered appropriate (McGee, 1985a).

McGee regards bonding as the basis of all learning and human interactions (McGee, 1985d). To provide plenty of opportunity to teach bonding the individual is continually redirected to developmental tasks which are error-free or taught by shaping techniques so that differential reinforcement of alternative or incompatible behaviours can be applied frequently.

Glynn (1985) has questioned this error-free approach to teaching and suggests that making mistakes and being 
shown the correct method is a natural process in the teacher-student relationship. However, functional analysis of the motivation of SIB suggests that less SIB will occur on error-free tasks. McGee tends to use developmental tasks initially to achieve this. However, age-appropriate functional tasks could also be made exror-free (Brown, Branston, Hamre-Nietupski, Pumpion, Gerto, \& Gruenewald, 1979).

Studies have shown that SIB increases following high task demands, difficult tasks, or low levels of attention (Carr et al., 1976; Carr \& Durand, 1985; Edelson et al., 1983; Gaylord-Ross et al., 1980; Iwata et al., 1982; Weeks \& Gaylord-Ross, 1981). Gentle teaching involves high task demands, high levels of social attention, and error-free tasks. However, with individuals who display avoidance behaviour SIB might increase initially with high task demands and an inability to escape SIB may eventually decrease.

Maladaptive behaviour which is likely to cause danger or injury to the self or others is reduced using a technique called "interrupt" in which aggressive or self-injurious behaviours are blocked using an open palm or the hands are continually shadowed (McGee, 1985b).

As Glynn (1985) points out, one of the major procedures within the Ignore-Redirect-Reward approach involves the 
commonly used behavioural techniques of extinction, differential reinforcement, shaping and chaining and stimulus control. McGee (1985a) acknowledges that the techniques used in gentle teaching are not new and involve commonly used behaviour modification techniques. He claims that where gentle teaching differs from applied behaviour analysis is by not using punishment techniques and the caregivers posture toward the retarded which combines affection and tolerance. McGee is highly critical of punishment procedures (McGee, 1985d). As the goal of gentle teaching is bonding, McGee regards any use of punishment procedures as incompatible with this goal (McGee, 1985d).

Some of the criticisms McGee has made regarding the use of punishment procedures used by well known researchers in the field have been unjustified and incorrect (Mudford, 1987). Mudford (1987) also points out that the technique McGee labels interrupt is in fact brief restraint, a punishment procedure. Following Mudford's suggestion it is debateable whether gentle teaching is a Level 1 treatment. This may depend on how the interrupt procedure is administered.

McGee (1985a) has suggested selecting a combination of techniques which prevent as many maladaptive behaviours as possible and continually evaluating this combination as the individual progresses through treatment. 
Gentle teaching involves the following techniques:maladaptive behaviour by giving no eye contact, attention, or speech. Simultaneously redirecting the individual nonverbally back to developmental tasks and giving verbal and tactile praise for on-task behaviour.

Interrupt-Ignore-Redirect-Reward. This technique is used for maladaptive behaviour likely to cause damage or injury to self or others. It involves interrupting the behaviours by blocking hits with an open palm or continually shadowing the hands. This technique is used as a last resort and emphasis is placed on identifying the antecedents and consequences of the behaviour to avoid it escalating to a level where this approach is needed. Simultaneously during interruption extinction is used and the individual is redirected to developmental tasks and verbal and tactile praise is given for on-task behaviour. is arranged in such a way as to increase the probability of on-task behaviour by preventing 
- maladaptive behaviours from occurring through consideration of environmental variables such as furniture arrangement, type of furniture, location of other persons in the room, accessibility to windows and doors and the location of the caregiver in relationship to the person. developmental tasks through consideration of such factors as the arrangement of tasks, control of materials, concentration of the task, and teaching methods.

Errorless Learning. A specific stimulus control technique provided by arranging the steps of a task sequentially so that the probability of success is close to $100 \%$.

Shaping and Fading. Rewarding successive approximations to the task and removing assistance gradually as the subject becomes independent on the task. nonverbal means of communication, e.g., gestures and signs and gradually using more language as on-task behaviour increases. 

sufficient degree of assistance to ensure success at developmental tasks and decreasing the degree of assistance as the individual becomes independent on the tasks. sufficient degree of verbal and tactile reward to ensure on-task behaviour and decreasing reward as the individual becomes independent on the tasks.

Ethical considerations and attempts by ethics. committees, professionals, and caregivers to follow the Least Intrusive Treatment Model have increased the need for empirical validation of the effectiveness of Level I techniques. Despite claims by McGee and his colleagues of the success of gentle teaching with over 600 mentally retarded individuals and across all levels of mental retardation (MCGee, 1985C) only B designs have been used to evaluate treatment effectiveness (McGee et al., in press; McGee, 1985c). Medications have been withdrawn during the course of other studies with only B designs evaluating treatment effectiveness (Menolascino \& McGee, 19831 .

Validation of gentle teaching with methodologically sound designs is needed particularly as the philosophy 
has received considerable publicity. As Mudford (1987) points out it would be premature to abandon the least intrusive treatment model until the techniques have been evaluated with methodologically sound designs.

For the purposes of generalisation, McGee suggests structuring the individual's day to teach functional skills and provide plenty of opportunity to teach reward (McGee et al., in press, p.116). This poses problems in an institutional setting where the environment may be barren and there may be a lack of staff or lack of consistency among staff. However, this is a problem found when attempting to obtain generalisation and maintenance with any behaviour modification programme.

If the gentle teaching techniques prove to be effective and interrupt is not used as brief restraint, this would provide another Level I treatment technique that could be used to treat SIB. It would not have the disadvantages of punishment techniques such as misuse by caregivers. It would also meet ethical considerations for the need to use reinforcement techniques before punishment techniques are used. Gentle teaching would also have the advantage over other less intrusive procedures such as extinction, DRO, response cost, and time out, of the individual being unable to engage in SIB by the use of the interrupt technique. 
Procedures Similar to Gentle Teaching

Procedures similar to gentle teaching have been used. Freshi and Dileo (1982) used a technique called "positive interference" in which SIB was blocked or prevented by the caregiver in a neutral manner. The child was then redirected back to the tasks and reinforcement was provided. However, this procedure also involved a technique called "restart" in which the child repeats the parts of the task interrupted by SIB. Unfortunately this was a case study so caution is required in interpreting the results. SIB was ancedotally reported to be maintained at near-zero levels 2 years later.

Fellner, Laroche, and Sulzer-Azaroff (1984) used a procedure called "interruption" combined with DRO and DRI to treat multiple stereotypic and SIB behaviours in a 6-year-old retarded girl. Interruption for the various target behaviours involved a verbal reprimand and such procedures as the trainer cupping his/her hand over the child's mouth or gently guiding the child's hand to his/her lap for $1-2$ seconds.

The results showed that a combination of DRO, DRI, and interruption was more effective than DRO and DRI combined and reduced SIB to near-zero levels which was maintained at a 4-month follow-up. However, no baseline 
data were reported. The authors put forward a number of hypotheses as to why the interruption techniques might be effective. These included an extinction effect which prevented the subject from obtaining sensory reinforcement for engaging in SIB, negative reinforcement where the subject engaged in adaptive behaviour to avoid the interruption procedure, or punishment in which the interruption procedure was aversive enough to prevent the subject from engaging in SIB. Similar hypotheses could be made concerning gentle teaching.

\section{Extinction}

Extinction involves the discontinuation of reinforcement of the response which is to be eliminated (Singh, 1976).

Many of the studies involving extinction were early studies with methodologically weak designs (Singh, 1981a). Few studies recently have used extinction alone although some studies have incorporated extinction as part of a treatment package. In fact the Association for Advancement of Behaviour Therapy Task Force (Favell, Azrin et al., 1982) recommend that researchers conducting any treatment programme should pay particular attention to reducing or eliminating the reinforcement that SIB envokes. This may involve educating staff in new methods of coping with SIB to avoid SIB being reinforced during or following treatment. 
The reason why there are few studies using extinction alone recently is probably due to the disadvantages and ethical concerns relating to extinction which were highlighted by the earlier studies.

Bearing in mind the methodological inadequacies of early studies, extinction alone has been found to be effective in controlling SIB (Lovaas \& Simmons, 1969; Jones, Simmons, \& Frankel, 1974). However, extinction tended to be a slow, gradual process with the subjects engaging in thousands of SIB responses before SIB was eliminated (Jones et al., 1974; Lovaas \& Simmons, 1969). Extinction has not been effective in all cases (Corte, Wolf, \& Locke, 1971 ).

There are a number of disadvantages with the use of extinction and it appears that extinction may only be appropriate if the SIB rate is low, the risk of injury is minor, and social attention is clearly maintaining the behaviour (Horner \& Barton, 1980). The disadvantages of extinction raises ethical problems regarding its use in treatment.

Extinction presupposes that clients have been reinforced for SIB (Schroeder, Schroeder, Rojahn, \& Mulick, 1980). If SIB is maintained by sensory reinforcement or negative reinforcement, extinction will not be 
effective. The reinforcement for SIB must be able to be identified for extinction to be effective (Favell, Azrin et al., 1982). The effectiveness of extinction will also depend on such factors as the subject's previous history of reinforcement and the length of time the subject has engaged in SIB (Singh, 1981a).

The effects of extinction may be situation specific (Lovaas \& Simmons, 1969) so that the extinction procedure may have to be repeated across settings and caregivers. This means that the risk of serious injury to the subject is high if SIB is severe (Singh, 1981a). This can be controlled for to some extent by padding surfaces and requiring the subject to wear padded protective equipment (Favell, Azrin et al., 1982). However, this procedure is termed sensory extinction (Rincover \& Devany, 1982).

The withdrawal of reward may lead to an increase in SIB before a decrease is observed (Lovaas et al., 1965) and may produce emotional responses such as anger, frustration, or aggression (Singh, 1981a).

Extinction should not be used unless reinforcement can be withheld consistently which may be difficult to ensure particularly in institutional settings. In such settings there is usually a high staff turnover and a 
low ratio of staff to subjects so that the probability of SIB being reinforced accidentally is high (Favell, Azrin et al., 1982; Singh, 1981a).

This poses problems particularly if SIB is reinforced during an extinction burst or during spontaneous recovery when the rate of SIB may be higher than previous levels. If SIB is reinforced during these times this places SIB on an intermittent schedule of reinforcement which makes SIB even more resistant to extinction (Singh, 1981a).

As with punishment procedures extinction should be used in combination with differential reinforcement procedures so the subject has the opportunity to learn adaptive behaviours to replace SIB.

\section{Response Cost}

Time out and response cost are punishment procedures that involve the witharawal of reinforcement contingent upon the occurrence of a given response (Singh, 1981a). With mild to moderately retarded persons token economy programmes can be used in which tokens are given to increase adaptive behaviours and are withdrawn if SIB occurs (Myers, 1975). In the case of severe or profoundly retarded persons vibration (Nunes, Murphy, \& Reprecht, 1977), social attention, edibles, or 
activities or any combination of these reinforcers may be witharawn (Lucero, Frieman, Spoering, \& Fehnenbacher, 1976; Augustine \& Cipani, 1982).

Singh (1981a) in a review of research in this area found that there had been only three well controlled studies using response cost alone. Other studies had used response cost as part of a treatment programme. Therefore further research is needed before strong conclusions can be made regarding the procedure's effectiveness.

Of the better designed studies, Lucero et al. (1976) found that the withdrawal of food and attention for 15 seconds contingent on SIB was more effective than the witharawal of attention alone in controlling the SIB of three profoundly retarded girls.

Nunes et al. (1977) were able to demonstrate that the witharawal of vibratory stimulation for 15 seconds resulted in a rapid decline in SIB for a profoundy retarded male.

Augustine and Cipani (1982) found that response cost added to DRO reduced the headbanging and headhitting of a severely retarded male to near-zero levels while positive vocalisations increased. The DRO procedure 
involved contact and praise, whereas the response cost procedure involved the withdrawal of food or toys for 30 seconds. This was also one of the few studies to incorporate social validation measures of the treatment techniques used. The intrusiveness of response cost was evaluated subjectively by ratings obtained from the institutional committee. Response cost was rated as one of the least intrusive procedures. However, medication was not kept constant in this study.

Hurley and Sovner (1986) have provided some useful guidelines for developing a response cost procedure. They recommend that when there are many adaptive behaviours and only one or two maladaptive behaviours to be eliminated a token economy be used. Whereas if there are few adaptive behaviours and a single undesirable behaviour this behaviour could be linked to a specific reward. Using small fines rather than large ones may have more effect and help stop the environment becoming punitive and escalating management problems if reward is withdrawn. It is recommended that the programme be continued indefinitely and if it is ineffective, examining how consistently the programme is used or re-evaluating the award system. However, this may be impracticable if the rate of SIB is high or if the consequences are severe. 
The advantages of the procedure include its flexibility as it is possible to manipulate rewards and fines if the programme is initially ineffective. As response cost is similar to traditional child-rearing techniques it is unlikely to have adverse reactions from ethical committees, staff, and parents (Hurley \& Sovner, 1986).

The disadvantages of the procedure are similar to those found with extinction and time out, in that reducing SIB may be a slow process and the subject is free to engage in SIB. There may also be an increase in SIB similar to an extinction burst or emotional reactions such as anger because a potent reinforcer is removed (Baumeister \& Rollings, 1976; Hurley \& Sovner, 1986; Singh, 1981a).

Future research to establish the effectiveness of response cost procedures should place particular emphasis on generalisation and longterm maintenance data as there is very little information available at present. As previously discussed, recent developments in procedures to establish reinforcer preferences and potency should increase the probability of treatment success if they are used prior to the implementation of response cost procedures.

\section{Time Out}

Time out involves isolating or removing the subject from a rewarding situation for a specified period of time 
(Singh, 1981a). Time out may be exclusionary in which the subject is temporarily removed from the environment or non-exclusionary in which the subject remains in the environment but does not have access to reinforcement. However, there are a variety of ways time out may be employed. These include contingent observation, withdrawal time out, and contingent restraint time out (Favell, Azrin et al., 1982; Schroeder, Schroeder, Rojahn \& Mulick, 1980).

Facial and visual screening have been considered to be variations of time out and although these have elements in common with time out, they are discussed in more detail separately. Short aurations of time out appear to be equally effective as long durations in controling SIB. White, Nielson, and Johnson (1972) compared the effectiveness of three different durations 11,15 , and 30 minutes). They found that 15 or 30 minutes were more effective than 1 minute. They also found that the order of presentation of the different durations was important.

An assumption that underlies time out is that the timein environment is reinforcing (Favell, Azrin et al., 1982). It has been suggested that the effectiveness of time out appears to be functionally related to the reinforcing effects of time-in (Solnick, Rincover, \& Peterson, 1977). 
In institutional settings the reinforcement during timein may be minimal (Singh, 1981a). To combat this, reinforcement of alternative behaviours and an enriched time-in environment may be used in combination with time out (Solnick et al., 1977).

As with other treatment procedures and particularly in the case of time out it is important to assess the function of SIB for the individual (Carr, 1977; Carr \& Durand, 1985). If SIB is motivated by escape or avoidance of events/situations and/or persons removing the individual will reinforce SIB. If SIB is maintained by its sensory consequences and the individual is able to engage in SIB during time out this may also be reinforcing (Solnick et al., 1977).

Singh (1981a) has reviewed the research for time out. It was concluded that the studies used were methodologically weak and failed to report interobserver reliabilities.

In a more recent study Rolider and Van Houten (1986) evaluated the effectiveness of movement suppression time out which prevented any movement or verbalisation by the subject during time out. Movement suppression of 2-3 minutes duration in combination with DRO rapidly reduced or eliminated SIB or stereotypy in 5 of the 6 
retarded or psychotic children. Movement suppression time out and DRO was found to be more effective than DRO alone, contingent restraint of one minute, exclusionary time out of 5 minutes duration, or nonexclusionary time out of 2 minutes. The authors suggest that movement suppression time out may have been more effective than other forms of time out because the subjects were prevented from engaging in SIB or sterotypy and it increased the discrepancy between reinforcement in the time-in and time out environment. It also has the advantage over physical restraint of lessening the possibility of reinforcing SIB. Further research on this version of time out is needed.

The disadvantages of time out are similar to those of response cost and extinction. The person is still free to engage in SIB. This can be overcome by incorporating physical restraint or possibly movement suppression time out. In fact, the Association for Advancement of Behaviour Therapy Task Force has recommended that if it is not possible to protect the client from engaging in SIB time out should not be used.

If exclusionary time out is used the person is removed from a learning environment which means that shorter durations of time out are preferable as with other punishment procedures and it should be used in 
conjunction with a differential reinforcement procedure. Control of SIB may be slow and there may be an initial increase in the rate of SIB (Baumeister \& Rollings, 19761.

The advantages of such procedures as time out and response cost are that they are more in line with normal child rearing practices (Hurley \& Sovner, 1986) and represent one of the least restrictive options to try when reinforcement programmes fail. Further research with methodologically sound designs is needed on the effectiveness of time out in treating SIB particularly with shorter durations (Singh, 1981a). The parameters of time out for SIB also requires further investigation.

\section{Satiation}

Satiation is a procedure which involves reducing or removing the reinforcing qualities of a reinforcer. This is achieved by providing excessive amounts of the reinforcer. The criterion by which satiation is measured is a lowered response rate to gain the reinforcer (Singh, 1981b).

The procedure has been used in a variety of settings with a number of different SIB behaviours. In the treatment of SIB satiation has been used predominantly with rumination. Rumination involves the bringing up of 
previously ingested food with no causitive organic basis for the behaviour (Winton \& Singh, 1983).

Rumination is some cases may result in the client being seriously underweight, malnourished, and may even lead to death (Rast, Johnston, Drum \& Conrin, 1981). For subjects in this situation satiation can fulfil a dual function of reducing rumination while increasing bodyweight.

Satiation has been successfully used to reduce rumination in a number of studies (Jackson, Johnston, Ackeron, \& Cowley, 1975; Lobato, Carlson, \& Barrera, 1986; Rast, \& Johnston, 1986; Rast, Johnston, \& Drum, 1984; Rast et al., 1981). The general finding appears to be that while satiation may result in a $50 \%-90 \%$ reduction in rumination it does not eliminate the behaviour (Lobato et al., 1986).

It may be necessary to combine satiation with other techniques such as oral hygiene to eliminate or achieve near-zero levels of rumination (Foxx et al., 1979). Further research might compare the differential effectiveness of oral hygiene and satiation in the treatment of rumination.

\section{Contingent Exercise}

Borreson (1980) reduced SIB in a profoundly retarded 
male using a forced running consequence contingent on SIB. The subject was required to run up and downstairs for one minute following SIB. The study used an $A B A B$ design. SIB was reduced to low levels and it was reported ancetodally that growling was suppressed and there was an increase in smiling, the rate of ascending and descending the stairs, and progress on tasks. At a 2-year follow-up no SIB was reported.

\section{Sensory Extinction}

In line with the hypothesis that SIB may be maintained by sensory reinforcement several treatment studies have been conducted involving sensory extinction procedures in which the consequences of SIB were prevented from occurring or alternative sensory stimulation was provided to mask the sensory consequences of SIB.

Rincover and Devany (1982) used sensory extinction
combined with DRA procedures to treat three profoundly
retarded subjects. Sensory extinction involved such
procedures as using gloves for scratching, cushioned
surfaces, and a helmet for headbanging to prevent the
sensory consequences of SIB. The study used an ABAB
design. As DRA and sensory extinction were used
together it is not possible to say which component of
the treatment was effective.


Procedures were carried out in the classroom setting and SIB was reduced to near-zero levels. In order to maintain treatment gains stimulus fading was used. Baseline conditions involved naturalistic observation and conditions varied within and across subjects. For example, some children received verbal reprimands for engaging in SIB.

Sensory extinction procedures have also been used successfully to treat stereotypy (Rincover, 1978; Rincover, Cook, Peoples, \& Packard, 1979). Rincover (1978) found that sensory extinction techniques only reduced $S I B$ if the procedures were topographically related to SIB. They suggested that these results do not fit the homeostatic theory of stereotypy or SIB of individuals being under-aroused as the suppressive effect of sensory extinction was specific to the particular sensory modality involved in stereotypy.

However, Rincover's hypothesis does not explain why visual screening is effective for topographically dissimilar behaviours, unless it functions as a punishment procedure.

Sensory integrative techniques were used to reduce SIB in four profoundly retarded and visually impaired subjects (Wells \& Smith, 1983). Sensory integrative 
techniques involved a combination of vestibular stimulation of slow rocking in a hammock and/or tactile and vibratory stimulation. Occasionally the subjects were briefly physically restrained by the therapist if SIB was severe. SIB was reduced to near-zero levels over 32 weeks. No follow-up data were reported. However, there were flaws with this study; an $A B$ design across four subjects was used and no reliability data were collected during the course of the study.

Favell, McGimsey, and Schell (1982) found that SIB was reduced in mentally retarded subjects when they were provided with toys that involved the same sense modality or body area involved in SIB for each subject.

Further replication of the results obtained in these studies is required before definite conclusions can be reached regarding the procedure's effectiveness. As mentioned earlier, these studies have not provided unequivocal evidence to support the self-stimulation hypothesis as rival explanations are possible.

\section{Psychodynamic}

As only case studies have been used without empircally evaluating results no conclusions can be drawn regarding the effectiveness of the psychodynamic techniques (Demchak \& Halle, 1985). 
The Present Study

The present study aimed to compare the effects of two different treatments for self-injurious behaviour. Gentle teaching has been espoused as a highly effective treatment for all topographies of SIB in mentally retarded persons of all levels of retardation (McGee et al, in press). However, as stated earlier, there is a lack of data on its efficacy and there is an urgent need for well-controlled evaluative studies of this procedure before it gets entrenched in institutional settings as the treatment of choice based on only a liberal philosophical position. Thus one of the treatments chosen was gentle teaching. The other treatment, visual screening, was chosen because of its well-established position in the treatment literature as a treatment which has been demonstrated in numerous well-controlled studies to be effective in controlling a wide range of topographically different SIBs and numerous other behaviours (see Lutzker \& Wesch, 1983). An alternating treatments design was used to assess the differential effects of these procedures against a no-treatment condition. As neither of the treatments produced substantially significant reductions in one of the client's SIB, a Level 2 procedure, oral hygiene, was used. 


\section{METHOD}

Subjects

All three subjects were assessed as profoundly mentally retarded using the Vineland Social Maturity Scale $(1984$ edition) and met the AAMD criteria (Grossman, 1983). Age equivalent scores were Desmond ( 0.1 month), Jillian ( 0.7 months) and Jeff $(0.9$ months $)$.

Jeff was 10-years-old and had been institutionalised for the past six years. His retardation was due to microcephaly with epilepsy (myclonic and tonic clonic seizures). He had engaged in headbanging for a number of years although the exact age he began headbanging was unable to be ascertained. Reasons for his referral at four years of age included seizures, aggressive behaviour, constantly demanding attention by crying and whining, and problems with toileting. He had minimal receptive language and no expressive language. Jeff also appeared to be short-sighted.

Jeff had a few self-care skills: he was able to finger feed himself, assist with dressing and undressing and was ambulatory. He also enjoyed being cuddled and tickled. Jeff exhibited no play behaviours but engaged in frequent stereotypic behaviours with favoured objects. He had been involved in a training group with the Training Officer who acted as co-therapist during 
the study. Prior to the study, however, he was removed from the training group because of his headbanging and screaming behaviours and the need for constant supervision to control his behaviour. Jeff's headbanging was restricted to banging against doors and the floor. This behaviour was often accompanied by high pitched screaming, crying, and whining. If Jeff engaged in these behaviours, nursing staff would place Jeff in his room, give him a spa, which was one of his favourite activities, give him a cuddle or some food or take him for a walk. A helmet had been used previously to prevent injury from headbanging. However, Jeff would headbang and scream if the helmet was placed on his head and attempt to remove it. The helmet would reopen a scar above his eye that was always present due to his seizures. For these reasons use of the helmet was discontinued.

After discussion with nursing staff it was hypothesised that Jeff's headbanging and screaming behaviours might be maintained by social attention and avoidance of activities. If Jeff was left alone for any length of time he would headbang and scream and only stop if nursing staff interacted with him. This behaviour was particularly likely to occur if Jeff heard voices within or outside the dayroom. Jeff would also use headbanging and screaming to terminate activities such as toileting, 
lunch, or dinner or tasks in the training area. If demands were removed he would cease these behaviours. However, as no data were collected no conclusions can be made regarding the motivation of SIB.

During the study the subject received the following medication: Sodium Valproate (Eplim Syrup) $400 \mathrm{mg} / 10$ mls T.D.S.; Carbamazepine (Tegretol Syrup) $200 \mathrm{mg} / 10 \mathrm{mls}$ T.D.S.; Nitrazepam (Mogadon) $5 \mathrm{mg} 1 / 2$ tab B.D.; Vi-Daylin (tonic) $5 \mathrm{mls}$ B.D.; PRN:Diazepam (Valium) $5 \mathrm{mg}$ for status epileptic. Medication was kept constant throughout the course of the study.

Jillian was a 20-year-old woman who had been institutionalised for 15 years. Retardation was caused by a subdural haemorrhage 5 days after birth. This resulted in hemiplagia of the left side. She was institutionalised at 5-years-of-age because of problems in managing her rumination and disrupted sleep patterns. The subject had a 17-year history of mouthing and rumination. Her mouthing behaviour had resulted in red, swollen, calloused hands and there was evidence of breakdown of tissue and infection. Rumination had resulted in low body weight $(37.2 \mathrm{~kg})$ and bad breath.

There was no record of any treatments being carried out prior to this study. Verbal reprimands and physical 
restraints (splints applied for an hour after each meal) were used by nursing staff to prevent rumination but had not decreased the behaviour. There were no consequences for mouthing.

Jillian had minimal receptive language and no expressive language. She was ambulatory but had no self-care skills. Jillian had never been included in any training group because of disruptive behaviour and nonperformance on tasks. During the study the subject received the following medication: Diazepam (Valium), $5 \mathrm{mg}$ B.D.; Tryptanol (Amitriptyline), $50 \mathrm{mg}$ daily; Temazepam (Norison), $20 \mathrm{mg}$ Nocte, when required. Medication was kept constant throughout the course of the study.

Desmond was a 44-year-old man who had been institutionalised for the past 41 years. His retardation was due to unknown causes. He had a long history of SIB although the exact age Desmond began engaging in SIB could not be ascertained. His files documented incidents of SIB in his early. twenties but: it was thought by nursing staff that he may have begun engaging in SIB at a much earlier age. His present SIB included using objects to hit his head, slapping and punching his head, body, or hard surfaces. He also had a history of headbanging however this behaviour was no longer in his repetoire. His head was physically deformed from 
engaging in SIB and constant falling due to an unsteady gait. He had cauliflower ears from slapping and punching and deep scars on his head and face from headbanging and falling. Previous attempts to control SIB included a long history of medication changes and physical restraint. However, these methods had been unsuccessful in reducing his SIB.

Desmond had minimal receptive language, no expressive language, and no self-care skills. Although he was ambulatory he had an unsteady gait which often caused him to fall. There was no documented evidence to suggest that Desmond had ever been included in a training group probably due to his frequent SIB and lack of skills. Desmond spent the majority of his day in the dayroom engaging in stereotypy or SIB. His SIB was often ritualistic in nature and he would walk around in circles flapping his hands, slapping his head, rubbing his body, chewing his clothes, and occasionally punching his chin with his fist.

During the study Desmond received the following medication: Stelazine $2 \mathrm{mg}$ T.D.S.; Largactil $100 \mathrm{mg}$ nocte; Largactil $100 \mathrm{mg} 1 \mathrm{~m}$ or oral PRN; Epilim $2 \mathrm{mg}$ T.D.S.; Dilantin $100 \mathrm{mg}$ Q.I.D.; Senekot 2 nocte. Medication was kept constant throughout the study. 


\section{Setting}

For Jillian and Jeff baseline and treatment sessions took place in a sparsely furnished activity room and in the subjects' residential ward. For Desmond baseline and treatment sessions took place in a sun room next to the dayroom so that nursing staff were able to see the study in progress. Only the toys and activities that were to be used in the study were made available. Functional tasks that were considered age-appropriate were used in the study (Brown et al., 1979).

\section{Response Definitions}

The following response definitions were used for SIB and collateral behaviours:

\section{Jeff}

Headbanging

- hitting the head against any surface

\section{Screaming}

- a loud noise that changes in pitch or volume

\section{Seizures}

- the following behaviours occurring together or immediately following one another :

Myclonic

- sudden flexion of the head, arms, or entire body

- rolling of eyes or fixed gaze

- child recovers immediately, no after effects, lasts a few seconds. 


\section{Tonic Clonic}

- rigidity of the muscles, limbs, or trunk

- turns head to side

- spasms of relaxation and contraction

- confusion, sleep, exhaustion

Jillian

\section{Mouthing}

- placing hand(s) or finger(s) in the mouth so that the fingernail is not visible

\section{Rumination}

- self-induced regurgitation of previously ingested food by either tongue thrusting or mouthing

Rumination was included as a response category for maintenance purposes however this category was not used. Desmond

\section{Head-Slapping}

- a slap to the head with the palm of the hand

\section{Other SIB}

SIB not included in the above categories includes:

- hitting head with fist/object

- hitting parts of the body with hand.

\section{General Categories}

These categories were used for all of the subjects

\section{Other}

- Behaviours not included in target behaviour categories On Task

- Any activity directed towards completion of the task and includes active manipulation of materials in the 
manner directed by the therapist, without physical assistance; excludes throwing, dropping, mouthing, hitting surfaces, passing objects repetitively from hand to hand, or manipulation of object in any way other than directed.

\section{Task Training}

- Active manipulation of materials. This includes activities directed towards completion of the task with full or partial physical guidance from therapist.

Bonding

A smile directed at the therapist either spontaneously or in response to the therapist and/or physical approach if subject moves to within $0.5 \mathrm{~m}$ with touching, hugging or shaking hands with the therapist lexcludes hand-holding).

\section{Data Collection and Reliability}

Data were collected 5 days a week for all three subjects. Treatment involved three 30-minute sessions for Jeff and Jillian. Due to Desmond's limited attention span this was shortened to three 15-minute sessions. Each treatment session was separated by a 5-minute break.

An interval recording technique was used to collect data with each session divided into 180 (Jeff and Jillian) and 90 (Desmond) 10-second intervals. These were 
signalled to the observer through an earphone and the observer recorded the occurrence or nonoccurrence of the behaviours in each category.

An independent observer was assigned to each subject and reliability checks were conducted every fourth session. Observers were trained prior to baseline recording until interobserver reliability agreement reached $85 \%$ over three consecutive sessions. All scheduled reliability checks were videoed. An agreement was defined as both observers recording the same response(s) during the same 10-second interval. Reliability was calculated for both occurrences and nonoccurrences of the target behaviours. Only raw data from the primary observer was included in the study. The following formulae were used to calculate reliability. 


\section{TABLE 1}

The mean interobserver reliabilities with ranges in parentheses were:

Jeff: Headbanging

Screaming

Seizure

On Task

Task Training

Bonding

Desmond: Headslapping

Other SIB

Task Training

Bonding

Jillian: Mouthing

On Task

Task Training

$$
\begin{array}{lll}
\text { occurrence } & 92 \% & (78-100) \\
\text { nonoccurrence } & 87 \% & (94-100) \\
\text { occurrence } & 97 \% & (82-100)
\end{array}
$$$$
\text { nonoccurrence } 97 \% \quad(93-100)
$$$$
\text { occurrence } \quad 84 \% \quad(67-100)
$$$$
\text { nonoccurrence } 99 \% \quad(98-100)
$$$$
\text { occurrence } \quad 88 \% \quad(75-100)
$$$$
\text { nonoccurrence } 97 \% \quad(92-100)
$$$$
\text { occurrence } \quad 90 \% \quad(78-100)
$$$$
\text { nonoccurrence } 77 \% \quad(54-100)
$$$$
\text { occurrence } \quad 91 \% \quad(67-100)
$$$$
\text { nonoccurrence } \quad 99 \% \quad(98-100)
$$$$
\text { occurrence } \quad 93 \% \quad(67-100)
$$$$
\text { nonoccurrence } 91 \% \quad \text { (69-100) }
$$$$
\text { occurrence } \quad 84 \% \quad(50-100)
$$$$
\text { nonoccurrence } 97 \% \quad(88-100)
$$$$
\text { occurrence } \quad 83 \% \quad(75-93)
$$$$
\text { nonoccurrence } 58 \% \quad(31-79)
$$$$
\text { occurrence } \quad 83 \% \quad(50-100)
$$$$
\text { nonoccurrence } 99 \% \quad(98-100)
$$$$
\text { occurrence } \quad 84.6 \% \quad(50-100)
$$$$
\text { nonoccurrence } \quad 95.3 \% \quad(88-100)
$$$$
\text { occurrence } \quad 73 \% \quad(71-75)
$$$$
\text { nonoccurrence } 96 \% \quad(96-96)
$$$$
\text { occurrence } \quad 86 \% \quad(77-93)
$$$$
\text { nonoccurrence } 76.7 \%(33-97)
$$ 


\section{Procedure}

The effectiveness of gentle teaching and visual screening were compared using an alternating treatments design (Barlow \& Hayes, 1979; Kazdin, 1982). A notreatment control condition was included to demonstrate experimental control. The no-treatment control was also included to determine whether the presence of the toys and/or equipment affected the subject's SIB.

There would be ethical arguments against using a control condition with SIB as the subjects were not prevented from engaging in this behaviour. However, for the remainder of the day during normal ward activities they would be left to engage in SIB in any case.

A discriminative stimulus was used prior to the commencement of each treatment session during the 5 minute break. This involved noncontingently or contingently administering the treatment procedure depending on the subjects behaviour for gentle teaching. This involved using the interrupt procedure.

McGee does not give any indication as to the appropriate duration of the interrupt procedure but indicated that it should be continued until the SIB has ceased. 
However, this is problematic in terms of working within an alternating treatments design as the procedures should be of a comparable duration.

Consequently it was decided that the interrupt procedure would be in effect until the end of the 10 second interval. As the interrupt procedure could take place anytime during the 10 second interval the duration would average out to approximately 5. seconds, making it comparable with visual screening. Recording of behaviours stopped during this time and the duration of interrupt was recorded using a stopwatch.

The procedure for visual screening involved either placing the hands over the eyes of the subject until 5 seconds had elapsed with no resistance to the procedure such as screaming, struggling, or aggression towards the therapist. Alternatively, placing one hand over both eyes while holding the back of the subjects head with the other hand depending on whichever form of the procedure was the easiest for the therapist to implement in the circumstances.

The overcorrection procedure of contingent toothbrushing with Listerine (Foxx et al., 1979) was used in a subsequent phase when neither gentle teaching nor visual screening appeared to be effective with one subject 
(Jillian). During overcorrection once SIB had occurred the subject was instructed to brush her teeth (with the toothbrush soaked in Listerine). If 5 seconds elapsed and no attempt was made by the subject to carry out the procedure partial guidance was used with the therapist assisting in the required activity. Guidance was to be gradually faded to allow the subject to carry out the activity independently. However, in practice this never occurred in this study as the subject never co-operated with the therapist.

The discriminative stimulus for the control condition involved instructing the subject to carry out the required activity, for example, "Jeff, ride the bike".

Each subject was treated separately. The study consisted of the following phases.

Baseline 1: Due to the severity of Jeff's headbanging baseline was conducted for five 10-minute sessions over two days. Only those toys or tasks to be used in the study were available to avoid confounding factors such as novelty of the toys. For Jeff, these involved a bike with trainer wheels, a jigsaw depicting a fire engine, a ball, and a plastic snake. Desmond's tasks consisted of cleaning equipment, a cloth to wipe the table, a shoe, and polishing cloth. Jillian's tasks included a 
hairbrush to brush her hair, a sanding board and sandpaper, a shoe, and a polishing cloth. No experimental manipulations were in effect at this time.

However for Jillian and Desmond whose activities were to be carried out at a table they were directed verbally or physically back to their seat if they left it. Jeff was not required to be seated as his primary activity was to learn to ride the bike which involved using the entire floor space.

Baseline 2 : Task training took place in two of the sessions while the third condition involved a control condition which was identical to baseline 1 conditions. The task training method was based on a technique used by Singh and Millichamp (1987) called independent toy play training. This procedure had been effective in increasing independent toy play in profoundly retarded subjects. Task training involved the following process: verbal cue, modelling, partial guidance, and finally full manual guidance. Modelling was used if a verbal prompt was unsuccessful. Similarly partial guidance was used if modelling was unsuccessful and so on. The more co-operative the subject was with the procedure the less guidance was used by the therapist. Following each step in the process there was a short pause to determine whether on-task behaviour was going to occur; if no on- 
task behaviour occurred the therapist would move to the next step. Once full manual guidance occurred the process would begin again. Social reinforcement in the form of tactile and verbal praise was given for any approximations of the task even if partial or full guidance was given by the therapist. Verbal and tactile praise was used as reinforcement as edibles are not permissable in gentle teaching and would confound comparison of the techniques. A task training phase was included to determine the effect of a differential reinforcement procedure on SIB and on task behaviour. Task Training (T) and the control (C) condition were counterbalanced in the following sequence, CTT, TCT and TTC.

Alternating Treatments 1 : In this condition gentle teaching, visual screening, and a no-treatment control were introduced. The toys and equipment were available in all phases. The order of the 3 phases was determined prior to baseline, and was counterbalanced.

The three conditions involved

a) No-Treatment Control. This was identical to control conditions in Baseline 1 and Baseline 2 .

b) Gentle Teaching. This condition involved using McGee's 9 steps to teach bonding and 
prevent SIB. Each occurrence of SIB resulted in the interrupt-ignore-redirect-reward technique. For Jeff, this involved using an open palm between the head and surface used to headbang. For Jillian, an open palm was placed in front of her mouth to prevent mouthing. Finally for Desmond, an open palm was used to block attempts to strike the head, bodily parts, or hard surfaces. At the end of the 10 second beep the subject was redirected back to the task and socially reinforced for approximations of the task. The average duration of the interrupt technique was 5.2, 5.3 , and 6.1 with ranges of $1-10$ seconds for Jeff, Desmond, and Jillian, respectively. This represents an average of $8.9,34$, and 42.5 times per session and as a percentage $5 \%$, $37.8 \%$ and $23.6 \%$ for Jeff, Desmond, and Jillian, respectively.

c) Visual Screening. In this phase the teaching method was identical to task training in Baseline 2. If SIB occurred the subject's eyes were either covered with both the therapist's hands to block vision or one hand was placed over the eyes and the other hand was placed at the back of the head to hold it. 


\begin{abstract}
Release from visual screening occurred after 5 seconds but only if no disruptive behaviour had occurred for 5 seconds. For Jeff, Desmond, and Jillian, respectively, the average duration of screening per session during this phase was $40.7,12.3$, and 13.2 seconds with ranges of 5 seconds to 3 minutes 50 seconds, 5 second to 45 seconds and 5 seconds to 3 minutes 18 seconds. This represented being visual screened an average of $3.7(2 \%), 34(37.8 \%)$, and $36.8(20.4 \%)$ for Jeff, Desmond and Jillian, respectively.
\end{abstract}

Alternating Treatments 2 : This was identical to the previous phase for Jeff and Desmond except that for Jeff gentle teaching was used during both treatment sessions and for Desmond, visual screening was used for both treatment sessions. Visual screening was the more effective treatment procedure for Desmond. For Jeff both gentle teaching and visual screening were effective so following the least restrictive treatment model gentle teaching was used as the treatment of choice. For Jeff, gentle teaching 1 and gentle teaching 2 were similar, the average duration of the interrupt procedure was 5.3 seconds (range $=3-9$ seconds) and 6.3 seconds (range $=2-10$ seconds), respectively. During gentle teaching 1 , interrupt occurred on average $0.75(0.4 \%)$ 
times per sessions. In gentle teaching 2 it occurred an average of $3.6(4 \%)$ times per session. For Desmond, the average duration of the visual screening 1 procedure was 11.2 seconds (range $=6-28$ seconds). For visual screening 2 the average duration was 9.9 seconds (range $=5-29$ seconds). The average number of screenings was 30.4 times $(33.8 \%)$ for visual screening 1 and 22.8 times $(25.3 \%)$ per session for visual screening 2 .

Oral Hygiene 1: Both gentle teaching and visual screening were not clinically effective in reducing Jillian's mouthing. As a result of this finding the Foxx et al (1979) oral hygiene procedure of contingent toothbrushing with Listerine was used as it has proved to be effective in the treatment of rumination and mouthing. The no-treatment control phase was continued and was identical to previous phases. The teaching method used was identical to task training in Baseline 2. On the occurrence of mouthing the subject was instructed to brush her teeth with a Listerine-soaked toothbrush. If no response was made full manual guidance was given by the therapist. This was later faded to partial guidance. The subject was required to brush her teeth for 2 minutes. During this procedure recording ceased and the duration of the procedure was timed with a stopwatch. The average duration for oral 
hygiene was 2.11 minutes (range $=2.03-2.25$ ). The average number of times the procedure was carried out was $6.8(3.8 \%)$. Only one oral hygiene session was implemented daily as the procedure was quite lengthy.

Final Phase : This phase was identical to the previous phase for Jeff and Desmond except that gentle teaching occurred over all 3 phases for Jeff and visual screening occurred over all 3 phases for Desmona.

For Jeff the average length of the interrupt procedure for the three daily sessions was $5.7,6.3$, and 5.5 seconds with corresponding ranges of $4-7,3-8$, and 2-10 seconds.

The average number of times interrupt occurred was 0.4 $(0.4 \%), 1.5(0.9 \%)$, and $3(1.7 \%)$ for gentle teaching 1 , 2 , and 3 , respectively.

For Desmond the average length of visual screening was $11.3,11.2$, and 10.2 seconds with ranges of $5-23,7-17$, and 5-28 seconds. The average number of times visual screening occurred was $5.6(6.2 \%), 6.6(7.3 \%)$, and 8.6 (9.6\%) during visual screening 1,2 , and 3 , respectively. 
As on-task behaviour increased for Jeff and he became more independent on the task, reinforcement became more intermittent. Two nurses were requested for Jeff to continue his programme on the ward. The shifts that the nurses worked meant that there was always one nurse with Jeff to carry out the programme. Staff members were all trained in the gentle teaching procedures using in vivo sessions with the therapists. The special nurses were trained during in vivo sessions with the therapists and also with video sessions of the treatment sessions. Unfortunately due to administrative difficulties with the rostering of nurses, maintenance data were not able to be collected. However, ancedotal reports from staff and the two special nurses noted that Jeff was less of a management problem, he no longer screamed as he used to and although he headbanged he would do this a few times and then move away. It was also noted that he interacted more with the other children in the ward and would play with objects apart from those objects he had only used for stereotypy. Special nurses were also requested for Desmond and Jillian; however these were not available, due to shortages in staff. 


\section{RESULTS}

Desmond

\section{Headslapping}

During Baseline 1, Desmond's overall mean rate of headslapping was about $89 \%$, decreasing to $69 \%$ during Baseline 2. This decrease was due to the lower rate of headslapping during the first two sessions of the new phase since it increased to about $90 \%$ during the last two sessions of Baseline 2. No significant decreases in headslapping occurred during either task training conditions during Baseline 2. Clear differential effects of visual screening and gentle teaching were evident in Alternating Treatments 1 phase. After the first few applications of visual screening, headslapping showed a steady decrease to low levels. However, with gentle teaching, after an initial decrease there was a steady increase in headslapping. This inverse relationship indicates that although the means for the two treatment conditions are similar (see Table 2), they show opposite trends. Headslapping during the no-treatment control condition remained at Baseline 2 levels.

Insert Table 2 about here

As shown in Figure 1, during the last three sessions in Alternating Treatments 2 headslapping stabilised at 
TABLE 2

Mean percentage of occurrence of Headslapping and Bonding for Desmond

Experimental phase/condition occurrence of behaviour

Headslapping

Bonding

Baseline 1

Session $A$

Session B

Session C

Baseline $(\bar{x} A B C)$

Baseline 2

Control

Task Training 1

Task Training 2

Task Training $(\bar{x} 1,2)$

Alternating Treatments 1

Control

Gentle Teaching

Visual Screening

Alternating Treatments 2

Control

Visual Screening 1

Visual Screening 2

Visual Screening $(\bar{x} 1,2)$

Visual Screening

Visual Screening 1

Visual Screening 2

Visual Screening 3

Visual Screening $(\bar{x} 1,2,3)$
87.5

0.0

85.5

0.0

94.5

0.5

89.2

0.2

73.3

0.0

78.5

0.3

59.5

0.5

69.0

0.4

75.0

0.0

34.4

3. 7

33.3

1. 3

68.6

0.0

22.6

1.6

17.3

2.9

20.0

2.3

2.6

9.0

5.0

2. 8

5.6

3. 8

4. 4

5. 2 
near-zero levels under the two visual screening conditions. There were, however, some high levels of SIB during this phase. These occurred at the beginning of the phase and also corresponded to breaks in the delivery of treatment. Desmond sustained a head-injury which resulted in a deep laceration above his eye requiring stitches. Consequently he was unable to be visually screened, resulting in a 2-week break after session \#17. On session \#20, Desmond sustained a head injury in the form of a deep graze but treatment was continued.

Insert Figure 1 about here

When visual screening was applied in all sessions in the final phase headslapping occurred at low levels (see Table 2 and Figure 1). There was a slight increase in headslapping at the beginning of this phase and then a return to near-zero levels. Ideally, this condition could have been longer to show greater stability at near-zero levels over a longer time period. However, Desmond sustained a further head-injury necessitating a break in treatment because the medical staff wished to change his medication.

\section{Bonding}

As shown in Figure 1, bonding occurred at near-zero levels during the first three phases. It occurred at 
Figure 1 . Percent intervals of headslapping and bonding by Desmond across all experimental conditions. 


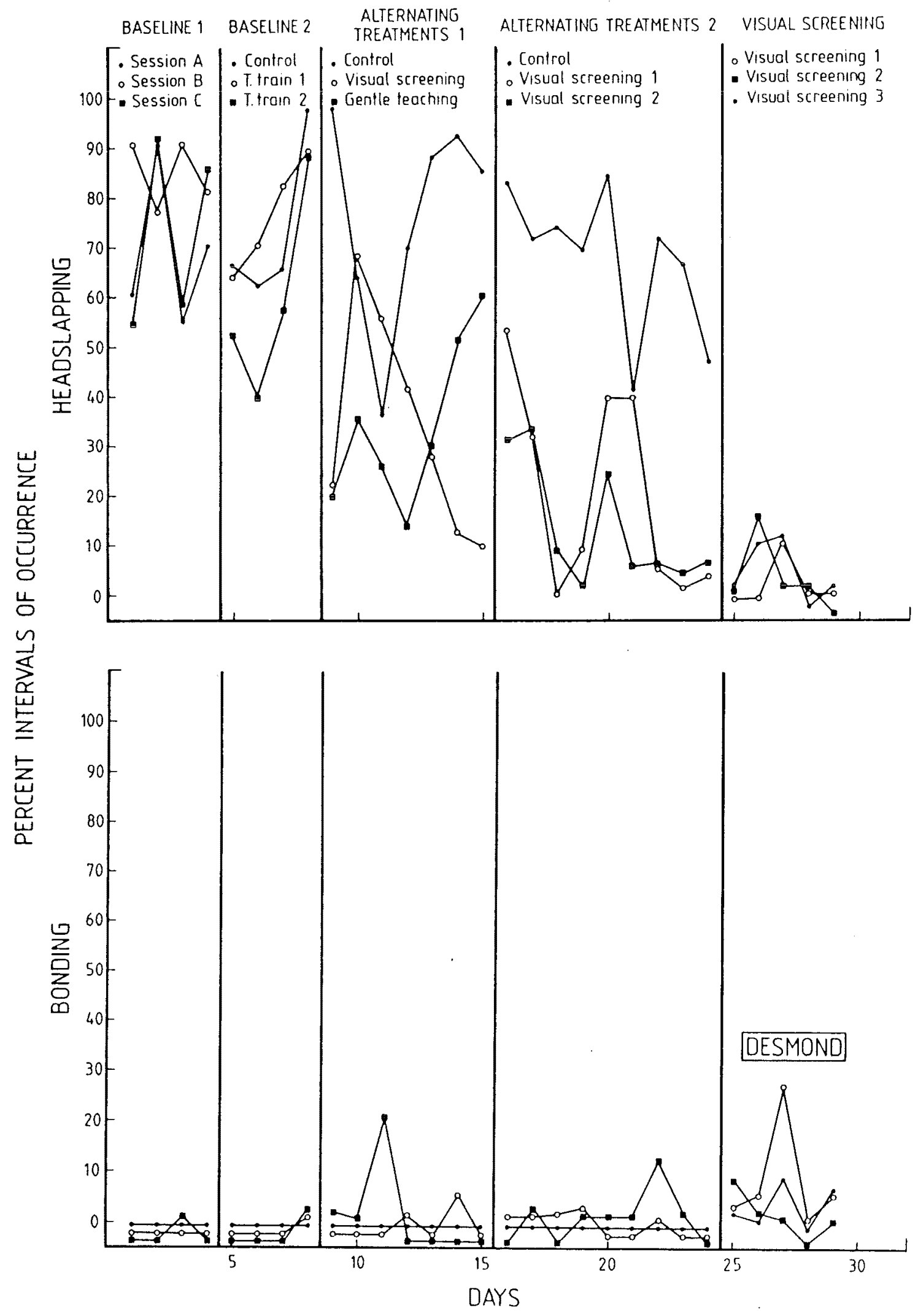


very low levels during Alternating Treatments 2 phase when visual screening was applied in two of the three daily sessions and increased to slightly higher levels in the final phase when visual screening was used during all three sessions.

\section{Other SIB}

Other SIB, which included such behaviours as hitting hard surfaces with the hands, punching the head with the fists or any other SIB apart from headslapping, occurred at a moderate but variable rate during Baseline 1 (see Figure 2). The rate of other SIB decreased during Baseline 2, during both the task training and no-treatment control conditions. Thereafter, other SIB occurred at a low but variable level under all conditions (see Table 3 ).

Insert Figure 2 and Table 3 about here

Task Training

As shown in Figure 3, Desmond did not engage in any age-appropriate tasks during Baseline 1 when no task training was instituted. Thus, task training was instituted from Baseline 2 and needed to be maintained at a high level, reaching an overall mean of over $80 \%$ in the final phase when the visual screening procedure was in effect.

Insert Figure 3 about here 
Figure 2. Percent intervals of other self-injurious behaviours by Desmond across all experimental conditions. 


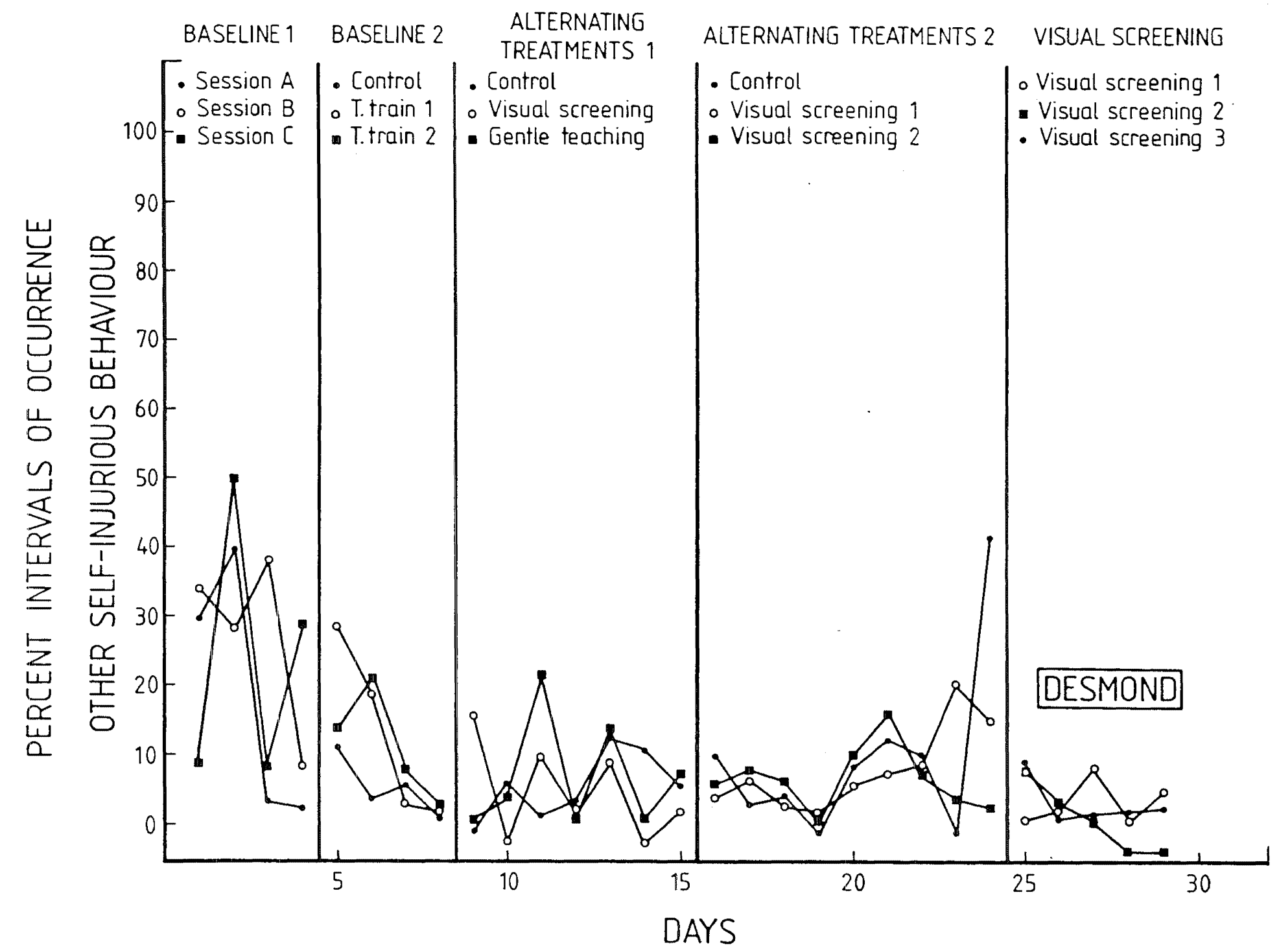


$\underline{\text { TABLE } 3}$

Mean percentage of occurrence of Other SIB and Task Training for Desmond

Experimental phase/condition occurrence of behaviour

Other SIB

Baseline 1

Session A

Session B

Session C

Baseline $(\bar{x} A B C)$

Baseline 2

Control

Task Training 1

Task Training 2

Task Training $(\overline{\mathrm{x}} 1,2)$

Alternating Treatments 1

Control

Gentle Teaching

Visual Screening

Alternating Treatments 2

Control

Visual Screening 1

Visual Screening 2

Visual Screening $(\bar{x} 1,2)$

Visual Screening

Visual Screening 1

Visual Screening 2

Visual Screening 3

Visual Screening $(\bar{x} 1,2,3)$
4.7

0.0

12.5

48.5

11.5

58.0

12.0

53.3

5.7

0.0

7.1

72.0

5.6

65.0

10.1

0.0

8.1

74.3

7.1

72.3

7.6

73.3

2. 8

81.2

5.0

85.6

5.6

80.8

4. 5

82.5 
Figure 3 . Percent intervals of task training by Desmond across all experimental conditions. 


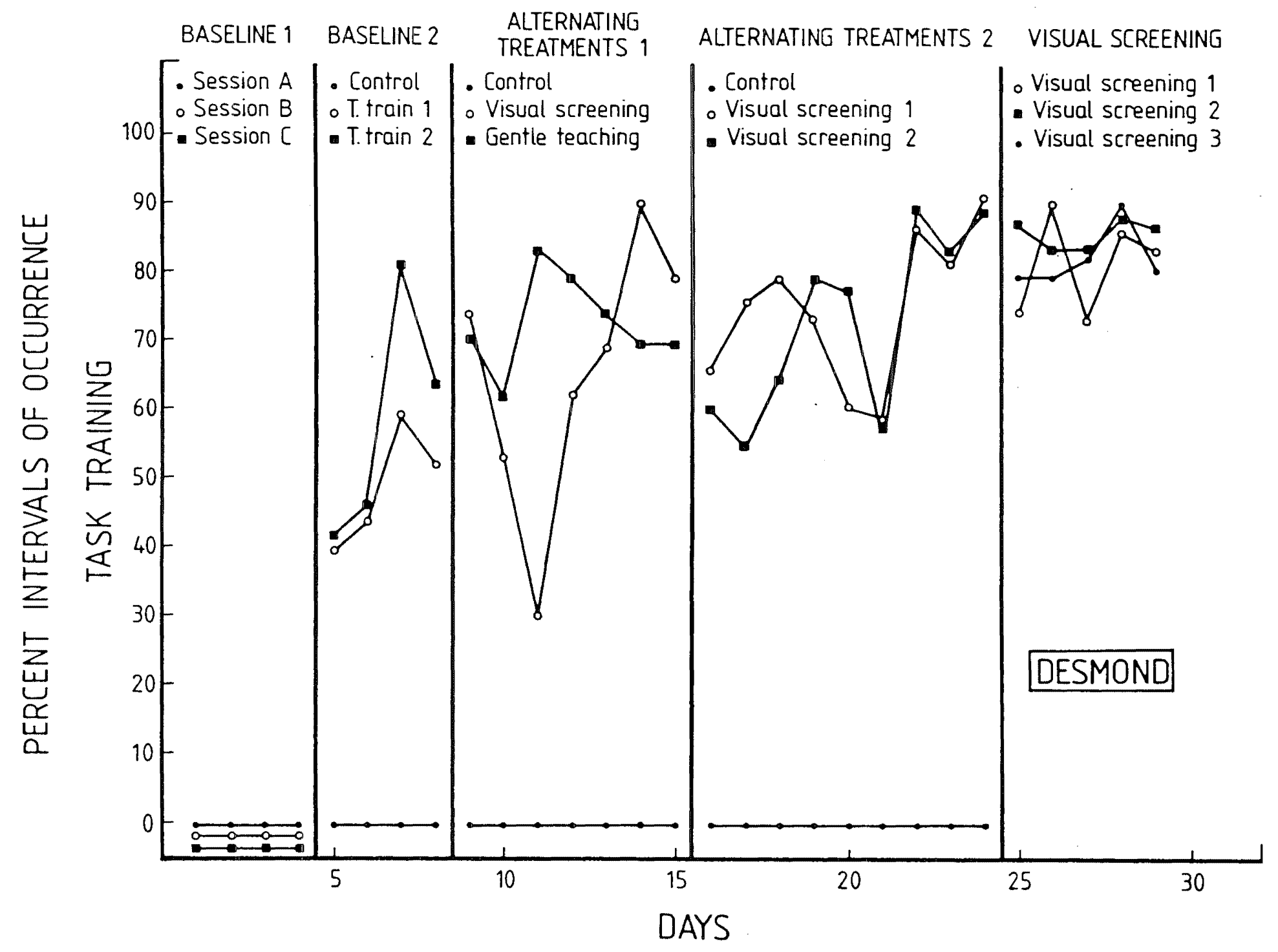


Jeff

\section{$\underline{\text { Headbanging }}$}

As shown in Figure 4, headbanging occurred at a moderate but variable level during Baseline 1 and decreased to low levels during Baseline 2. Headbanging decreased to near-zero levels in the Alternating Treatments 1 phase, showing a similar decrement under both visual screening and gentle teaching treatments. There was a reduction in headbanging in the no-treatment control condition as well but the reduction was not as marked as under the treatment conditions. Headbanging was maintained at near-zero levels under gentle teaching during the following two phases.

Insert Figure 4 about here

\section{Bonding}

Jeff showed low levels of bonding during Baseline 1 (see Table 4) and Baseline 2. Bonding occurred the most during the no-treatment control condition during Baseline 2. There was a small decrement in bonding across all conditions during the Alternating Treatments 1 phase when the effects of gentle teaching and visual screening were compared. Bonding increased again during the second alternating treatments phase, with the no-treatment control condition showing the highest once again. As shown in Figure 4, bonding increased somewhat 
Figure 4 . Percent intervals of headbanging and bonding by Jeff across all experimental conditions. 


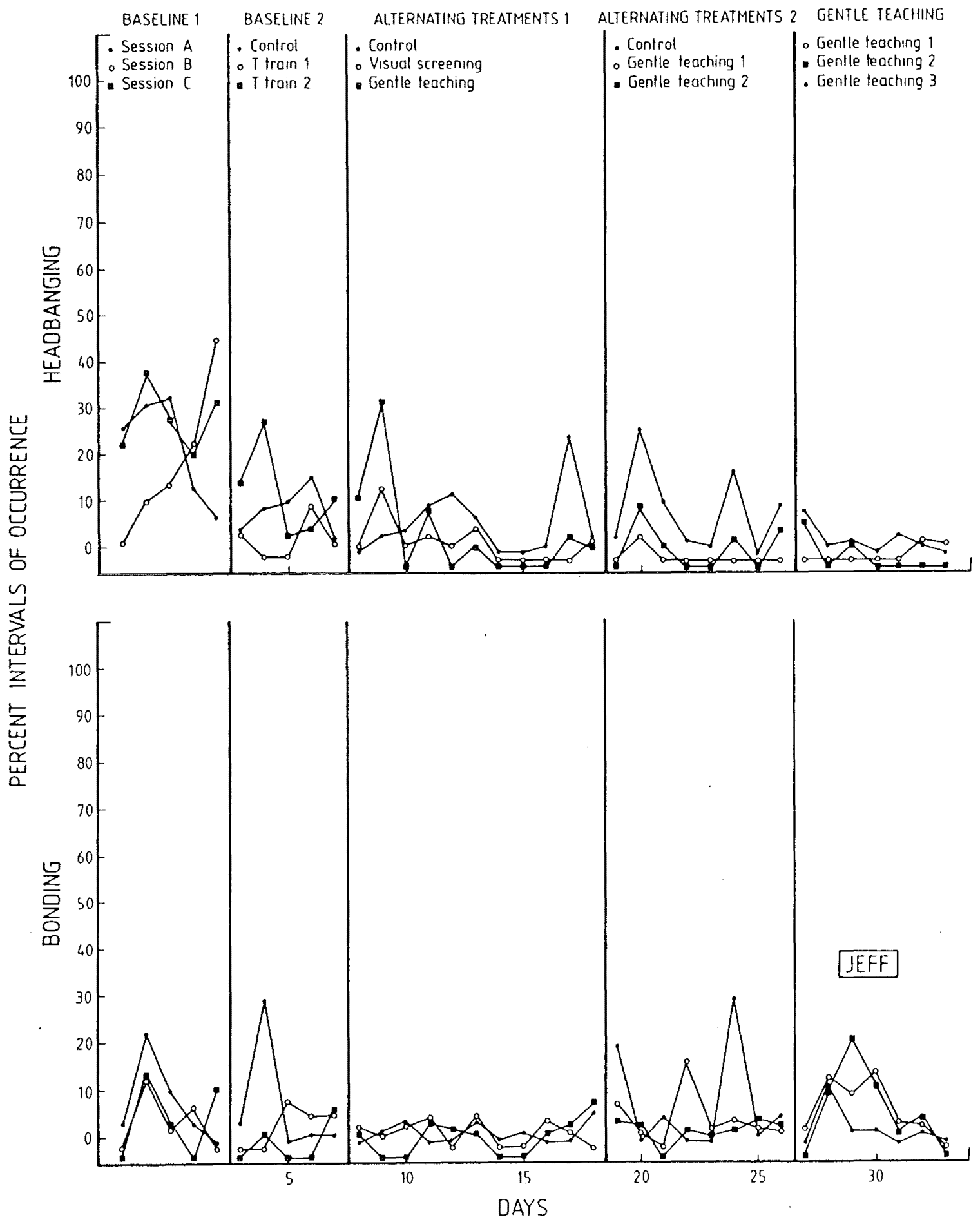


during the final phase when gentle teaching was used across all three daily sessions.

Insert Table 4 about here

Screaming

As shown in Figure 5, Jeff's screaming occurred at a moderate but variable rate. During Baseline 1, his screaming averaged about $12 \%$ of the sessions and increased to about $16 \%$ during Baseline 2. Screaming was at its worst during one of the task training conditions in this phase, reaching an average of about $27 \%$ of the sessions. There was a differential effect on screaming when visual screening and gentle teaching were used for headbanging, with less screaming occurring in the visual screening sessions. Further reductions in screaming occurred during the second alternating treatments phase when gentle teaching was used in two of the three daily sessions. Screaming remained at low levels during the final phase but became more variable across days.

Insert Figure 5 about here

\section{Seizures}

As shown in Table 5 and Figure 6, Jeff's seizures occurred at a low level showing no particular pattern during the course of the study. 


\section{TABLE 4}

Mean percentage of occurrence of Headbanging and Bonding for Jeff

Experimental phase/condition $\%$ occurrence of behaviour

Headbanging

Bonding

Baseline 1

Session A

21.4

7.6

Session B

19.0

5.0

Session C

25.4

4.8

Baseline $(\bar{x} A B C)$

21.9

5.8

Baseline 2

Control

7.8

6.6

Tașk Training 1

2.8

3.0

Task Training 2

11.8

1.2

Task Training $(\bar{x} 1,2)$

7.3

2.1

Alternating Treatments 1

Control

Gentle Teaching

Visual Screening

Alternating Treatments 2
5.6

5.1

2.2

9.6

0.6

2.0

1.3

Gentle Teaching $(\bar{x} 1,2)$

Gentle Teaching

Gentle Teaching 1

Gentle Teaching 2

Gentle Teaching 3

Gentle Teaching $(\bar{x} 1,2,3)$
0.4

6.0

1.0

6.1

2.0

2.3

3.4
1.0

1.6

1.0
7.0

5.7

1.7

3.7 
Figure 5. Percent intervals of screaming by Jeff across all experimental conditions. 


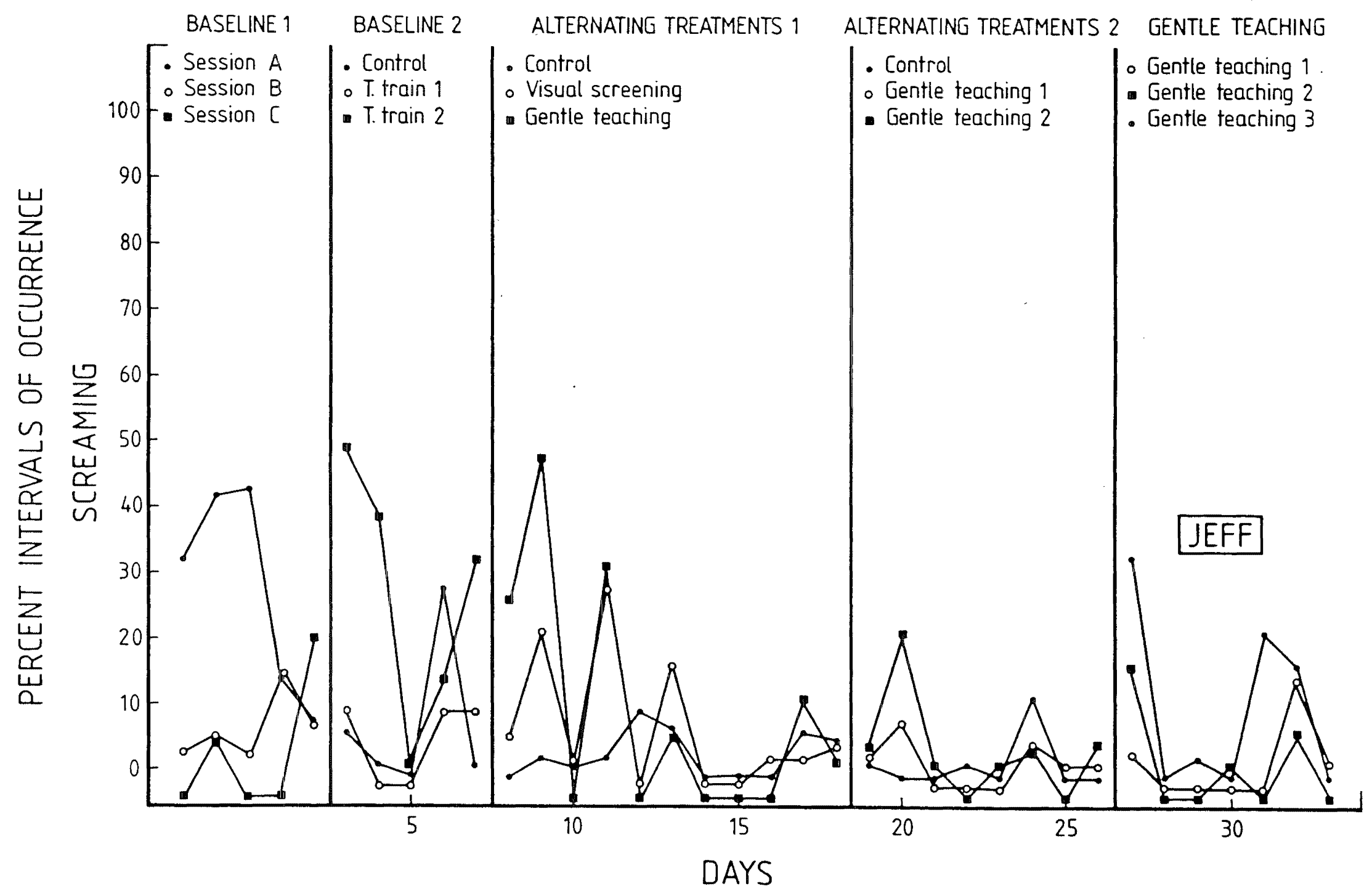


Insert Figure 6 and Table 5 about here

\section{Task Training}

As evident in Figure 7, no task training was programmed for Baseline 1. It was introduced during Baseline 2 and maintained throughout the rest of the study. Jeff required task training between $45 \%$ to $75 \%$ of the sessions across the two treatment conditions (see Table 6 and Figure 7). There was no clinically significant difference between gentle teaching and visual screening for task training during Alternating Treatments 1 .

Insert Figure 7 and Table 6 about here

\section{On-Task Behaviour}

Jeff did not engage in any on-task behaviour during Baseline 1 or during the no-treatment control condition during Baseline 2. On-task behaviour increased during Baseline 2 to very low levels when task training was provided. It gradually increased under both the visual screening and gentle teaching procedures in the two alternating treatments phases (see Figure 8 and Table 6). Little change was noted in the no-treatment control condition until the last phase when on-task behaviour reached an average of about $26 \%$ across the three daily sessions. 
Figure 6 . Percent intervals of occurrence of seizures by Jeff across all experimental conditions. 







\section{TABLE 5}

Mean percentage of occurrence of Screaming and Seizures for Jeff

Experimental phase/condition occurrence of behaviour

Screaming

Seizures

Baseline 1

Session A

Session B

Session C

Baseline $(\bar{x} A B C)$

Baseline 2

Control

Task Training 1

Task Training 2

Task Training $(\bar{x} 1,2)$

Alternating Treatments 1

Control

Gentle Teaching

Visual Screening

Alternating Treatments 2

Control

Gentle Teaching 1

Gentle Teaching 2

Gentle Teaching $(\bar{x} 1,2)$

Gentle Teaching

Gentle Teaching 1

Gentle Teaching 2

Gentle Teaching 3

Gentle Teaching $(\bar{x} 1,2,3)$
27.4

0.2

6.6

0.4

4.0

1.6

12.7

0.7

7.0

0.2

5. 4

1. 2

26.8

1.1

16.1

1.1

2.6

1.0

11.0

1.9

7.1

1.1

1.6

1. 7

1.9

0.5

4. 1

1.0

3.0

0.8
2.6

0.0

3. 3

0.1

10.3

0.4

5.4

0.3 
Figure 7 . Percent intervals of task training by Jeff across all experimental conditions. 





TABLE 6

Mean percentage of occurrence of Task Training and On

Task for Jeff

Experimental phase/condition occurrence of behaviour

Task

On Task

Baseline 1

Training

Session A

0.0

0.0

Session B

0.0

0.0

Session C

0.0

0.0

Baseline $(\bar{x} A B C)$

0.0

0.0

Baseline 2

Control

0.0

0.0

Task Training 1

54.9

1.8

Task Training 2

44.2

1.0

Task Training $(\bar{x} 1,2)$

49.6

1.4

Alternating Treatments 1

Control

0.0

0.3

Gentle Teaching

59.0

9.9

Visual Screening

60.0

8.7

Alternating Treatments 2

Control

0.0

0.4

Gentle Teaching 1

73.6

23.2

Gentle Teaching 2

74.7

17.8

Gentle Teaching $(\bar{x} 1,2)$

74.2

20.5

Gentle Teaching

Gentle Teaching 1

66.3

$28 \cdot 3$

Gentle Teaching 2

66.8

24.5

Gentle Teaching 3

57.1

23.9

Gentle Teaching $(\bar{x} 1,2,3)$

63.4

25.6 
Insert Figure 8 about here

Jillian

Mouthing

As shown in Figure 9, Jillian exhibited variable but moderately high levels of mouthing during Baseline 1 . Mouthing remained variable during Baseline 2 but decreased overall by about $16 \%$ (see Table 7). During Alternating Treatments 1, mouthing decreased slightly under both visual screening and gentle teaching but the decrement was not clinically significant. In addition, there was an increasing trend in mouthing over the last three days during this phase. Thus, this phase was terminated and an oral hygiene treatment procedure was instituted. Mouthing decreased sharply with oral hygiene and was maintained at a very low level in the final phase when it was used during both daily sessions.

Insert Figure 9 about here

\section{Bonding}

Bonding occurred at clinically insignificant levels during the first three phases and not at all when oral hygiene was used (see Table 7). 
Figure 8 . Percent intervals of on-task behaviour by Jeff across all experimental conditions. 


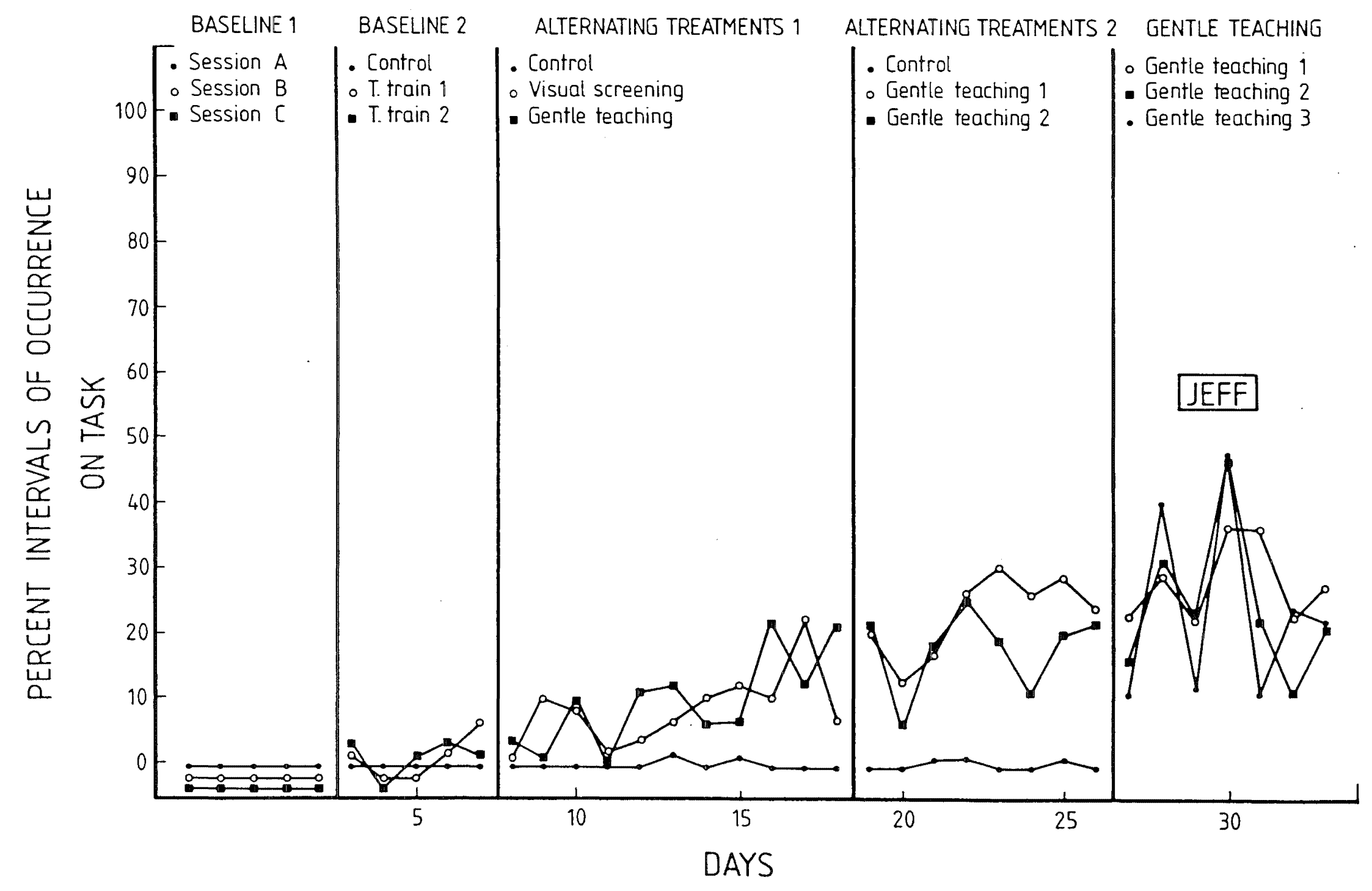


Figure 9. Percent intervals of mouthing and bonding by Jillian across all experimental conditions. 


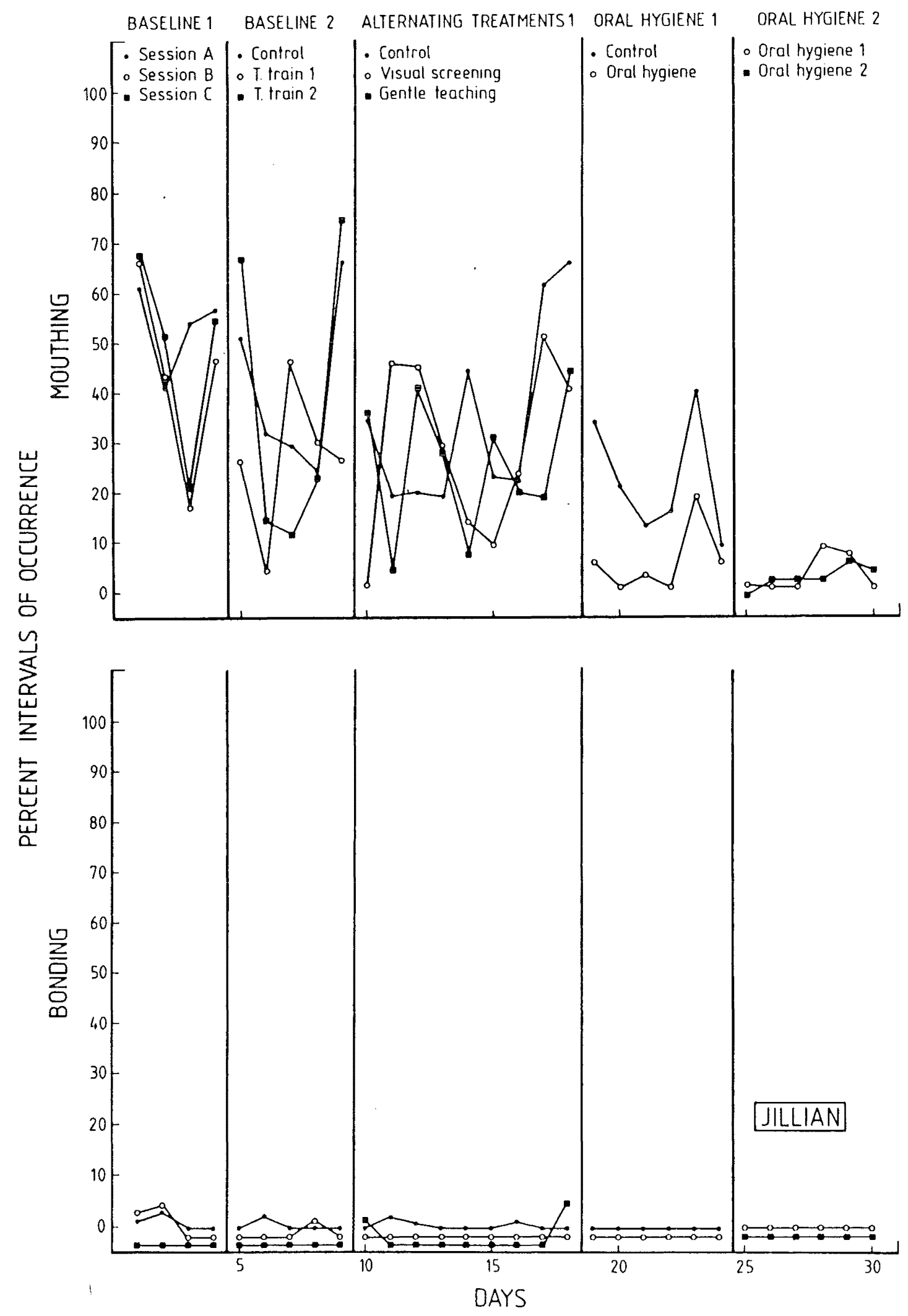


TABLE 7

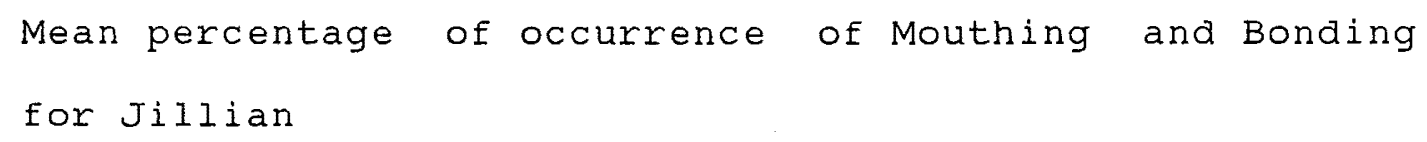

Bonding

Baseline 1

Session A

Session B

Session C

Baseline $(\bar{x} A B C)$

Baseline 2

Control

Task Training 1

Task Training 2

Task Training $(\bar{x} 1,2)$

Alternating Treatments 1

Control

Gentle Teaching

Visual Screening

Oral Hygiene 1

Control

Oral Hygiene

Oral Hygiene 2

Oral Hygiene 1

Oral Hygiene 2

Oral Hygiene $(\bar{x} 1,2)$
53.3

0.8

43.3

1.3

48.5

0.0

48.4

1.1

40.6

0.4

26.6

0.2

38.2

0.0

32.4

0.3

28.8

0.4

25.4

0.0

34.4

1.3
0.0

5.8

0.0

2.2
3.5

0.0

2.7

0.0

3. 1 


\section{Task Training}

As shown in Figure 10, Jillian required task training at a variable level, ranging from $42 \%$ to $64 \%$ of the session across phases. During Alternating Treatments 1, less task training was required during gentle teaching than during visual screening.

Insert Figure 10 about here

\section{On-Task Behaviour}

As shown in Figure 11, Jillian did not engage in on-task behaviour throughout the study except for the last phase when she was on task for less than $2 \%$ (see Table 8 ) of the sessions.

Insert Figure 11 and Table 8 about here 
Figure 10 . Percent intervals of task training by Jillian across all experimental conditions. 


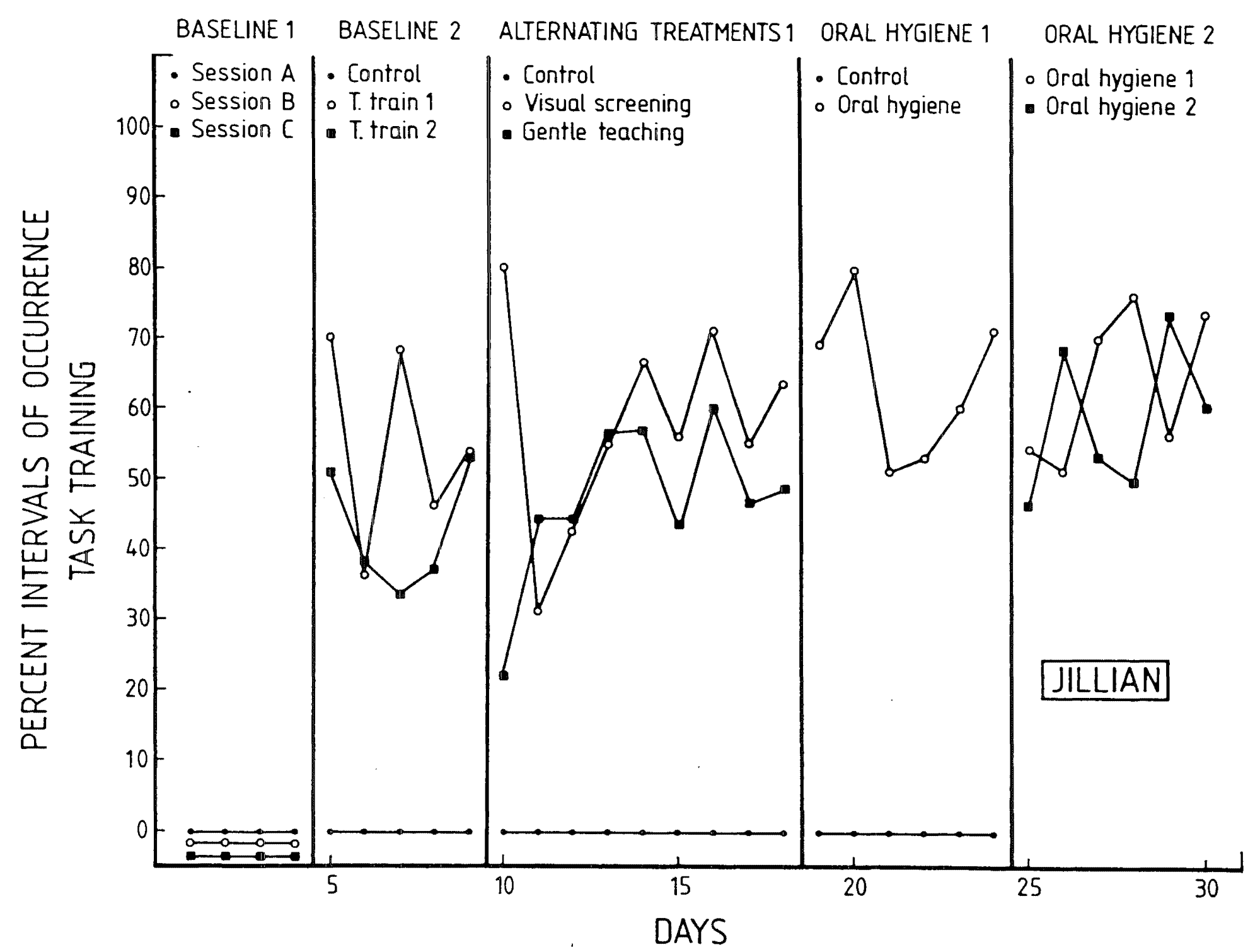


Figure 11. Percent intervals of on-task behaviour by Jillian across all experimental conditions. 


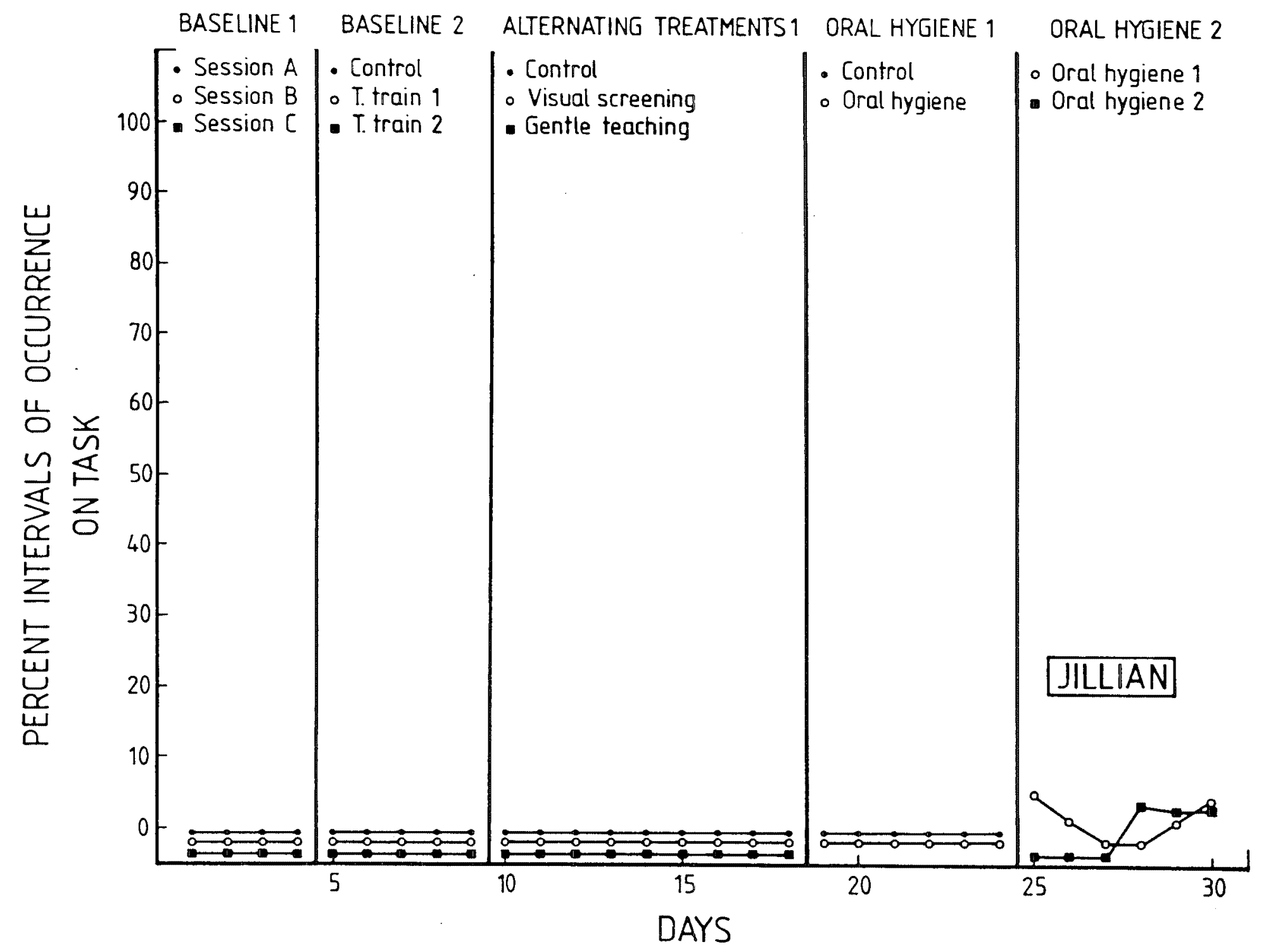


TABLE 8

Mean percentage of occurrence of On Task and Task Training for Jillian

Experimental phase/condition occurrence of behaviour

$\underline{\text { Task }}$

Training $\quad$ On Task

Baseline 1

$\begin{array}{lll}\text { Session A } & 0.0 & 0.0 \\ \text { Session B } & 0.0 & 0.0 \\ \text { Session C } & 0.0 & 0.0 \\ \text { Baseline }(\bar{X} \text { ABC) } & 0.0 & 0.0\end{array}$

Baseline 2

Control

0.0

0.0

Task Training 1

54.8

0.0

Task Training 2

42.2

0.0

Task Training $(\overline{\mathrm{x}} 1,2)$

48.5

0.0

Alternating Treatments 1

Control

0.0

0.0

Gentle Teaching

46.8

0.0

Visual Screening

57.9

0.0

Oral Hygiene 1

Control

0.0

0.0

Oral Hygiene

64.0

0.0

Oral Hygiene 2

Oral Hygiene 1

$63.3 \quad 2.0$

Oral Hygiene 2

58.2

1.3

Oral Hygiene $(\bar{x} 1,2)$

51.0

1.7 


\section{DISCUSSSION}

Desmond

The present results show that visual screening was more effective than gentle teaching, and the no-treatment control conditions in suppressing SIB. Visual screening was effective in suppressing Desmond's SIB at near-zero levels. Visual screening produced a rapid suppression of headslapping compared to gentle teaching which showed a steady increase; after an initial suppressive effect therefore indicating quite clearly that visual screening was the more effective treatment.

The results for other SIB are not as clear. Visual screening is effective in maintaining other SIB at nearzero levels during the final phase compared to moderate levels during Baseline 1. However, SIB in the control condition also tends to occur at low levels across treatment phases and there are no significant differences between gentle teaching and visual screening. Other SIB occurred at low levels in both conditions. However, the final phase does show a stabilising of other SIB at near-zero levels. A possible explanation for this might be that headslapping and other SIB are part of a behaviour chain which is stereotypic in nature, an observation made by both therapists, so that when headslapping, the target behaviour, stabilised at near-zero levels, a similar pattern was seen for other SIB. 
Apart from Baseline 2 there tends to be an inverse relationship between headslapping and task training so that when headslapping increased task training decreases and visa versa. This seems a logical relationship as there would be more opportunity for the therapist to engage in task training with Desmond if SIB was low. This relationship is particularly noticeable during Alternating Treatments 1. Task training shows a steady increase after the first few sessions of visual screening which corresponds to a steady decrease in headslapping. Whereas task training shows a steady decrease during gentle teaching at this point corresponding to an increase in headslapping.

The fact that no on-task behaviour occurred for Desmond might be because SIB behaviour only stabilised at nearzero levels during the final phase and this phase was discontinued early. If it had continued on-task behaviour may have emerged.

There were no differential effects between gentle teaching and visual screening for bonding. In both conditions it occured at near-zero levels. Bonding occured at slightly higher levels when visual screening was implemented across conditions during the final phase. 
Jef $\mathrm{f}$

Both gentle teaching and visual screening were equally effective in suppressing SIB to near-zero levels when compared to baseline and a no-treatment control condition.

Following the least restrictive model gentle teaching was chosen as the treatment of choice.

Prior to treatment it was hypothesised by the therapists, after consultation with staff, that Jeff's headbanging was maintained by both social attention and avoidance behaviour. Jeff's headbanging was frequently accompanied by screaming, crying, and whining. During baseline and the treatment sessions this appeared to be supported by Jeff's behaviour. During baseline and the no-treatment control conditions Jeff engaged in a number of behaviours. He would sleep or engage in stereotypy; however, if he heard voices outside the door he would go to the door and headbang and scream. If he heard voices within the room he would go up to the therapist and grasp the therapist's clothes or body and headbang on the floor and scream. This behaviour occurred for the most part during Baseline 1 and tended to decrease across treatment phases. It was hypothesised by the therapists that Jeff had had his need for social attention met during the treatment conditions and this 
was responsible for the decrease in headbanging during the control condition.

It was also noted that during treatment sessions, Jeff was less likely to headbang and scream in the first of the three daily treatment sessions and would tend to show avoidance behaviour in the following sessions; this occurred across phases. At this time Jeff had been riding the bike (his age-appropriate task) for some time and he would show avoidance behaviour by headbanging and screaming when he was led to the bike or placed on the bike. However, as soon as the therapist released his hand or he was free to get off the bike he would immediately discontinue this behaviour.

There was no consequence for screaming; it was ignored when it occurred. Jeff's special nurses reported ancedotally that Jeff seldom engaged in screaming during maintenance. They also reported that Jeff rarely headbanged and when he did he would only bang his head a few times rather than engage in this behaviour over an extended period of time as he had done prior to the commencement of the study.

Both on-task and task training tended to be inversely related to screaming and headbanging. When headbanging stabilised at near-zero levels, on-task and task training behaviours increased and stabilised at their highest levels. 
It was hypothesised by nursing staff that Jeff's seizures may be a form of avoidance behaviour or they were brought on by stress as they occurred for the most part during lunchtime which was a stressful time for Jeff as he refused to eat and was physically given food by placing it in his mouth on occasions. As the study took place during a time of day that corresponded to Jeff's lunchhour, the therapists decided to monitor Jeff's seizures hypothesising that if the nurses were correct Jeff would be more likely to have seizures during the treatment sessions when high demands were placed on him. However there was no predictable pattern to seizures and this hypothesis appears to be incorrect.

There were no differential effects between gentle teaching and visual screening for bonding. In both conditions it occured at near-zero levels. The highest levels of bonding occured during the baseline and no-treatment control conditions.

Jillian

The results show that visual screening and gentle teaching did not have a substantial clinically significant effect on mouthing when compared to a no-treatment control and task training condition. Mouthing was reduced to moderate levels but did not stabilise in both the gentle teaching and visual 
screening conditions. Introduction of oral hygiene resulted in a dramatic reduction in mouthing and was maintained at near-zero levels. Generalisation to the control condition also occurred with mouthing decreasing to substantially lower levels. In addition, on-task behaviour emerged for the first time once mouthing had been maintained at near-zero levels in the final phase.

Differential effects between gentle teaching and visual screening did not occur for bonding. In both conditions bonding occured at near-zero levels.

The present study shows mixed results in terms of the comparative efficacy of visual screening and gentle teaching. Visual screening was effective in reducing headbanging for Jeff, and headslapping and a variety of collateral SIB's for Desmond, to near-zero levels. Gentle teaching was effective in reducing headbanging for Jeff to near-zero levels also. Both visual screening and gentle teaching did not prove to be as effective in reducing or eliminating mouthing for Jillian.

Few studies are available on the comparative efficacy of different treatments. The present results appear to indicate that treatments may be differentially effective across subjects and behaviours. 
Whether visual screening and gentle teaching are less effective than alternative treatments for mouthing requires further investigation. At present no studies have used visual screening to treat mouthing. Although MCGee (1985a) advocates that gentle teaching is effective in the treatment of all SIB there is no empirical evidence to support such claims. Such behaviours as mouthing, pica, and rumination are internal/ingestion types of self-injury and it has been suggested that visual screening may only be effective in treating external self-injury such as headbanging and headslapping (Fulcher, 1984). However, visual screening has been used to treat pica (Singh \& Winton, 1984) and self-injurious finger sucking (Watson, Singh, \& Winton, $1986)$ and proved to be very successful. Obviously, replication of the present results are needed before any conclusions can be drawn regarding the efficacy of visual screening in the treatment of mouthing. It is unfortunate that studies involving procedures which have failed tend not to be published.

Replication of the present results is also needed before conclusions can be drawn regarding the efficacy of gentle teaching in the treatment of mouthing. It may be that differential reinforcement procedures are not successful in reducing mouthing to near-zero levels.

McGee (1985) might argue that the procedure failed for a number of reasons. First the duration of the gentle 
teaching session was short, i.e., half an hour lJillian and Jeff), and 15 minutes (Desmond) every day may not have been enough. Menolascino and McGee (1985) recommend 60-90 minute daily sessions for severe or profoundly retarded persons who engage in self-injury. However, this is not practical in terms of the experimental design used in which the other conditions would also have to be of the same duration. On the other hand, gentle teaching was successful in reducing Jeff's self-injury to near-zero levels with only half hour sessions.

Second, he might argue that the procedure failed because of the required use of brief physical restraint. The interrupt procedure was difficult to implement on occasions when the frequency and severity of mouthing resulted in tissue damage (bleeding) and Jillian's hand had to be pulled from her mouth. With Desmond, on occasions, it was impossible to use an open palm in the strictest sense due to the high frequency of headslapping. During these times the therapist placed Desmond's arm between the thumb and index finger to support the arm but extended the palm in an open manner in an attempt to overcome this problem. There were no problems implementing the procedure with Jeff, and an open palm was used at all times.

As noted by Mudford (1987) McGee also used brief physical restraint in gentle teaching despite it being a 
punishment procedure. Other practical limitations of gentle teaching included the gentle posture required such as sitting with the subject. This was not always feasible with only one therapist as Jillian and Desmond would engage in out-of-seat behaviour, direct the head away from the therapist, or practical problems of attempting to teach a task at the table and prevent high frequency self-injury.

Finally, McGee might argue that gentle teaching was unsuccessful as the therapists were required to carry out both the gentle teaching and visual screening procedures. Bonding might therefore be jeopardised as the therapists simultaneously implemented a punishment procedure. Following McGee's philosophy a more appropriate design to test the effectiveness of gentle teaching would be a multiple baseline across subjects and/or settings.

However, for scientific reasons it is important to be able to compare techniques particularly as there is not much data available on the comparative efficacy of alternative treatments for SIB.

It should be noted however that these arguments do not explain why gentle teaching produced successful results with Jeff but failed to significantly reduce SIB for 
Jillian and Desmond. One possible explanation relates to the antecedents and maintaining variables of the subjects' self-injury. It was hypothesised that Jeff's SIB was maintained by social attention and avoidance of activities. However, the maintaining variables for Jillian's and Desmond's self-injury were less clear.

For both subjects, there were no observed consequences given by nursing staff for SIB. It could be hypothesised that although the maintaining variables in the past may have been more tangible their SIB might now be maintained by sensory consequences. Since gentle teaching places high task demands on the individual, it is possible that Jeff may have learnt that his SIB was ineffective in removing task demands and gaining social attention. In order to gain social attention Jeff was required to comply with task demands and to not engage in SIB. The behaviours required to gain social attention and avoid tasks had therefore been changed.

During the course of the study the therapists also attempted to teach Jeff to sign 'open door' whenever he left the room. Due to Jeff's lack of communication skills and the fact that he mainly banged his head against the door, teaching Jeff to communicate that he wanted the door open might be a useful skill. This was carried out informally and was not included as part of 
the study. However, it proved to be unsuccessful as Jeff would scream, arch his back, and/or headbang and not co-operate with the procedure.

As visual screening was effective in reducing headbanging (Jeff) and headslapping and a variety of collateral SIB behaviours for Desmond, this adds to the body of literature proving visual screening to be a successful technique for controlling SIB. It also provides further support that visual screening is effective using a 5 -second duration as it has been in other studies (MCGonigle et al., 1982; Watson et al., 19861.

The successful implementation of oral hygiene adds to the literature supporting its use for self-injurious mouthing. Oral hygiene dramatically suppressed mouthing which stabilised at low levels. The one high data point may have been caused by an extraneous variable specific to the subject on that day, as the high level in the control condition would suggest. Ideally, the final intervention phase should not have been introduced until SIB in the control increased to previous levels but due to time factors this was not possible. However there was some generalisation to control as soon as the oral hygiene procedure was introduced. Near-zero levels of mouthing occurred during the last phase. It is possible 
that complete suppression of mouthing may have occurred with a greater time duration or if the final phase had continued with more treatment sessions. When compared to baseline, however, the suppression of mouthing during oral hygiene is quite outstanding. There were also practical problems with implementation of the procedure when the subject resisted the treatment and would not co-operate with toothbrushing. Brushing her teeth was not a skill in her behavioural repetoire and she actively resisted the procedure.

None of the subjects showed complete suppression of SIB. As the final phase was short for all the subjects it is unclear whether SIB would have eventually been completely suppressed if this phase had continued.

The present results do not confirm McGee's assumptions regarding bonding. McGee (1985b) claims that individuals who engage in SIB have not bonded. However, bonding occurred during baseline for all subjects. McGee (1985b) also claims that although punishment procedures may suppress SIB behaviour, the individuals will not bond. Although Jillian did not show any instances of bonding during visual screening and oral hygiene conditions, Desmond and Jeff showed instances of bonding during the visual screening conditions. There were also no significant differences in bonding during gentle teaching and visual screening. 
MCGee might argue that the near-zero levels of bonding throughout the study for Desmond and Jillian were the reason why gentle teaching was not successful with these subjects. However, this is a circular argument, as inadequacies of the gentle teaching procedures may well have caused bonding to fail. The definition of bonding used in this study may have been too strict. However other examples of bonding include eye contact which is impractical to measure in this type of study and teasing which is difficult to empirically define. Handholding was excluded after it appeared that the subjects used this frequently to have demands met. Handshaking was excluded as it seemed a rather artificial display of affection. Touching and smiling were therefore used in this study as a measure of bonding. In any case, a search of McGee's writings thus far failed to unearth a suitable definition of bonding.

There is some doubt whether Jillian and Desmond's bonding behaviour reflected a special affection between therapist and subject. Jeff frequently made affectionate responses toward staff prior to the study and this is perhaps reflected in his higher levels of bonding. It appears that individuals who engage in SIB may display bonding behaviour if social attention actually maintains their SIB, as was the case with Jeff. 
In accordance with the least restrictive treatment model, DRI/DRA was used in the first intervention phase and in the visual screening and oral hygiene conditions. An independent toy play procedure (Singh \& Millichamp, 1987 ) with age-appropriate tasks (Brown, et al., 1979) was also used. Independence on the task was not achieved for Desmond. Jillian only engaged in on-task behaviour during the final treatment phase when her mouthing had stabilised at near-zero levels.

The reason on-task behaviour occurred for Jeff early in the study and was maintained at low levels may be due to a number of factors. First, Jeff responded well to social attention and showed affectionate responses toward the therapists so that social attention appeared to be an effective reinforcer for Jeff. Also the bicycle was decided on as the main task for a variety of reasons. Unlike toys which are often misplaced and not replaced in a dayroom situation, a bike was likely to always be present in the dayroom. It was also a functional task for a 10-year-old child. Finalyy, Jeff appeared to enjoy being placed on the bike prior to the study and would attempt to move the bike by rocking his body backwards and forwards. It was therefore hoped that riding the bike would be intrinsically rewarding. Finding tasks which are both functional and 
intrinsically rewarding can be difficult for profoundly retarded persons. Also Jeff's SIB was of a lower frequency than the other subjects and it stabilised at near-zero levels earlier, thus promoting on-task behaviour.

The reason why no on-task behaviour occurred for Desmond is unclear. Possible reasons include the task being too difficult, the steps in the task were too complicated, no reinforcement was associated with the task, or the social attention used to encourage on-task behaviour was not powerful enough. Like Jillian, on-task behaviour may have occurred if the final phase was longer and SIB had stabilised at near-zero levels for a longer period of time.

For Jillian and Desmond edible reinforcers may have been more effective in promoting on-task behaviour. These were not able to be used during the alternating treatments phase in order to make the reinforcers used during visual screening and gentle teaching sessions comparable. They could have been added during the final phase for both subjects had it continued.

It appears that task training was necessary to teach ontask behaviour as no on-task behaviour occurred during baseline although the tasks were present. Task training tended to stabilise and still had to be maintained at 
high levels once SIB had decreased and been maintained at zero or near-zero levels.

All subjects showed resistance to treatment and engaged in other behaviours. For example, aggressive behaviours such as pinching and biting (Jeff) and pushing the therapists hands away (all subjects) were observed. It was impossible to screen all subjects initially using both hands to cover the eyes. One hand had to be used to restrain the subjects and occasionally this was too difficult for one therapist and assistance from nurses or other therapists was needed to restrain the subject. These difficulties also occurred during oral hygiene and gentle teaching for Jillian due to the damage she caused by biting her hand until it bled.

Gentle teaching was only effective in reducing the SIB of one subject. Replication of the results using methodologically sound designs is needed before conclusions can be arawn regarding the procedure's effectiveness. This means that caution is needed regarding claims of the procedure's effectiveness.

The effectiveness of visual screening in reducing headbanging and face slapping adds to the number of studies that have shown it to be an effective procedure in reducing a variety of SIB. However, the 
effectiveness of visual screening in reducing mouthing requires further investigation. In this study visual screening failed to reduce mouthing significantly. If visual screening is found to be ineffective in reducing mouthing in future research such results should be reported in the literature. The present trend to not report unsuccessful results does not prevent researchers from choosing ineffective procedures.

Oral hygiene produced immediate and substantial reductions in mouthing. This replicates the results of previous research which has shown oral hygiene to be effective in reducing mouthing (Doke \& Epstein, 1975; Foxx \& Azrin, 1973). It also suggests that overcorrection of the type used in this study may be particularly appropriate with internal/ingestion behaviours which includes mouthing. 
REFERENCES

Abe, K., Oda, N., \& Amatorni, M. (1984). Natural History and Predictive Significance of Headbanging, Head-rolling, and Breath-holding Spells. Developmental Medicine and Child Neurology, 26 , $644-648$.

Altman, K., Haavik, S., \& Cook, J.W. (1978). Punishment of self-injurious behaviour in natural settings using contingent aromatic ammonia. Behaviour Research and Therapy, 16, 85-96.

Altman, K., Haavik, S., \& Higgins, S. T. (1983). Modifying the self-injurious behaviour of an infant with spina bifida and diminished pain sensitivity Journal of Behaviour Therapy and Experimental Psychiatry, 14, 165-168.

Altmeyer, B.K., Locke, B.J., Griffin, J.C., Ricketts R.W. Williams, D.E., Mason, M., \& Stark, M.T. (1987). Treatment strategies for self-injurious behaviour in a large service-delivery network American Journal of Mental Deficiency, 91, 333-340. Altmeyer, B.K., Williams, D.E., \& Sams, V. (1985). Treatment of severe self-injurious and aggressive biting. Behaviour Therapy \& Psychiatry, 16 , $169-172$.

Aman, M.G. (1984). Drugs and learning in mentally retarded persons. In G.D. Burrows \& J.S. Werry (Eds.), Advances in Human Psychopharmacology Vol.3. Greenwich, Conn: JAI Press. 
Aman, M.G., \& Singh, N.N. Pharmacological intervention in mental retardation. In J.L. Matson and J.A. Werry (Eds.), Handbook of Mental Retardation (pp. 317-337). Elmsford, New York: Pergamon Press. Ananth, J., Kaplin, H.S., \& Lin, K.M. (1984). Self-Inflicted enucleation of an eye: Two case reports. Canadian Journal of Psychiatry, $\underline{29}$, $145-146$.

Augustine, A., \& Cipani E. (1982). Treating self-injurious behaviour: Initial effects, maintenance and acceptability of treatment. Child and Family Behaviour Therapy, $\underline{4}, 53-69$.

Bachman, J.A. (1972). Self-injurious bevaviour: A behavioural analysis. Journal of Abnormal Psychology, 80, 211-224.

Bailey, S.L., Pokrzywinski, J., \& Bryant,L.E. (1983). Using water mist to reduce self-injurious and stereotypic behaviour. Applied Research in Mental Retardation, $4,229-241$.

Ball, T.S., Datta, P.C., Rios, M., Constantine, C. (1985). Flexible arm splints in the control of a Lesch-Nyhan victim's finger biting and a profoundy retarded client's finger sucking. Journal of Autism \& Developmental Disorders, $15,177-184$.

Barmann, B.C., \& Murray, W.J. (1981). Suppresion of inappropriate sexual behaviour by facial screening. Behaviour Therapy, $12,730-735$. 
Barmann, B.C., \& Vitali, D.L. (1982). Facial screening to eliminate trichotillomania in developmentally disabled persons. Behaviour Therapy, 13 , $735-742$.

Barrett, R.P., Staub, R.W., \& Sisson, L.A. (1983). Treatment of compulsive rituals with long-term follow-up. Journal of Behaviour Therapy and Experimental Psychiatry, 14, 55-59.

Barron, J., \& Sandman, C.A. (1983). Relationship of sedative-hypnotic response to self-injurious behaviour and stereotypy by mentally retarded clients. American Journal of Mental Deficiency, 88, 177-186.

Barron, J.L., \& Sandman, C.A. (1984). Self-Injurious behaviour and Stereotypy in an institutionalized mentally retarded population. Applied Research in Mental Retardation, $\underline{5}, 499-511$.

Barron, J., \& Sandman, C.A. (1985). Paridoxical excitement to sedative-hypnotics in mentally retarded clients. American Journal of Mental Deficiency, $\underline{190}, 124-129$.

Barlow, D.H., \& Hayes, S.C. (1979). Alternating treatments design: One strategy for comparing the effects of two treatments in a single subject. Journal of Applied Behaviour Analysis, 12 , $199-210$.

Bartak, L., \& Rutter, M. (1976). Differences between mentally retarded and normally intelligent autistic children. Journal of Autism and Childhood Schizophrenia, $\underline{6}, 109-120$. 
Barton, L.E., \& Lagrow, S.J. (1983). Reducing self-injurious and aggresive behaviour in deaf-blind persons through overcorrection. Journal of Visual Impairment and Blindness, $77,421-424$.

Bates, W.J. \& Smeltzer, D.J. (1982). Electroconvulsive treatment of psychotic self-injurious behaviour in a patient with severe mental retardation. American Journal of Psychiatry $\underline{139}, 1355-1356$.

Baumeister, A.A., \& Baumeister, A.A. (1978). Suppression of repetitive self-injurious behaviour by contingent inhalation of aromatic ammonia. Journal of Autism and Childhood Schizophrenia, $\underline{8}, 71-77$.

Baumeister, A.A., \& Rollings, J.P. (1976). Self-injurious behaviour. International Review of Research in Mental Retardation, $\underline{8}, 1-34$.

Becker,J.V., Turner, S.M., \& Sajwaj, T.E. (1978). Multiple behavioural effects of the use of lemon juice with a ruminating toddler-age child. Behaviour Modification, $\underline{2}$ ，267-278.

Beckwith, B.E., \& Couk, D.I., Schumacher, K. (1986). Failure of naloxone to reduce self-injurious behaviour in two developmentally disturbed females. Applied Research in Mental Retardation, 7 , $183-188$.

Borrenson, P.M. (1980). The elimination. of a self-injurious avoidance response through a forced running consequence. Mental Retardation, 18 , $73-77$. 
Brown, L., Branston, M.B., Harnre-Nietupski, S., Pumpion I., Gerto, N., Gruenewald, L. (1979). A strategy for developing chronological age appropriate and functional curricular content for severely handicapped adolescents and young adults. Journal of Special Education, $13,81-90$.

Bryson, Y., Sakati, N., Nyhan, N.L., \& Fish, C.H.

(1971). Self-mutilative behaviour in the Cornelia de Lange syndrome. American Journal of Mental Deficiency, $76,319-321$.

Burke, M.M., Burke, D., \& Forehand, R. (1985).

Interpersonal antecedants of self-injurious behaviour in retarded children. Education and Training of the Mentally Retarded, September , 204-208.

Carr, E.G. (1977). The motivation of self-injurious behaviour : A review of some hypotheses Psychological Bulletin, $\underline{84}, 800-816$.

Carr, E.G., \& Durand, V.M. (1985). Reducing behaviour problems through functional training. Journal of Applied Behaviour Analysis, $18,111-126$.

Carr, E.G., \& McDowell, J.J. (1980). Social control of self-injurious behaviour of organic etiology. Behaviour Therapy, 11, 402-409.

Carr, C.G., Newsom, C.D., \& Binkoff, J.A. (1976). Stimulus control of self-destructive behaviour in a psychotic child. Journal of Abnormal Child Psychology, $\underline{4}, 139-153$.

Cataldo, M.F., \& Harris, J. (1982). The biological basis for self-injury in the mentally retarded. Analysis and Intervention in Developmental Disabilities, $\underline{2}, 21-39$. 
Corte, H.E., Wolf, M.M., \& Locke, B.J. (1971). A comparision of procedures for eliminating self-injurious behaviour of retarded adolesents. Journal of Applied Behaviour Analysis, 4 , 201-213. Corte, H.E., Wolf, M.M., \& Locke, B.J. (1971). A comparision of procedures for eliminating self-injurious behaviour of retarded adolesents. Journal of Applied Behaviour Analysis, $\underline{4}$, 201-213. Davidson, P.W., Kleene, B.M., Carroll, M. \& Rockowitz, R.J. (1983). Effects of Naloxone on self-injurious behaviour: A case study. Applied Research in Mental Retardation , $\underline{4}, 1-4$.

Deitz, S.M. (1977)." An analysis of programming DRL schedules in educational settings. Behaviour

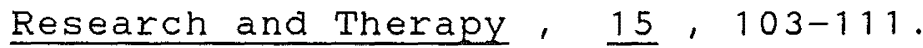

De Lissovoy, V. (1961). Headbanging in early childhood: A study of incidence. Journal of Pediatrics, $\underline{58}, 803-805$.

De Lissovoy, V. (1963). Headbanging in early childhood: A suggested cause. The Journal of Genetic Psychology, 102, 109-114.

Demchak, M.A., \& Halle, J.W. (1985). Motivational assessment: A potential means of enhancing treatment sucess of self-injurious behaviour. Education and Training of the Mentally Retarded , 20, 25-38.

Demetral, G.D., \& Lutzker, J.R. (1980). The parameters of facial screening in treating self-injurious behaviour. Research of Severe Developmental Disabilities , $1,261-277$. 
Demuth, G.W., Strain, J.J., \& Lombardo-Maher, A.

(1983). Self-amputation and restitution. General Hospital Psychiatry ， $\underline{5}, 25-30$.

Deutsch, S.I. (1986). Rationale for the administration of opiate antagonists in treating infantile autism. American Journal of Mental Deficiency, 90 , $631-635$.

Dick, D.M., \& Jackson, H.J. (1983a). The reduction of stereotypic screaming in a severely retarded boy through a visual screening procedure. Journal of Behaviour Therapy \& Experimental Psychiatry , 14 , $363-367$.

Dick, D.M., \& Jackson, H.J. (1983b). 3. The Parent-administered treatment of the inappropriate behaviours of a retarded infant. British Journal of Mental Subnormality, $\underline{29}, 81-86$.

Doctors, S. (1981). The symptom of delicate self-cutting in adolescent females: A developmental view. Adolescent Psychiatry, $9,433-460$.

Doke, L.A., \& Epstein, L.H. (1975). Oral overcorrection: Side effects and extended applications. Journal of Experimental Child Psychology , 20,496-511.

Dorsey, M.F., Iwata, B.A., Ong, P., \& McSween, T.E. (1980). Treatment of self-injurious behaviour using a water mist: Initial response suppression and generalization. Journal of Applied Behaviour Analysis, $13,343-353$. 
Dorsey, M.F., Iwata, B.A., Reid, D.H., \& Davis, P.A. (1982). Protective equipment: Continuous versus contingent application in the treatment of self-injurious behaviour. Journal of Applied Behaviour Analysis, $\underline{2}, 32-45$.

Duker, P.C. (1975). Behaviour control of self-biting in a Lesch-Nyhan patient. Journal of Mental Deficiency Research , 19, 11-19.

Duker, P.C., \& Seys, D.M. (1983) 2. Long-term follow-up effects of extinction and overcorrection procedures with severely retarded individuals. British Journal of Mental Subnormality, $\underline{29}, 74-80$.

Durand, V.M. (1982a). A behavioural/pharmacoligical intervention for the treatment of severe self-injurious behaviour. Journal of Autism \& Developmental Disabilities , 12 , 243-250.

Durand, V.M. (1982b). Analysis and Intervention of seif-injurious behaviour. Journal of the Association for the Severely Handicapped, $I$, $44-53$.

Durand, V.M., \& Carr, E.G. (1985). Self-injurious behaviour: Motivating conditions and guidelines for treatment. School Psychology Review, 14 , $171-176$

Durand, V.M., \& Crimmins, D.B. (1987). Identifying the variables maintaining self-injurious behaviour. Unpublished manuscript: State University of New York at Stony Brook. 
Edelson, S.M. (1984). Implications of sensory stimulation in self-destructive behaviour. American Journal of Mental Deficiency, $\underline{89}, 140-145$.

Edelson, S.M., Taubman, M.T., \& Lovaas, O.I. (1983). Some social contexts of self-destructive behaviour. Journal of Abnormal Child Psychology, 11, 299-312.

Favell, J.E., Azrin, N.H., Baumeister, A.A., Carr, E.G., Dorsey, M.F., Forehand, R., Foxx, R.M., Lovaas, O.I., Rincover, A., Risley, T.R., Romanczyk, R.G., Russo, D.C., Schroeder, S.R., Solnick, J.V. (1982). The treatment of self-injurious behaviour. Task force report of the Association for the Advancement of Behaviour Therapy. Behaviour Therapy, 13 , $529-554$.

Favell, J.E., McGimsey, J.F., \& Jones, M.L. (1978). The use of physical restraint in the treatment of self-injury and as positive reinforcement. Journal of Applied Behaviour Analysis , $11,225-241$.

Favell, J.E., McGimsey, J.F., Jones, M.L., \& Cannon, P.R (1981). Physical restraint as positive reinforcement American Journal of Mental Deficiency, 85 , $425-432$.

Favell, J.E., McGimsey, J.F., \& Schell, R.M.: (1982). Treatment of self-injury by providing alternative sensory activities. Analysis and Intervention in Developmental Disabilities , $\underline{2}, 83-104$.

Fellner, D.J., Laroche, M., \& Sulzer-Azaroff, B. (1984) The effects of adding interruption to differential reinforcement and novel self-stimulatory behaviours. Journal of Behaviour Therapy \& Experimental Psychiatry , 15, 351-321. 
Forehand, R., \& Baumeister, A.A. (1976). Deceleration of aberrant behaviour amoung retarded individuals. In M. Hersen, R.M. Eisler, \& P.M. Miller (Eds.), Progress in Behaviour Modification, (Vol.2). New York: Academic Press.

Foxx, R.M., \& Azrin, N.H. (1972). Restitution: A method of eliminating aggressive-disruptive behaviour of retarded and brain damaged patients. Behaviour

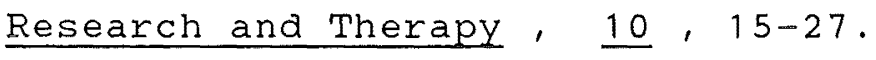

Foxx, R.M., \& Azrin, N.H. (1973). The elimination of autistic behaviour by overcorrection. Journal of Applied Behaviour Analysis, $6,1-14$.

Foxx, R.M., \& Bechtel, D.R. (1982a). Overcorrection: In M. Herson, R.M. Eisler, \& P.M. Miller (Eds.), Progress in Behaviour Modification , (pp. 227-288). New York: Academic Press.

Foxx, R.M., \& Bechtal, D.R. (1982b). Overcorrection:

A review and analysis. In S. Axelrod \& J. Apsche (Eds.), The effects of punishment on human behaviour, (pp. 133-220). New York: Academic Press. Foxx, R.M., \& Dufrense, D. (1984). "Harry". The use of physical restraint as a reinforcer, timeout from restraint, and fading restraint in treating a self-injurious man. Analysis and Intervention in Developmental Disabilities, $14,1-13$.

Foxx, R.M., \& Livesay, J. (1984). Maintenance of response suppression following overcorrection: A 10-year retrospective examination of eight cases. Analysis and Intervention in Developmental Disabilities , $\underline{4}, 65-79$. 
Foxx, R.M., Snyder, M.S., \& Schroeder, F. (1979). A food satiation and oral hygiene punishment program to suppress chronic rumination by retarded persons. Journal of Autism and Developmental Disorders, $\underline{9}$, $399-412$.

Freschi, D.F., \& Dileo, P.D. (1982). Treatment of self-abusive behaviour using positive intervention with an autistic boy. Exceptional Chilaren, $\underline{49}$, $77-78$.

Fulcher, G. (1984). A review of self-injurious behaviour. Australia \& New Zealand Journal of Developmental Disabilities, 10, 51-67.

Gardner, D.L., \& Cowary, R.W. (1985). Suicidal \& Parasuicidal behaviour in borderline personality disorder. Psychiatric Clinics of North America, $\underline{8}, 389-403$.

Gaylord-Ross, R.J., Weeks, M., \& Lipner, C. (1980). Analysis of antecedant, response, and consequence events in the treatment of self-injurious behaviour. Education and Training of the Mentally Retarded, $15,35-42$.

Gibbs, J.W., \& Luyben, P.D. (1985). Treatment of self-injurious behaviour contingent versus noncontingent positive practice overcorrection Behaviour Modification, $9,3-21$.

Gluck, J.P., Otto, M.N., \& Beauchamp, A.J. (1985). Respondent conditioning of self-injurious behaviour in early socially deprived rhesus monkeys (Macaca mulatta). Journal of Abnormal Psychology, 94 , 
Glynn, T. (1985). Providing a context for gentle teaching: An invited reply to gentle teaching by $D r$ J.J. McGee. Mental Handicap in New Zealand, $\underline{9}$, $21-23$

Gorman-Smith, D., \& Matson, J.L. (1985). A review of treatment research for self-injurious and stereotyped responding. Journal of Mental Deficency Research, $\underline{29}, 295-308$.

Green, A. (1967). Self-mutilation in schizophrenic children. Archives of General Psychiatry, 17 , $232-244$

Griffin, J.C., Williams, D.E., Stark, M.T., Altmeyer, B.K., Mason, M. (1986). Self-injurious behaviour: A state-wide prevalence survey of the extent and circumstances. Applied Research in Mental Retardation, $7,105-116$.

Grossman, H. J. (1983). Classification in mental retardation. Washington: American Association on Mental Deficiency.

Gualtieri, C.T., \& Hawk, B. (1980). Tardive dyskenesia and other drug induced movement disorders amoung handicapped children and youth. Applied Research in Mental Retardation, $1,55-69$.

Halpern, L.F., \& Andrasik, F. (1986). The immediate and long term effects of overcorrection in treating self-injurious behaviour in a mentally retarded adult. Applied Research in Mental Retardation, I, 59-65. 
Hamad, C.D., Isley, E., \& Lowry, M. (1983). The use of mechanical restraint and response incompatability to modify self-injurious behaviour. Mental $\underline{\text { Retardation, }} \underline{21}, 213-217$.

Heidorn, S.D, \& Jenson, C.C. (1984). Generalization and maintenance of the reduction of self-injurious behaviour maintained by two types of reinforcement. Behaviour Research and Therapy, $\underline{22}, 581-586$.

Horner, R.D. (1980). The effects of an environmental "enrichment" programme on the behaviour of institutionalized profoundly retarded children. Journal of Applied Behaviour Analysis, 13 , $473-491$.

Horner, R.D., \& Barton, E.S. (1980). Operant techniques in the analysis and modification of self-injurious behaviour: A review. Behaviour Research in the Severexly Developmentally Disabled, $1,61-91$.

Hurley, A.D.N., \& Sovner, R. (1986). Behaviour modification. 4. Response cost procedures. Psychiatric Aspects of Mental Retardation, $\underline{5}$, $7-10$.

Iwata, B.A., Dorsey, M.F., Slifer, K.E., \& Richman, G.S. (1982). Toward a functional analysis of self-injury. Analysis and Intervention in Developmental Disabilities, $\underline{2}, 41-66$.

Jackson, G., Johnson, C., Ackeron, G., \& Crowley, R. (1975). Food satiation as a procedure to decelerate vomiting. American Journal of Mental Deficiency, $\underline{80}, 223-227$. 
Jenner, S. (1984). The effectiveness of abbreviated overcorrection-based treatments. Behavioural Psychotherapy, $12,175-187$.

Jenson, W.R., Rovner, L., Cameron, S., Peterson, B.P., \& Kesler, J. (1985). Reduction of self-injurious behaviour in an autistıc girl using a multifaceted treatment programme. Journal of Behaviour Therapy and Experimental Psychiatry , 16, 77-80.

Johnson, W.L., \& Baumeister, A.A. (1978). Self-injurious behaviour. A review and analysis of methodological details of published studies. Behaviour Modification , $\underline{2}, 465-487$.

Jones, I.H. (1982). Self-Injury: Toward a biological basis. Perspectives in Biological and Medicine, $\underline{26}, 137-149$.

Jones, M., \& Anderson, M. (1981). Problems involved in the use of ammonia in the treatment of self-injurious behaviour. Australian Journal of Developmental Disabilities, $\underline{7}, 27-31$.

Jones, F.H., Simmons, J.G., \& Franke1, F. (1974). Case study: An extinction procedure for eliminating self-destructive behaviour in a 9-year-old autistic girl. Journal of Autism and Childhood Schizophrenia , $\underline{4}, 241-250$.

Kazdin, A.E. (1982). Single-case resarch designs: Methods for clinical and applied settings, (pp172-1980). New York: Oxford University Press. Kohleis, B. (1986). The effects of visual screening on two maladaptive behaviours. Mental Handicap in New $\underline{\text { Zealand }}, \underline{10}, 8-17$. 
Kravitz, H., \& Boehm, S. (1962). Rythmic habit patterns in infancy: Their sequence, age of onset, and frequency. Child Development, $\underline{33}, 43-56$.

Larkin, K.C., Hill, B.K., Hauber, F.A., \& Brunicks, R.H. (1983). New admissions and readmissions to a national sample of public residential facilities. American Journal of Mental Deficiency, $88,13-20$. Lesch, M., \& Nyhan, W.A. (1964). A familial disorder of uric acid metabolism and central nervous system function. American Journal of Medicine, 36 , $561-570$.

Levinson, C.A. (1970). The development of headbanging in a young rhesus monkey. American Journal of Mental Deficiency, $\underline{75}, 323-328$.

Lichstein, K.L., \& Schreibman, L. (1976). Employing electric shoock with autistic children: A review of the side effects. Journal of Autism and Childhood Schizophrenia , $\underline{6}, 163-173$.

Lobarto, D., Carlson, E.I., \& Barrera, R.D. (1986). Modified satiation reducing ruminative vomiting without excessive weight gain. Applied Research in Mental Retardation , $\underline{7}, 337-347$.

Lockwood, K., \& Bourland, G. (1982). Reduction of self-injurious behaviours by reinforcement and toy use. Mental Retardation, $\underline{20}, 169-173$.

Lovaas, O.I., Freitag, G., Gold, V.J., \& Kassorla, I.C. (1965) Experimental studies in childhood schizophrenia: Analysis of self-destructive behaviour. Journal of Experimental Child Psychology , $\underline{2}, 67-84$. 
Lovaas, O.I., \& Simmons, J.Q. (1969). Manipulation of self-destructive in three retarded children. Journal of Applied Behaviour Analysis , $\underline{2}, 143-157$. Lucero, W.J., Frieman, J., Spoering, K., \& Fehrenbacher, J. (1976). Comparision of three procedures in reducing self-injurious behaviour. American Journal of Mental Deficiency, $\underline{80}, 548-554$.

Lutzker, J.R. (1978). Reducing self-injurious behaviour by facial screening. American Journal of Mental Deficiency, $84,510-513$.

Lutzker, J.R., \& Wesch, D. (1983). Facial Screening: History and critical review. Australia and New Zealand Journal of Developmental Disabilities , $\underline{9}$, $209-223$.

Mayhew, G., \& Harris, F. (1979). Decreasing selfinjurious behaviour: Punishment with citric acid and reinforcement of alternative behaviour. Behaviour Modification, $\underline{3}, 322-336$.

Maisto, C.R., Baumeister, A.A., \& Maisto, A.A. (1978). An analysis of variables related to self-injurious behaviour amoung institutionalized retarded persons. Journal of Mental Deficiency Research , $\underline{22}, 27-36$.

Matson, J.L. (1986). Self-injury and its relationship to diagnostic schemes in psychopathology. Applied Research in Mental Retardation, $\underline{7}, 223-227$.

Matson, J.L., \& Frame, C.L. (1986). Self-injury. In Atypical stereotyped movement disorders (pp. 1-27). New York: Guilford Press. 
Maurice, P., \& Trudel, G. (1982). Self-injurious behaviour prevalence and relationship to enviromental events. In J.H. Hollis \& C.E. Meyers (Eds.), Life-threatening behaviour: Analysis and intervention (p 81-103). Washington, DC: American Association on Mental Deficiency.

McGee, J.J. (1985a). "Gentle Teaching". Mental Handicap in New Zealand, $9,13-24$. McGee, J.J. (1985b). Bonding as the goal of teaching. Mental Handicap in New Zealand, $\underline{9}, 5-10$. McGee, J.J. (1985c). Examples of the use of gentle teaching. Mental Handicap in New Zealand, $\underline{9}$, $11-20$.

McGee, J.J. (1985d). Mental Handicap interviews John McGee. Mental Handicap in New Zealand, $\underline{9}, 24-26$. McGee, J.J., Menolascino, F.J., \& Menousek, P.E. (in press). Gentle Teaching . Texas: Pro-Ed. McGonigle, J.J., Duncan, D., Cordisco, L., \& Barrett, P. (1982). Visual screening: An alternative method for reducing stereotypic behaviours. Journal of Applied Behaviour Analysis, $15,461-467$. Menolascino, F.J., \& McGee, J.J. (1983). Persons with severe mental retardation and behavioural challenges: From disconnectedness to human engagement. Journal of Psychiatric Treatment \& Evaluation , $\underline{5}, 187-193$. Morris, R.J., \& Brown, D.K. (1983). Legal and ethical issues in behaviour modification with mentally retarded persons. In J.L. Matson, \& F. Andrasik (Eds.), Treatment issues and innovations in mental retardation.(pp. 61-95). New York: Plenum. 
Mudford, O.C. (1986). Attitudes to visual screening. Mental Handicap in New Zealand, $10,8-12$.

Mudford, O.C. (1987). Treatment selection in behaviour reduction: Gentle teaching versus the least intrusive treatment model. Australian and New Zealand Journal of Developmental Disabilities , 11 , $33-37$.

Mueller, K., Saboda, S., Palmour, R., \& Nyhan, W.L.

(1982). Self-injurious behaviour produced in rats by daily caffeine and continous amphetamine. Pharmacology, Biochemistry, \& Behaviour, 17 , $613-617$.

Murphy, R.J., Ruprecht, M., \& Nunes, D.L. (1979). Elimination of self-injurious behaviour in a profoundly retarded adolescent using intermittent time out, restraint, and blindfold procedures. American Association for the Education of the Severely and Profoundly Handicapped Review, $\underline{4}$, $334-345$.

Myers, D.V. (1975). Extinction, DRO, and response-cost procedures for eliminating self-injurious behaviour: A case study. Behaviour Research and Therapy, $13,189-191$.

Nagata, Y., Suehiro, T., \& Nikawa, N. (1984). Self-scratching injuries on the newborns face. Early Child Development and Care, 17, 123-130. 
Nunes, D., Murphy, R., \& Ruprecht, M.L. (1977). Reducing self-injurious behaviour of severely retarded individuals through withdrawl of reinforcement procedures. Behaviour Modification, $1,499-516$.

Nyhan, N.L. (1976). Behaviour in the Lesch-Nyhan syndrome. Journal of Autism and Childhood Schizophrenia , $6,235-252$.

Pace, G.M., Ivacic, M.T., Edwards, G.L., Iwata, B.A., \& Page, T.J. (1985). Assessment of stimulus preference and reinforcer value with profoundly retarded individuals. Journal of Applied Behaviour Analysis $, \underline{18}, 249-256$

Paniagua, F.A., Braverman, C., \& Capriotti, R.M. (1986). Use of a treatment package in the management of a profoundly mentally retarded girls pica and self-stimulation. American Journal of Mental Deficiency, $90,550-557$.

Parrish, J.M., Iwata, B.A., Dorsey, M.F., Bunck, T.J. \&

Slifer, K.J. (1985). Behaviour analysis, program development, and transfer of control in the treatment of self-injury. Behaviour Therapy \& Experimental Psychiatry, $16,159-168$.

Pattison, E.M., \& Kahan, J. (1983). The deliberate self-harm syndrome. American Journal of Psychiatry, $140,869-871$.

Peterson, R.F., \& Peterson, L.R. (1968). The use of positive reinforcement in the control of self-destructive behaviour in a retarded boy. Journal of Experimental Child Psychology, $\underline{6}$, $351-360$. 
Pond, C.L. \& Rush, H.G. (1983). Self-aggression in macaques: Five case studies. Primates, $\underline{24}$, $127-134$.

Primrose, D.A. (1979). Treatment of self-injurious behaviour with a gaba (gamma-amino buteric acid) analogue. Journal of Mental Deficiency Research , $\underline{23}, 163-173$.

Radler, G.A., Plesa, C., \& Senini, K. \& Reicha, J. (1985). Treatment of self-injurious behaviour in a severely handicapped adolescent: A case study. Australian and New Zealand Journal of Developmental Disabilities, $11,107-112$.

Rast, J., \& Johnston, J.M. (1986). Social versus dietary control of ruminating by mentally retarded persons. American Journal of Mental Deficiency, 90, $464-467$.

Rast, J., Johnston, J.M., \& Drum, C. (1984). A parametric analysis of the relation between food quantity and ruminative behaviour. Journal of the Experimental Analysis of Behaviour , $\underline{41}, 125-134$. Rast, J., Johnston, J.M., Drum, C., \& Conrin, J. (1981). The relation of food quantity to rumination behaviour. Journal of Applied Behaviour Analysis, $14,121-130$.

Richardson, J.S., \& Zaleski, W.A. (1983). Naloxone and self-mutilation. Biological Psychiatry, 18, $99-101$ 
Richardson, J.S., \& Zaleski, W.A. (1986). Endogenous opiates and self-mutilation. American Journal of Psychiatry, $143,938-939$.

Rincover, A. (1978). Sensory extinction: A procedure for eliminating self-injurious behaviour in developmentally disabled children. Journal of Abnormal Child Psychology, $\underline{6}, 299-310$.

Rincover, A., Cook, R., Peoples, A., \& Packard, D. (1979). Sensory extinction and sensory reinforcement principles for programing multiple adaptive behaviour change. Journal of Applied Behaviour Analysis, $12,221-223$.

Rincover, A., \& Devany, J. (1982). The application of sensory extinction procedures to self-injury. Analysis and Intervention in Developmental Disabilities, $\underline{2}, 67-81$.

Rincover, A., \& Newsom, C.D. (1985). The relative motivational properties of sensory and edible reinforcers in teaching autistic children. Journal of Applied Behaviour Analysis, $18,237-248$.

Rojahn, J. (1984). Self-injurious behaviour in institutionalized severely/profoundly retarded adults prevalence data and staff agreement. Journal of Behavioural Assessment , $\underline{6}, 13-27$.

Rojahn, J. (1986). Self-injurious and stereotypic behaviour of noninstitutionalized mentally retarded people: Prevalence and classification. American Journal of Mental Deficiency , 91, 268-276. 
Rojahn, J., McGonigle, J.J., Curcio, C., \& Dixon, M.J. (1987). Suppression of pica by watermist and aromatic ammonia a comparitive analysis. Behaviour Modification, $11,65-74$.

Rojahn, J., Mulick, J.A., McCoy, D., \& Schroeder, S.R.

(1978). Setting events, adaptive clothing, and the modification of headbanging and self-restraint in two profoundly retarded adults. Behaviour Analysis and Modification, $\underline{2}, 185-196$.

Rojahn, J., Schroeder, S.R., \& Mulick, J.A. (1980). Ecological assesssments of self-protective devices in three profoundly retarded adults. Journal of Autism and Developmental Disabilities, $10,59-66$.

Rolider, A., \& Van Houten, R. (1985). Movement suppression time-out for undesirable behaviour in psychotic and severely developmentally delayed children. Journal of Applied Behaviour Analysis, $18,275-288$.

Romanczyk, R.G., \& Goren, E.R. (1975). Severe self-injurious behaviour: The problem of clinical control. Journal of Consulting and Clinical Psychology, $\underline{43}, 730-739$. Russo, D.C., Carr, E.G., \& Lovaas, O.I. (1979). Self-injury in pediatric populations. In $J$. Ferguson and C.B. Taylor (Eds.), Advances in behavioural medicine, Holliswood, New York: Spectrum. 
Sajwaj, T., Libet, J., \& Agras, S. (1974). Lemon juice therapy: The control of life threatening rumination in a six-month-old infant. Journal of Applied Behaviour Analysis, $1,557-563$.

Sandler, A.G., \& McLain, S.C. (1987). Sensory reinforcement : Effects of response-contingent vestibular stimulation on multiply handicapped children. American Journal of Mental Deficiency, 91, $373-378$.

Sandman, C.A., Datta, P.C., Barron, J., Hoehler, F.K., Williams, C., \& Swanson, J.N. (1983). Naloxone attenuates self-abusive behaviour in developmentally disabled clients. Applied Research in Mental Retardation, $\underline{4}, 5-11$.

Schaffer, L.B., Carroll, J., \& Abramaowitz, S.I. 1982. Self-mutilation and the borderline personality. The Journal of Nervous and Mental Disease, 170 , $468-473$.

Schroeder, S.R., Mulick, J.A., \& Rojahn, J. (1980). The definition, taxonomy, epidemiology, and ecology of self-injurious behaviour. Journal of Autism and Developmental Disorders , $10,417-432$.

Schroeder, S.R., Schroeder, C.S., Rojahn, J., \& Mulick, J.A. (1980). In self-injurious behaviour: An analysis of behaviour management techniques. Handbook of Behaviour Modification with the Mentally Retarded , (pp. 61-114), New York: Plenum Press. 
Schroeder, S.R., Schroeder, C.S., Smith, B., \& Delldorf, J. (1978). Prevalence of self-injurious behaviour in a large state facility for the retarded: $A$ three year follow-up study. Journal of Autism \& Childhood Schizophrenia , $\underline{8}, 261-269$.

Sherman, J.S., Swinson, R.P., \& Lorimer, W.P. (1984). On the importance of reliable equipment in the shock punishment of self-injurious behaviour. Analysis and Intervention in Developmental Disabilities,$\underline{4}$, $81-84$

Silverman, K., Watanabe, A.M., Marshall, A.M., \& Baer, D.M. (1984). Reducing self-injury and corresponding self-restraint through the strategic use of protective clothing. Journal of Applied Behaviour Analysis, $17,545-552$.

Singh, N.N. (1976). Psychological treatment of self-injury. New Zealand Medical Journal,$\underline{84}$, $484-486$.

Singh, N.N. (1977). Behavioural control of self-injury in the mentally retarded. New Zealand Psychologist, $6,52-58$.

Sing, N.N. (1979). Aversive control of rumination in the mentally retarded. Journal of Practical Approaches to Developmental Handicaps , $\underline{3}, 2-6$. Singh, N.N. (1980). The effects of facial screening on infants self-injury. Journal of Behaviour Therapy and Experimental Psychiatry, $11,131-134$. 
Singh, N.N. (1981a). Current trends in the treatment of self-injurious behaviour. In L.A. Barness (Ed.), Advances in Paediatrics, vol. 28, (pp. 377-439). Chicago: Year Book Medical Publishers.

Singh, N.N. (1981b). Rumination. Reprinted from: N.R. Ellis (Ed.), International Review of Research in Mental Retardation, vol. 10, (pp. 139-182). New York: Academic Press.

Singh, N.N., \& Aman, M.G. (1981). Effects of thioridazine dosage on the behaviour of severely mentally retarded persons. American Journal of Mental Deficiency, $\underline{85}, 580-587$.

Singh, N.N., Beale, I.L., \& Dawson, M.J. (1981). Duration of facial screening and suppression of self-injurious behaviour: Analysis using an alternating treatments design. Behavioural Assessment, $3,411-420$.

Singh, N.N., Dawson, M.J., \& Gregory, P.R. (1980). Self-injury in the profoundly retarded: Clinically significant versus therapeutic control. Journal of Mental Deficiency Research $, \underline{24}, 87-96$.

Singh, N.N., Dawson, M.J., \& Manning, P.J. (1981). The effects of physical restraint on self-injurious behaviour. Journal of Mental Deficiency Research, $\underline{25}, 207-216$.

Singh, N.N., Gregory, P.R., \& Pulman, R.M. (1980). Treatment of self-injurious behaviour. A three year follow-up. New Zealand Psychologist, $\underline{9}$, 65-67. 
Singh, N.N., Manning, P.J., \& Angell, M.J. (1982). Effects of an oral hygiene punishment procedure on chronic rumination and collateral behaviours in monozygous twins. Journal of Applied Behaviour Analysis, $15,309-314$.

Singh, N.N., \& Mililichamp, C.J. (1984). Effects of medication on a self-injurious behaviour of mentally retarded persons. Psychiatric Aspects of Mental Retardation Reviews, $3,13-16$.

Singh, N.N. \& Militchamp, C.J. (1985). Pharmacological treatment of self-injurious behaviour in mentally retarded persons. Journal of Autism and Developmental Disabilities, $15,257-267$.

Singh, N.N., \& Millichamp, C.J. (1987). Independent and social play in profoundly mentally retarded adults: Training, maintenance, generalization, and long-term followup. Journal of Applied Behaviour Analysis, $\underline{20}, 23-34$.

Singh, N.N., \& Pulman, R.M. (1979). Self-injury in the de Lange Synarome. Journal of Mental Deficiency $\underline{\text { Research }}, \underline{23}, 79-84$.

Singh, N.N., Watson, J.E. \& Winton, A.S.W. (1986). Treating self-injury: Water mist spray versus facial screening or forced-arm exercise. Journal of Applied Behaviour Analysis, $19,403-410$.

Singh, N.N., \& Winton, A.S.W. (1984a). Behavioural monitoring of pharmacological interventions for self-injury. Applied Research in Mental $\underline{\text { Retardation }, ~} \underline{5}, 161-170$. 
Singh, N.N., \& Winton, A.S.W. (1984b). Effects of a screening procedure on pica and collateral behaviours. Journal of Behaviour Therapy and Experimental Psychiatry, 15, 59-65.

Singh, N.N., \& Winton, A.S.W. (1985). Controlling pica by components of an overcorrection procedure. American Journal of Mentai Deficiency, $90,40-45$. Singh, N.N., \& Winton, A.S.W., \& Dawson, M.J. (1982). Suppression of antisocial behaviour by facial screening using multiple baseline and alternating treatments design. Behaviour Therapy, 13 , $511-520$.

Skinner, B.F. (1953). Science and Human Behaviour, New York. Free Press.

Slifer, K.J., Iwata, B.A., \& Dorsey, M.F. (1984). Reduction of eye-gouging using a response interruption procedure. Journal of Behaviour Therapy and Experimental Psychiatry, $\underline{15}, 369-375$. Solnick, J.V., Rincover, A., \& Peterson, C.R. (1979). Some determinants of the reinforcing and punishing effects of time out. Journal of Applied Behaviour Analysis, $10,415-424$.

Sovner, R., \& Hurley, A.D. (1985). Assessing the quality of psychotropic drug regimes prescribed for mentally retarded persons. Psychiatric Aspects of Mental Retardation Reviews , $8-9,31-38$.

Spain, B., Hart, S.A., \& Corbett, J. (1984). The use of appliances in the treatment of severe self-injurious behaviour. Occupational Therapy , Nov, $353-357$. 
Swett, C. (1985). Psychotropic medications used during mechanical restraint of patients. Current Therapeutic Research , $38 ， 621-626$.

Tanner, B.A., \& Zeiler, M. (1975). Punishment of self-injurious behaviour using aromatic ammonia as the aversive stimulus. Journal of Applied Behaviour Analysis, $8,53-57$.

Tate, B.G., \& Baroff, G.S. (1966). Aversive control of self-injurious behaviour in a psychotic boy. Behaviour Research and Therapy, $\underline{4}, 281-287$. Wacker, D.P., Berg, W.K., Wiggins, B.M.M., \& Cavanagh, J. (1985). Evaluation of reinforcer preferences for profoundly handicapped students. Journal of Applied Behaviour Analysis, $18,111-126$. Watson, J., Singh, N.N., \& Winton, A.S.W. (1986). Suppressive effects of visual and facial screening on self-injurious finger-sucking: A comparative analysis. American Journal of Mental Deficiency, $\underline{90}, 526-534$.

Weeks, M., \& Gaylord-Ross, R. (1981). Task difficulty and aberrant behaviour in severely handicapped students. Journal of Applied Behaviour Analysis, $14,449-463$.

Wells, M.E., \& Smith, D.W. (1983). Reduction of SIB of mentally retarded persons using sensory-integrative techniques. American Journal of Mental Deficiency, $\underline{87}, 664-666$. 
White, G., Nielson, G., \& Johnston, S. (1972). Time-out duration and the suppression of deviant behaviour in children. Journal of Applied Behaviour Analysis, $\underline{5}, 111-120$.

Wieseler, N.A., Hanson, R.H., Chamberlain, T.P., \& Thompson, T. (1985). Functional taxonomy of stereotypic and self-injurious behaviour. Mental $\underline{\text { Retardation, }} \underline{23}, 230-234$.

Wiesenfeld, Z., \& Hallin, R.G. (1983). Continuous naloxone administration viz osmotic mini pump decreases autonomy but has no effect on nociceptive threshold in the rat. Pain, $16,145-153$.

Winton, A.S.W., \& Singh, N.N. (1983). Rumination in pediatric populations: A behavioural analysis. Journal of the American Academy of Child Psychiatry , $\underline{22}, 269-275$.

Winton, A.S.W., Singh, N.N., \& Dawson, M.J. (1984). Effects of facial screening and blindfold on self-injurious behaviour. Applied Research in Mental Retardation, $\underline{5}, 29-42$.

Wurtele, S.K., King, A.C., \& Drabman, R.S. (1984). Treatment package to reduce SIB in a Lesch-Nyhan patient. Journal of Mental Deficiency Research, $\underline{28}, 227-234$.

Young, J.A., \& Wincze, J.P. (1974). The effects of reinforcement of compatible and incompatible alternative behaviours on the self-injurious and related behaviours of a profoundy retarded female adult. Behaviour Therapy, $\underline{5}, 614-623$. 
Zegiob, L.E., Jenkins, J., Becker, J., \& Bristow, A. (1976). Facial screening: Effects on appropriate and inappropriate behaviours. Journal of Behaviour Therapy and Experimental Psychiatry , $\underline{7}, 355-357$. Zuk, G.H. (1960). Psychodynamic implications of self-injury in defective children and adults. Journal of Clinical Psychology, $16,58-60$. 